Portland State University

PDXScholar

\title{
Quantifying the Impacts of a Novel Predator: the Distinctive Case of the Oregon Spotted Frog (Rana pretiosa) and the Invasive American Bullfrog (Rana (Aquarana) catesbeiana)
}

Kyle Scott Tidwell

Portland State University

Follow this and additional works at: https://pdxscholar.library.pdx.edu/open_access_etds

Part of the Animal Sciences Commons, and the Biology Commons Let us know how access to this document benefits you.

\section{Recommended Citation}

Tidwell, Kyle Scott, "Quantifying the Impacts of a Novel Predator: the Distinctive Case of the Oregon Spotted Frog (Rana pretiosa) and the Invasive American Bullfrog (Rana (Aquarana) catesbeiana)" (2017). Dissertations and Theses. Paper 3504.

https://doi.org/10.15760/etd.5388

This Dissertation is brought to you for free and open access. It has been accepted for inclusion in Dissertations and Theses by an authorized administrator of PDXScholar. Please contact us if we can make this document more accessible: pdxscholar@pdx.edu. 
Quantifying the Impacts of a Novel Predator: The Distinctive Case of the Oregon Spotted Frog (Rana pretiosa) and the Invasive American Bullfrog (Rana (Aquarana) catesbeiana)

by

Kyle Scott Tidwell

A dissertation submitted in partial fulfillment of the requirements for the degree of

Doctor of Philosophy

in

Biology

Dissertation Committee:

Deborah Duffield, Chair

David Shepherdson, Co-Chair

Marc Hayes

Deborah Lutterschmidt

Yangdong Pan

Randy Zelick

Portland State University

2017 
(C) 2017 Kyle Scott Tidwell 


\begin{abstract}
The decline of the Oregon Spotted Frog (Rana pretiosa), a Pacific Northwest endemic now federally listed as threatened, has been attributed to several aspects of ecosystem alteration, primarily habitat degradation and loss. The introduced American Bullfrog (Rana (Aquarana) catesbeiana) has been widely implicated in those declines, but the basis of that contention has been difficult to characterize. The bullfrog occurring at every site of recent Oregon Spotted Frog extirpation has focused concern about its impact.
\end{abstract}

Here, I present a suite of interconnected studies that examine the behavioral ecology of both species to better understand the potential for bullfrog-mediated Oregon Spotted Frog extirpation. I quantified Oregon Spotted Frog anti-predator behavior from the only known population successfully co-occurring with bullfrogs (Conboy Lake) and a population devoid of bullfrog impact (Big Marsh), and compared these behaviors to the predatory traits of the bullfrog. The initial study revealed that captive-reared individuals from the Oregon Spotted Frog population that has successfully co-occurred with bullfrogs respond faster to a predatory stimulus (measured as latency to response) than Oregon Spotted Frogs from a population not to exposed to bullfrogs. Subsequent field investigations of the approach distance allowed by a predator stimulus before taking evasive action (termed the flight initiation distance: FID) conducted with the Oregon Spotted Frog population co-occurring with bullfrogs first demonstrated that FID of recently metamorphosed bullfrogs is consistently greater than that of recently metamorphosed Oregon Spotted Frogs. Further, examination of FID across all post- 
metamorphic age classes of Oregon Spotted Frogs revealed that older frogs do not allow as close approach as recently metamorphosed Oregon Spotted Frogs. This age class shift in FID did not occur in the Oregon Spotted Frog population not exposed to bullfrogs. In the latter population, FID did not differ among age classes.

Since the bullfrog might be driving this age-based change in anti-predator behavior, I explored the variation in strike distance of bullfrogs from the site of cooccurrence in both the field and laboratory to determine the extent of overlap with Oregon Spotted Frog FID. I found that the bullfrog strike distance significantly overlaps the FID of all ages of Oregon Spotted Frogs from the bullfrog-free site but only that of youngest (recently metamorphosed) frogs at the site of co-occurrence. Older Oregon Spotted Frogs from the site of co-occurrence generally escaped at distances greater than the strike distance of bullfrogs.

I also collected $>880$ bullfrogs from the site of co-occurrence and analyzed the stomach contents to assess their dietary trends. I found that bullfrogs consume Oregon Spotted Frogs at the site, but do not eat the larger (older) frogs. Moreover, the body size ratio between Oregon Spotted Frogs as prey and bullfrogs as predators suggests that nearly all of the adult size distribution of bullfrogs at Conboy would be incapable of preying on adult Oregon Spotted Frogs.

Collectively, these studies strongly suggest that bullfrogs have altered the escape behavior of Oregon Spotted Frogs at Conboy Lake and that most adult Oregon Spotted Frogs at Conboy may have a size-based release from predation by bullfrogs. Implicit in this finding is that bullfrogs may pose a real threat via predation to other Oregon Spotted 
Frog populations with which they might come into contact where the distribution of bullfrog body sizes differ substantially from that at Conboy Lake. 
The disparity between theory and empiricism is particularly conspicuous in anuran ecology and behavior, where detailed studies of natural populations are rare.

- Arnold G. Kluge (1981)

Detailed studies of anuran ecology and behavior, when conducted with attention to natural history, have advanced our understanding of the ecological and behavioral complexities inherent to the taxa, but the scope of such studies has remained narrow. Continued prodding is required to better understand the depth of their behavior.

Of the many things anurans are, they are not simple.

- K. S. Tidwell (2017) 


\section{ACKNOWLEDGEMENTS}

First and foremost, I would like to recognize Marc Hayes, whose selfless time and passion for our studies were at times all that kept me going. While measuring frogs at the Oregon Zoo in 2010, we had a conversation regarding my career aspirations which changed my entire trajectory, and for that I am forever grateful. Thank you, Marc.

This dissertation is the culmination of six years of work. Six of the most tumultuous, entertaining, and enlightening years of my life. As such, many people must be recognize and thanked: First, I would like to thank my committee Debbie Duffield, Marc Hayes, Deborah Lutterschmidt, David Shepherdson, Yangdong Pan, and Randy Zelick and the rest of the Biology department at Portland State. I appreciate each and every one of you that took the time to help me. In particular, I would like to the thank Stan Hillman, Ed De Grauw, and Mike Murphy for the conversations and support that encouraged me to reach beyond my specific focus, and develop a holistic education. I would also like to recognize my co-author and statistical mentor, Paul Yarnold, for his time, tutelage and stories.

Many institutions and people contributed to this body of work. Funding agencies and people involved are recognized at the end of every chapter. Specifically, I would like to thank the Mid-Columbia National Wildlife Refuges complex, which oversees Conboy Lake National Wildlife Refuge and the personnel who helped me over the years: Lisa Wilson, Sara McFall, Joe Engler, Heidi Newsome, and the Youth Conservation Corps students. Jay and Teresa Bowerman of the Sunriver Nature Center and Mark Nebeker of 
the Oregon Department of Fish and Wildlife Sauvies Island Management area for providing endless samples of bullfrogs and, at times, excellent duck hunting.

Joan Kittrell of the Crescent Ranger District of the National Forest Service and Lizz Smock and Karla Ellis of the U.S. Army Corps of Engineers, Portland District. I would especially like to thank the field technicians, undergraduate research assistants, friends, and partners who aided in this research. Each of you helped guide, inform, and facilitate this work more than you know: Anh Le, Andre Garrett, Bill Brady, Chase Spearing, Joe Kobler, Josh Jenks, Kate Bonn, Leila Duchac, Matthew Edwards, Rebecca Cates, Ricky Scott, Ryan Linden, Sam Ekhoff, and Tom Munger, it has been my pleasure to work with you and I am excited for what your futures will bring.

Lastly, I would like to thank the support base who helped me through the years. Lane Tidwell, thank you for all that you are. We continue to show that with hard work and dedication we can accomplish anything. You provided the moral gription I needed to keep moving forward. Jan Laney and Vaughn Tidwell, the nurturing you provided early in life and the support you continue to offer is the reason for my success. Thank you.

To my peers; James Powell, Kessina Lee, Catherine Dayger-Forbes, Claire Riggs, Whitney Gayer, and Dan Kim, you are the best friends, scientists, and intellects a colleague could ask for. Thanks also to Ed May, for the several years of formal and informal training on waterfowling and life. Finally, thank you to my entire Oregon Ducks Unlimited family, and the several tuna boat captains and hunting friends who gave me a 
release from the stress of research and provided opportunities, support, and understanding. 


\section{TABLE OF CONTENTS}

ABSTRACT

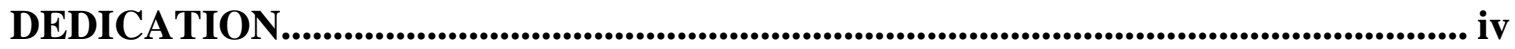

ACKNOWLEDGEMENTS .....................................................................................................

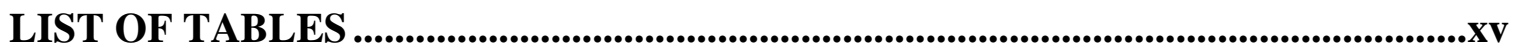

LIST OF FIGURES

PREFACE........................................................................................................................ xxii

CHAPTER 1: Introduction ........................................................................................................1

BACKGROUND OF OREGON SPOTTED FROG-BULLFROG

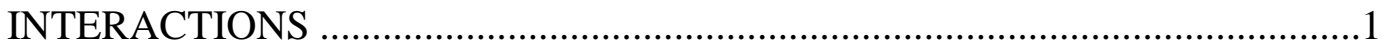

NATURAL HISTORY OF THE OREGON SPOTTED FROG

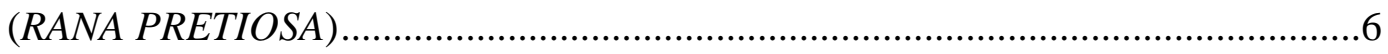

NATURAL HISTORY OF THE AMERICAN BULLFROG

(RANA (AQUARANA) CATESBEIANA) ……………....................................13

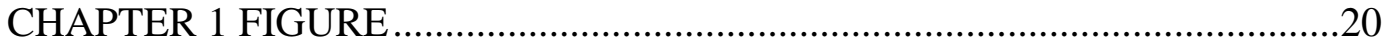

CHAPTER 2: Interpopulation Variability in Evasive Behavior in the Oregon

Spotted Frog (Rana pretiosa) ....................................................................................................21

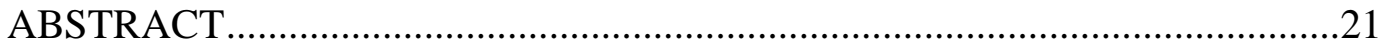

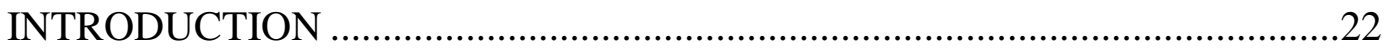

MATERIALS AND METHODS.....................................................................22

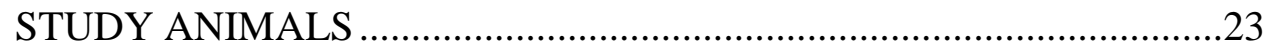




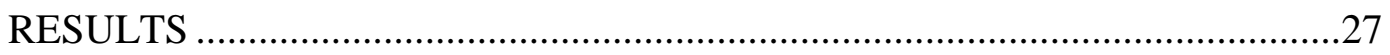

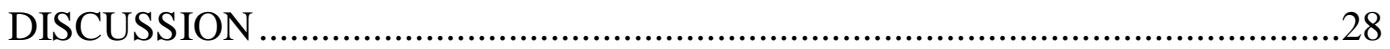

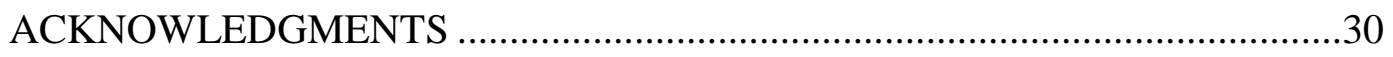

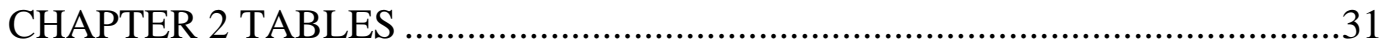

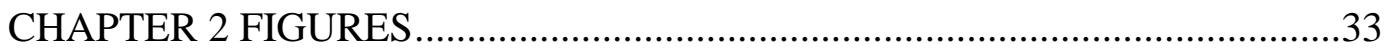

\section{CHAPTER 3: Difference in Flight Initiation Distance Between Recently}

\section{Metamorphosed Oregon Spotted Frogs (Rana pretiosa) and American bullfrogs}

(Rana (Aquarana) catesbeiana) .........................................................................................35

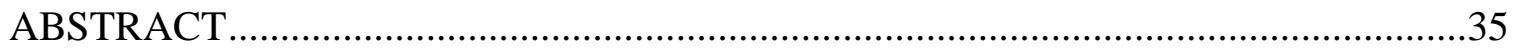

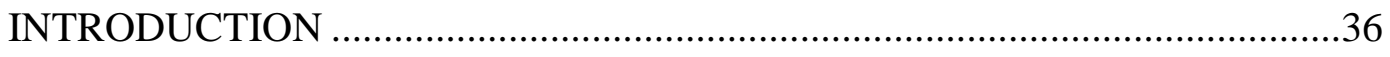

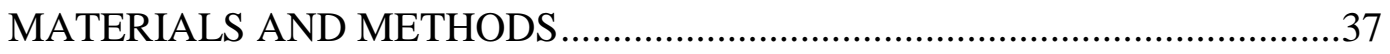

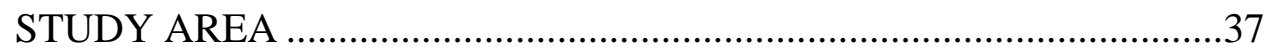

RECONNAISSANCE SURVEYS ..................................................38

QUANTIFICATION OF FLIGHT INITIATION DISTANCE.................38

MEASUREMENT OF POTENTIAL CO-FACTORS ............................40

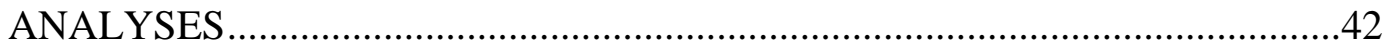

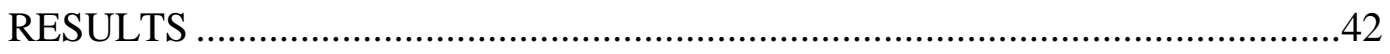

COMPARISON OF FLIGHT INITIATION DISTANCES .....................42

CO-FACTORS VERSUS FLIGHT INITIATION DISTANCES .............43

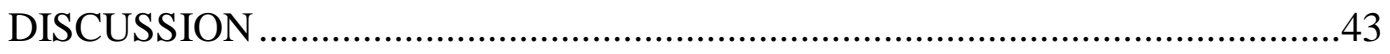




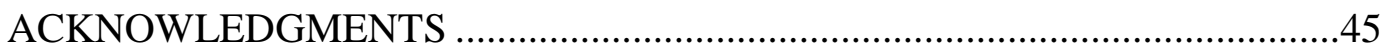

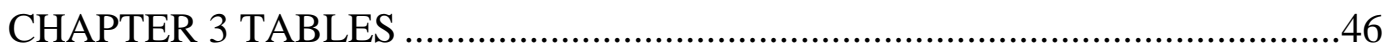

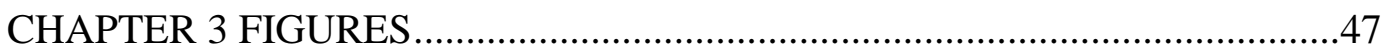

CHAPTER 4: Age-based Shift in Flight Initiation Distance for a Crypsis-Dependent

Aquatic Frog................................................................................................................................50

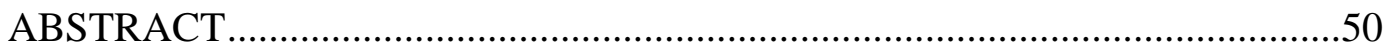

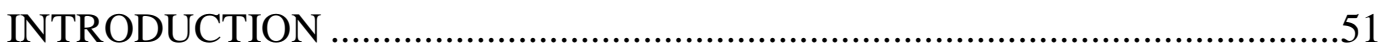

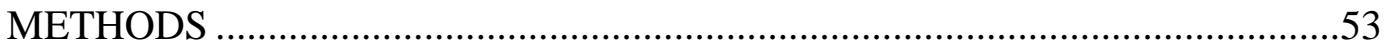

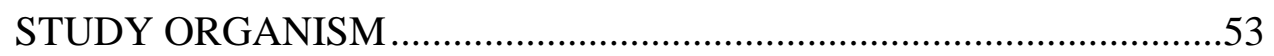

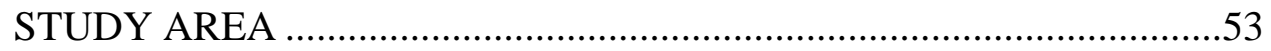

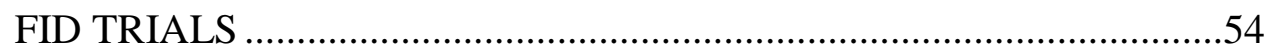

MEASUREMENT OF CO-FACTORS .....................................................56

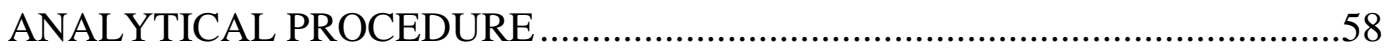

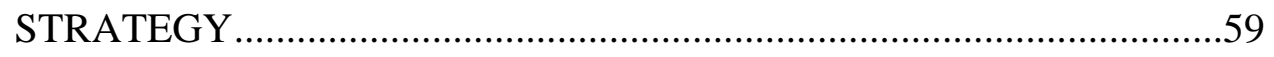

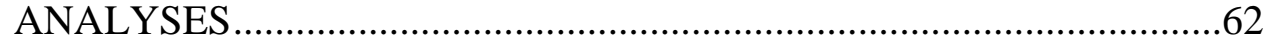

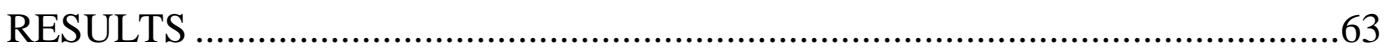

COMPARISON OF FID AMONG YOY FOR 2012 VERSUS 2013.......63

VARIATION IN FID WITH AGE ........................................................64

VARIATION IN SD WITH AGE ………………………………….......65

VARIATION IN COVER AND ORIENTATION WITH AGE .................65

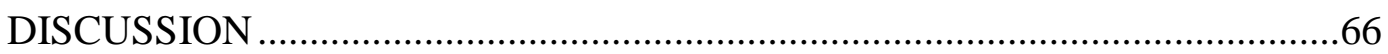


ACKNOWLEDGMENTS

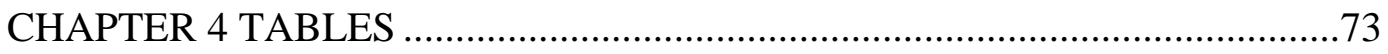

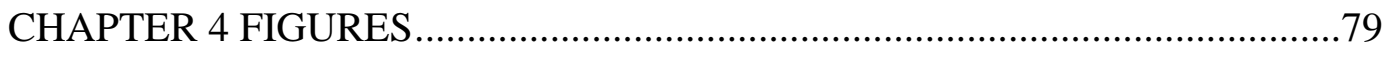

\section{CHAPTER 5: Differences in Escape Behavior Between Two Populations of}

Oregon Spotted Frogs (Rana pretiosa) Identify American Bullfrogs

(Rana (Aquarana) catesbeiana) as a Behavior-Modifying Agent...............................81

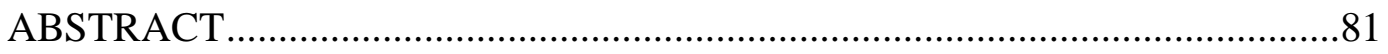

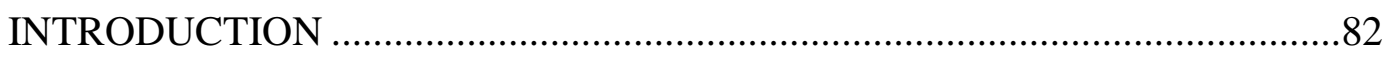

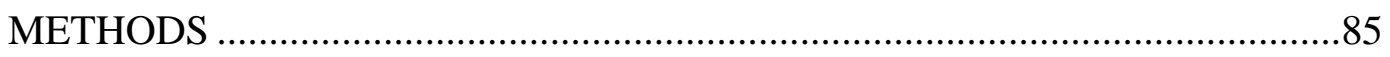

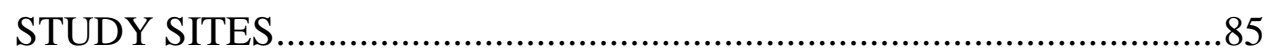

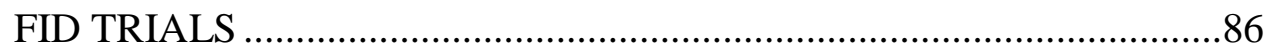

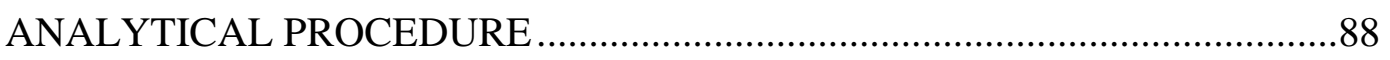

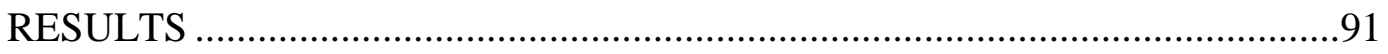

BETWEEN-SITE COMPARISONS OF THE PROPORTION OF

FROGS ALLOWING TOUCH ..................................................99

DESCRIPTIVE STATISTICS FOR FID AND SD..............................92

THE RELATIONSHIP OF AGE AND FID AT BIG MARSH ................92

BETWEEN-SITE COMPARISON OF FID BY AGE GROUP ..............93

THE RELATIONSHIP OF AGE AND SD AT BIG MARSH.................94

BETWEEN-SITE COMPARISON OF SD SEPARATELY BY FROG

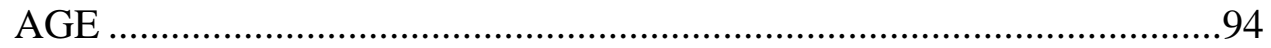

THE RELATIONSHIP OF AGE AND COVER AT BIG MARSH .........95 


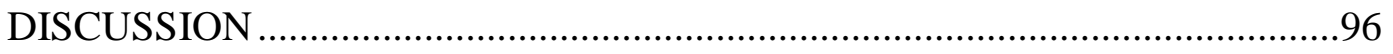

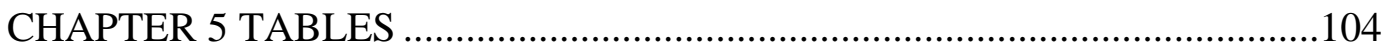

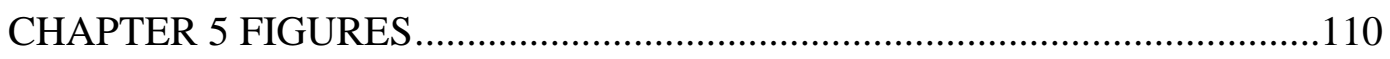

\section{CHAPTER 6: Predatory Strike Distance of the American Bullfrog (Rana}

(Aquarana) catesbeiana) and the dynamic response of a native anuran....................111

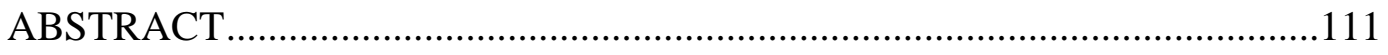

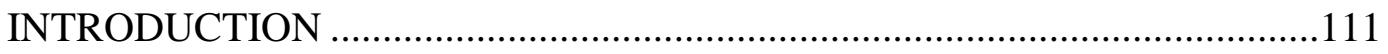

MATERIALS AND METHODS.............................................................114

STUDY AREAS ……………………………………..................114

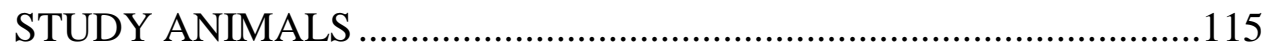

EXPERIMENTAL DESIGN ...............................................................115

LABORATORY ANALYSIS OF STRIKE DISTANCE.............117

FIELD ANALYSIS OF STRIKE DISTANCE ...........................119

LABORATORY ANALYSIS OF FID......................................120

FIELD ANALYSIS OF FID .................................................121

ANALYTICAL PROCEDURE .............................................................122

APPROACH TO STATISTICAL ANALYSIS ............................122

PREDATORY ACTION OF THE BULLFROG ……………......122

CONCEPTUAL DESCRIPTION OF ODA ALGORITHM .......123

ANALYTICAL APPROACH ………………………….............124

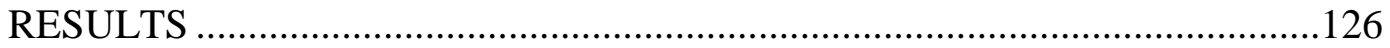

PREDATORY ACTION OF THE BULLFROG ....................................126 
COMPARISON OF BULLFROG STRIKE DISTANCE AND OSF

FID IN THE LABORATORY

COMPARISON OF BULLFROG STRIKE DISTANCE AND OSF

FID IN THE FIELD.

.128

COMPARISON OF BULLFROG STRIKE DISTANCE AND OSF FID

OF NON-BULLFROG IMPACTED POPULATION .129

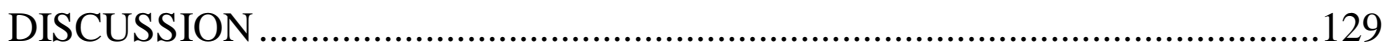

ACKNOWLEDGMENTS .....................................................................133

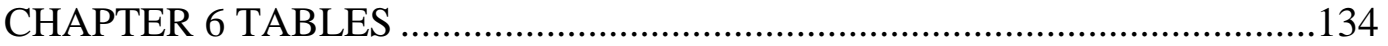

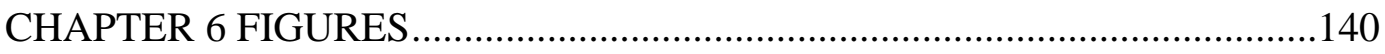

CHAPTER 7: Vertebrate Prey Contents of Bullfrogs.............................................145

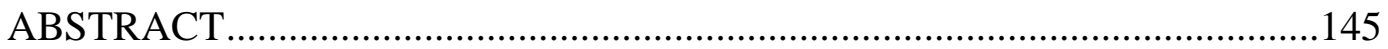

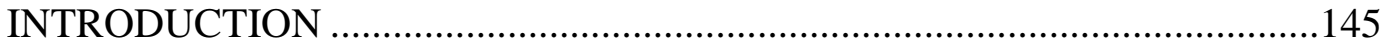

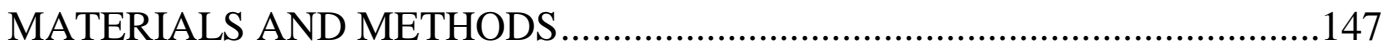

BULLFROG COLLECTION ....................................................147

SPECIMEN HANDLING AND DISSECTION PROCEDURE .............148

ANALYTICAL PROCEDURE ......................................................149

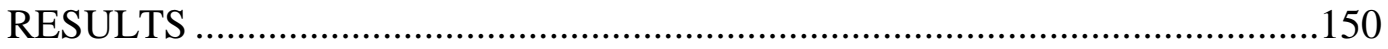

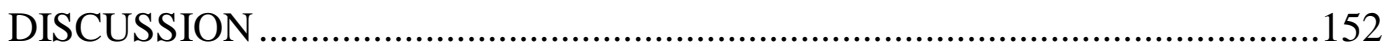

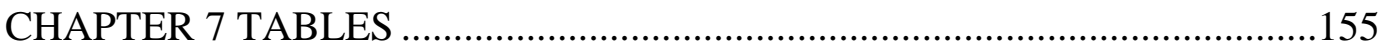

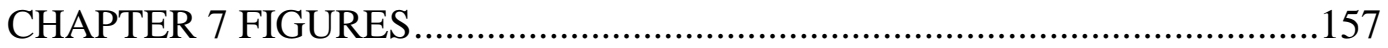

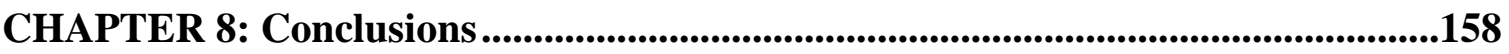


REFERENCES .............................................................................................................................167

APPENDIX: Chapters 2, 3, and 4 Copyright Information .......................................186 


\section{LIST OF TABLES}

\section{CHAPTER 2 TABLES}

Table 2.1 Variation in response time to a pseudo-predator stimulus for juvenile Oregon Spotted Frogs in 2010 experiments.

Table 2.2 Relationship between the sequence in which Oregon Spotted Frogs were tested and latency in response time for all population samples used in 2010 experiments

\section{CHAPTER 3 TABLES}

Table 3.1 Variation in flight initiation distance and co-factors in Rana pretiosa (RAPR) and Rana (Aquarana) catesbeiana (RACT)

\section{CHAPTER 4 TABLES}

Table 4.1 Flight initiation distance and starting distance metrics (in meters) by age class for Oregon Spotted Frogs

Table 4.2 ODA analysis of the frequency of zero versus non-zero flight initiation distances (FID) among Oregon Spotted Frogs by age class .74

Table 4.3 Training (total sample) and LOO validation analyses assessing the relationship between flight initiation distances (FID) and the co-factors, orientation and cover, for post-metamorphic Oregon Spotted Frogs partitioned by age class

Table 4.4 Summary of field studies of flight initiation distance (FID) as a function of age or size in lower vertebrates 
Table 4.5 Pairwise comparisons between Oregon Spotted Frog age classes for Flight Initiation Distance (FID) ...............................................77

Table 4.6 Pairwise comparisons between Oregon spotted

Frog age classes for Starting Distance (SD) .78

\section{CHAPTER 5 TABLES}

Table 5.1 Flight initiation distance and starting distance metrics (in meters) by age class for Oregon Spotted Frogs from Big Marsh and Conboy

Table 5.2 Comparison of the proportions of zero versus non-zero flight initiation distances (FID) among Oregon Spotted Frogs between sites, separately by age class

Table 5.3 Training (total sample) and LOO validation analyses assessing the relationship between flight initiation distances (FID) and cover, for postmetamorphic Oregon Spotted Frogs from Big Marsh partitioned by age class...106 Table 5.4. Directional pairwise comparisons between Oregon Spotted Frog age classes from Big Marsh for the Flight Initiation Distance

(FID) Training Analysis

Table 5.5. Directional pairwise comparisons between Oregon Spotted Frog age classes from Big Marsh and Conboy Lake for Flight Initiation Distance (FID) 108

Table 5.6. Pairwise comparisons between Oregon Spotted Frog age classes from Big Marsh for the Starting Distance Training Analysis .109

\section{CHAPTER 6 TABLES}


Table 6.1. Descriptive statistics of bullfrog strike distance and OSF FID for laboratory and field experiments at Conboy Lake and OSF FID at Big Marsh. All measurements of distance are in meters

Table 6.2 Descriptive statistics of snout-vent-length (SVL) for bullfrogs used in laboratory and field experiments at Conboy Lake to measure strike distance. All measurements of distance are in millimeters .135

Table 6.3. Measurement of variables taken on frogs used in laboratory analysis of bullfrog strike distance .136

Table 6.4. Directional pairwise comparisons between OSF age classes from Conboy Lake in the laboratory for vulnerable and not vulnerable frogs. Cut-point refers to the proportion of vulnerable versus not vulnerable that was the optimal model separating age classes. Abbreviations are Effect Strength for Sensitivity (ESS), Vulnerable (V), Not Vulnerable (NV) and Young of year (YOY)

Table 6.5. Directional pairwise comparisons between OSF age classes from Conboy Lake field experiments for vulnerable and not vulnerable frogs. Cut-point refers to the proportion of vulnerable versus not vulnerable that was the optimal model separating age classes. Abbreviations are Effect Strength for Sensitivity (ESS), Vulnerable (V), Not Vulnerable (NV) and Young of year (YOY) .138 Table 6.6. Directional pairwise comparisons between OSF age classes from Big Marsh field experiments for vulnerable and not vulnerable frogs. Cut-point refers to the proportion of vulnerable versus not vulnerable that was the optimal model 
separating age classes. Abbreviations are Effect Strength for Sensitivity (ESS),

Vulnerable (V), Not Vulnerable (NV) and Young of year (YOY)

\section{CHAPTER 7 TABLES}

Table 7.1 Prey items from bullfrogs at Conboy Lake.........................................155

Table 7.2 Vertebrate prey contents found in bullfrogs at Conboy Lake...............156

Table 7.3 Ratio of consumed prey size by bullfrog body size.............................156 


\section{LIST OF FIGURES}

\section{CHAPTER 1 FIGURES}

Figure 1.1 Historic and current distribution of Rana pretiosa (adapted from Hayes et al., 1997). Blue circles indicate recently described populations in

Whatcom and Skagit counties, Washington State (Bohannon et al., 2016)

\section{CHAPTER 2 FIGURES}

Figure 2.1 Apparatus used in experiments in 2009-2010

Figure 2.2 Latency-to-response results (in seconds) from early (3 August) and late

(2 September) experiments in 2010 .

\section{CHAPTER 3 FIGURES}

Figure 3.1 Aerial photograph of the portion of Conboy Lake National Wildlife Refuge showing the Cold Springs Ditch and Outlet Creek conveyance channels and study reaches used in the flight initiation distance trials

Figure 3.2 Distributions of flight initiation distances for recently metamorphosed individuals of Rana pretiosa (RAPR) and Rana (Aquarana)catesbeiana (RACT) at Conboy Lake National Wildlife Refuge on 2-3 September 2012

Figure 3.3. Distributions of flight initiation distance for recently metamorphosed individuals of Rana pretiosa (RAPR) and Rana (Aquarana) catesbeiana (RACT) at Conboy Lake National Wildlife Refuge on 2-3 September 2012 for those individuals that fled at distances $\leq 2 \mathrm{~m}$

\section{CHAPTER 4 FIGURES}

Figure 4.1 Distribution of flight initiation distances for YOY, $2^{\text {nd }}$-year, and adult Oregon Spotted Frogs sampled at Conboy Lake National Wildlife Refuge xix 
in 2013

Figure 4.2 Distribution of flight initiation distances for YOY, $2^{\text {nd }}$-year, and adult Oregon Spotted Frogs sampled at Conboy Lake National Wildlife Refuge in 2013 that allowed approach $\leq 2 \mathrm{~m}$

\section{CHAPTER 5 FIGURES}

Figure 5.1 Distribution of flight initiation distance by age class (Young-the-Year [YOY], $2^{\text {nd }}-$ year, and adult [ $>2^{\text {nd }}-$ year $]$ ) Oregon Spotted Frogs sampled at Big

Marsh and Conboy in 2013 110

\section{CHAPTER 6 FIGURES}

Figure 6.1 Image of testing tank with visual barrier. .140

Figure 6.2 Image of the Oregon Spotted Frog prey model

Figure 6.3 Laboratory FID testing tank

Figure 6.4 Cumulative frequency distribution of OSF FID and bullfrog strike distance from Lab experiments at Conboy Lake. YOY = Young of year

Figure 6.5 Cumulative frequency distribution of OSF FID and bullfrog strike distance from field experiments at Conboy Lake. YOY = Young of year

Figure 6.6 Plots of field observations of OSF FID at Big Marsh (BM) and Conboy Lake (CB) and bullfrog strike distance at Conboy Lake. The red line indicates the maximal strike distance of bullfrogs measured in field experiments (aka.

vulnerability line)

\section{CHAPTER 7 FIGURES}


Figure 7.1. Plot of bullfrog snout-vent-length (SVL) by the SVL of prey items consumed at Conboy Lake. 


\section{PREFACE}

CHAPTER 2 is published in The Journal of Herpetology:

Tidwell, K. S., D. J. Shepherdson. \& M. P. Hayes. 2013. Inter-population Variability in Evasive Behavior in the Oregon Spotted Frog (Rana pretiosa). Journal of Herpetology 47:93-96.

CHAPTER 3 is published in Herpetological Conservation and Biology:

Tidwell, K. S. \& Hayes, M. P. 2013. Difference in flight initiation distance between recently metamorphosed Oregon Spotted Frogs (Rana pretiosa) and American Bullfrogs (Lithobates catesbeianus). - Herpetol. Conserv. Biol. 8: 426-434.

CHAPTER 4 is in review in Behaviour:

Hayes, M. P., Tidwell, K. S., Shepherdson, D. J., \& Yarnold, P. R. In review. Age-based shift in flight initiation distance for a crypsis-dependent aquatic frog. Behaviour.

CHAPTER 5 is in preparation for submittal to Animal Behavior:

Tidwell, K. S., Yarnold, P. R., \& Hayes, M. P. In prep. Differences in escape behavior between two populations of Oregon Spotted Frogs (Rana pretiosa) identify American Bullfrogs (Rana (Aquarana) catesbeiana) as a behavior-modifying agent

Please see the APPENDIX for the copyright information regarding these publications. 


\section{CHAPTER 1}

\section{BACKGROUND OF OREGON SPOTTED FROG-BULLFROG INTERACTIONS}

The Oregon Spotted Frog (OSF; Rana pretiosa), a Pacific Northwest endemic listed as threatened by U.S. Endangered Species Act (USFWS 2014), and endangered in the state of Washington, is postulated to be affected by the invasive American Bullfrog (Rana (Aquarana) catesbeiana; hereafter bullfrog) based on the latter's presence at virtually all historic sites from which OSF have disappeared (Hayes, 1997). Once widespread across its geographic range (British Columbia through northern California), the OSF has been reduced to 50-odd isolated populations, accounting for a $>90 \%$ range reduction in the last 150 years (Hayes, 1997, Hallock, in press). This decline is likely due to a combination of environmental pressures; however, the decline in OSF populations when coupled with the spread of the bullfrog makes the bullfrog predation on OSF hypothesis particularly compelling for study.

Impacts of the notoriously invasive bullfrog in western North America have been investigated using diverse methods. However, the experimental work has focused either on competition with larvae of native amphibians (Kupferberg, 1997) or behaviors that may indirectly facilitate predation on native amphibian larvae (Kiesecker and Blaustein, 1998; Kupferberg, 1997; Pearl et al., 2003; Paoletti, 2009). Though predation is the mode via which the bullfrog is frequently postulated to have impacted native western North American ranid frogs, with selected rare exceptions (Pearl et al., 2004; Fuller, 2008), the 
study of predation on native ranid frogs has addressed larvae. This bias originates in part from the fact that introduced fish predation was initially suggested as being potentially more important than predation by bullfrogs (Jennings and Hayes, 1985), and in part because larvae lend themselves more easily to experimental manipulation. Even in the absence of exotic predators, survival of the larvae of native ranid frogs in the wild is typically low (<5\%) (Licht, 1971, 1974), leading to the expectation that predation by exotic fishes might have the potential to eliminate annual larval cohorts. However, where survival to metamorphosis occurs, predation by exotics must now incorporate surface water interactions in which predation by post-metamorphic bullfrogs can potentially play a much greater role than fishes. Hence, expanding the scope of investigation to include the postmetamorphic predatory behavior of bullfrogs is pivotal to understanding the extent of impact this invasive species may have on native western North American ranid frogs.

Bullfrogs have historically been known as voracious, opportunistic predators (Schwalbe and Rosen, 1988) that employ a sit-and-wait strategy and will readily attack any animal smaller than themselves, including other frogs (Bury and Whelan, 1984) and conspecifics, which can compose up to 80\% of their diet (Stuart and Painter, 1993). Frost (1935) performed stomach dissections on bullfrogs from their native range and found that smaller bullfrogs eat mostly insects, while larger bullfrogs typically eat frogs. Adult bullfrogs can locate and eat smaller frogs by orienting to breeding (Green and Pauley, 1987) or distress (Collins and Collins, 1991) calls. Recent work suggests that the predatory nature of the bullfrog is more complex than the oft-used sit-and-wait predatory description, 
as studies have documented that bullfrogs will also engage in actively stalking their prey (Werner et al., 1995; Wu et al., 2005).

In a predatory context, selected behavioral and morphological attributes may give post-metamorphic bullfrogs an advantage over the equivalent life stages of native western ranid frogs (Pearl et al., 2004; Cooper, 2011a). Given the highly aquatic nature of the bullfrog, the threat of predation by post-metamorphic bullfrogs would be greatest for animals that share its habitat. Indeed, studies have found that habitat requirements are the primary factors driving the predatory effect of the bullfrog on native frogs (Pearl et al. 2004; Da Silvia et al., 2011). It follows that areas of co-occurrence where permanent water becomes seasonally restricted may increase the likelihood of predation. Although habitat overlap is necessary for bullfrogs to manifest an effect, it is not a sufficient condition to support the basis of a negative interaction given that several field studies with Pacific Northwest amphibians other than OSFs have revealed that bullfrogs have little or no effect (Adams, 1999, 2000; Ostergaard et al., 2008; Adams et al., 2011). Since bullfrogs now inhabit all sites where OSFs have gone extinct (Hayes, 1997), it is critical to directly assess the post-metamorphic interactions of the two species to determine how OSFs may be vulnerable to bullfrogs.

To address this question of impact, I elected to study inter-population differences in OSF behavior at sites with and without bullfrogs. Conboy Lake National Wildlife Refuge, a wetland complex managed by the Mid-Columbia National Wildlife Refuge system, near Glenwood, Washington, USA offered an ideal opportunity to study potential bullfrog impact on OSFs. It is unique for three reasons: first, it has one of the largest 
populations of OSFs across the species' geographic range; second, the east Cascade slope OSF populations, which includes Conboy Lake, harbor the highest level of genetic diversity relative to other population locations (Blouin, 2010), and as such may be uniquely equipped to respond to environmental changes; and third, Conboy Lake is the only site of long term (> 58 years) bullfrog co-occurrence ${ }^{1}$. Thus, using Conboy Lake as the experimental site, with a control site lacking bullfrogs as reference (Big Marsh, Crescent Range District, Oregon), I implemented laboratory and field experiments to explore differences between populations if post-metamorphic bullfrog predation was occurring and having an impact.

Herein, I describe, quantify, and test two aspects of OSF anti-predator behavior thought to be biologically relevant to bullfrog predation. I first analyzed the speed of response to a predatory stimulus (which I termed the latency to respond [LTR]) to assess if anecdotal observations of Conboy Lake frogs exhibiting faster responses to potential predators are indeed true (Chapter 2). Secondarily, I measured the distance between OSFs and an approaching predator stimulus when evasive action was taken (termed the Flight Initiation Distance [FID]) (Chapters 3-5). These metrics are effective measures of wariness (Cooper and Blumstein 2015) and have been analyzed in diverse taxa to inform escape

\footnotetext{
${ }^{1}$ As per a conversation with Douglas Troh on 29 July, 2014, he stated that in 1958 his ranching father, Norman Troh, along with old man "Levias," left for Carson (near the Bridge of the Gods) to obtain bullfrogs. They caught 20 large adult frogs, and filled two 5-gallon buckets with tadpoles. These animals were introduced in the late summer to the pond behind his house on Troh Lane. The intent was to farm them. The levee of the pond broke four years later, which allowed the frogs to move into Bird Creek, north of what is now Conboy Lake National Wildlife Refuge (the refuge was created in 1964).
} 
theory (Ydenberg and Dill, 1989; Cooper and Blumstein 2015). Moreover, they are increasingly being used to assess species responses to changing environments (Berger et al., 2007; Bergseth et al., 2016). These metrics have not been measured for OSFs (and rarely measured in any anuran [see Hayes et al. in press for review]), but offer descriptive measures of OSF anti-predator behavior and identify testable hypotheses of potential bullfrog impact. I tested the primary hypothesis that bullfrog predation alters the antipredator behavior of OSFs by describing and quantifying the bullfrog predatory strike distance (SD). This study provides quantitative support for two aspects of bullfrog impact. First, it supports that the sit-and-wait strategy of bullfrog predation is more complex than historically described, and second, it provides evidence that the FID of OSFs at Conboy Lake is likely responsive to the SD of the bullfrog (Chapter 6).

The first part of the analysis of OSF anti-predator behavior (LTR) was conducted using frogs raised in captivity as part of a head-start program (Chapter 2). Given that the roots of this dissertation stem from the head-start program, a brief description and background is warranted. The distinct declines of OSF populations spurred initiatives to assess the efficacy of head-starting the species for re-introduction to historic locations. A pilot program was started to investigate the feasibility of head-starting the species and in doing so, the Washington Oregon Spotted Frog Recovery Team was formed. Composed of federal and state agencies, local zoological institutions, private landowners and concerned private parties, the team launched a rearing program that involved re-location of wild OSF eggs from Conboy Lake and Black River (a composite of Puget Sound lowland OSF populations near the Black River) to rearing facilities at the Woodland Park Zoo, Oregon 
Zoo, and Cedar Creek Correctional Center, where eggs where hatched, and tadpoles reared through metamorphosis to the maximum size they could grow prior to fall release. Recently metamorphosed frogs were released at Dilman Lake and vicinity on Joint Base LewisMcChord in Washington State. The decision to use eggs from Conboy Lake was in part due to the large population size, and in part due to the uniqueness of the population given the long term co-occurrence with bullfrogs, which was thought to potentially give the reintroduced population an advantage if exposed to bullfrogs.

Over a six-year period, this program released >6,200 frogs and monitored their success by surveying egg masses. The program had limited recruitment success gauged on reproduction and no egg masses have been found for several years (11 Oregon Spotted Frog egg masses produced in situ only in year three of this program). However, the program accomplished several positive things for the species including: development of an effective method with which to rear the species through metamorphosis, focus of public attention on the seriousness of the species decline, and creation of unique opportunities for laboratory analysis of the ontogeny and behavior of the species. Chapter 2 of this dissertation is a result of such laboratory experiments and helped guide the rest of the studies presented herein.

\section{NATURAL HISTORY OF THE OREGON SPOTTED FROG (RANA PRETIOSA)}

Historically called the Western Spotted Frog (Rana pretiosa pretiosa; Baird and Girard, 1853 sensu stricto), the Oregon Spotted Frog (OSF; Rana pretiosa) was recently 
defined as a cryptic species apart from the Columbia Spotted Frog (Rana luteiventris) complex by genetics and morphometrics analysis (Green et al. 1997). The disjunct distribution and population structrure of these ecologically similar species is likely a result of topography and Pleistocene glaciation events (Funk et al. 2005, 2008), wherein extant populations of OSF are geographically isolated, have very low genetic diversity, and small effective population sizes (Blouin et al. 2010).

The OSF is a Pacific Northwest endemic that historically ranged from the Pit River Drainage in northeastern California to the Fraser River system in extreme southwestern British Columbia (Fig. 1.1) with populations broadly distributed from lowland marshes to high elevation lakes of the Cascades mountain range (Hayes, 1997). Significant range contraction has occurred in the last 150 years and extant populations now range from southern Oregon to the Fraser River system of Vancouver, British Columbia. Except for a handful of sites in the Puget Trough, they are largely extirpated from lowland areas, being primarily found in mid-elevation lakes and marshes east of the Cascades axis (Pearl and Hayes 2005; Pearl et al., 2005a). Recent discovery of scattered populations in Whatcom and Skagit Counties in Washington State (Bohannon et al. 2012, Bohannon et al. 2016), provides potential for connectivity to the remnant Canadian populations in the Fraser River system.

The OSF is unique among native northwestern anurans due to its entirely aquatic life history, wherein all life stages of the species are found in or immediately adjacent to water. Seasonal use of different aquatic habitats is most easily partitoned into three broad categories: oviposition, active season, and overwintering habitats. Utilizing floodplain 
wetlands, side channels, and sloughs associated with permanent water bodies, this moderate-sized ranid (50-105 mm snout-to-vent length [SVL]) emerges from the overwintering season during post-winter thaw and migrates to suitable ovipostion sites where they begin to breed in Feburary through early April, depending on elevation and latitude. Telemetry of adults during the breeding season has found the species capable of considerable movement to and from breeding sites (i.e., up to 2.5 km) (Watson et al., 2003; Waddell 2014).

Utilizing seasonally inundated, shallow (0.25 m) stillwater habitat for oviposition, the sexually dimorphically larger females select the site of oviposition and deposit a single unattached egg mass containing 150-1500 eggs directly on vegetation or substrate (Pearl and Hayes 2004). Oviposition typically occurs close to the seasonal hydrological peak resulting from winter rains and/or snow melt. Post-breeding, adults return to somewhat deeper active-season water habitat for the remainder of spring and summer. Depending on environmental conditions, tadpoles hatch in 2.5-7 weeks and move as water recedes toward more permanent active-season water bodies containing diverse matrices of submerged, floating, and emergent vegetation that provide food and refuge (Licht, 1971, 1975). Tadpoles metamorphose 3-4 months post hatching as 22-30 mm SVL frogs and continue to gain mass until the late fall, when adult and recently metamorphosed frogs move to overwintering sites, charaterized by deeper, oxygen-rich waters near springs and areas of moving water (Watson et al., 2003; Pearl and Hayes, 2004). The overwintering period is the least studied aspect of the species' ecology, but data indicate that frogs move to permanent water bodies containing structure (e.g. 
vegetation, woody debris) that allows frogs to find refuge in thick vegetation or organic matter matrix (McAllister and Leonard, 1997; Hallock and Pearson, 2001). Frogs are active throughout this period and have been found to move below 5-10 cm of ice to seek out locations with more dissolved oxygen and thermal insulation that also likely provide important protection from predators (Hallock and Pearson, 2001; Hayes et al., 2001; Risenhoover et al., 2001; Watson et al., 2003; Tattersall and Ultsch, 2008).

Dorsally rotated eyes, an identifying characteristic of the species, enable a 360degree view of the surroundings (Licht, 1971). This morphology is nicely suited to the sedentary predation strategy employed by the species, whereby metamorphosed animals maintain immobility until a prey item moves into the strike range of the frog or can be approached and captured. With several cautious strokes of the hind limbs and positioning of the body via the front limbs, the frogs move to a capture position but remain completely in the water. Prey capture involves propulsion of the body utilizing the extensive webbing of the hind limbs, and either the tongue or the entire mouth enveloping the prey, depending on its size. Prey items are often taken at the water-air interface and swallowed below the waters surface (Licht, 1971). Similar to their predatory behavior, OSFs exploit the vegetative structure of aquatic habitats to evade predators, whereby escape typically involves quick repulse off the vegetation using the forelimbs followed by a series of rapid, synchronous hindlimb contractions that propels the frog into the water column and submerged vegetated matrix (Licht 1986a, Hallock, in press) . 
The predator-prey dynamics of the species are diverse and fluctuate with age and the transition indicative of metamorphosis. As tadpoles, OSFs are herbivorous and consume vegetation, detritus, biofilms, and proteinaceous materials at the benthos of slow moving fresh water streams, lakes, and lentic water (Licht, 1971). In the captive environment, I reared tadpoles to metamorphosis with a largely vegetarian diet of processed Kale, Romaine, and Spirulina and vitamin supplements of calcium and B vitamins combined with occasional proteinaceous materials of bloodworm cubes, boiled egg whites, and commercial fish food.

Metamorphosed OSFs are gape-limited opportunistic predators. Insects dominate their diet, largely because of OSF's modest body size and relative importance of insects in aquatic systems; in some systems, OSFs may function as a top predator of aquatic invertebrates (Pearl et al., 2005b). Detailed analysis of diet is limited; Hallock (in press) synthesized the following information from Licht's work on 41 post metamorphic OSFs sampled in British Columbia (Licht, 1986b). Of the stomach and intestinal contents sampled for 18 recently metamorphosed (33-37 mm SVL [Licht, 1971]) OSFs, 85.3\% was insects (representing 25 families) and the balance was spiders (Arachnida). Insect families contributing $\geq 10 \%$ of food items were: spittlebugs (Cercopidae; $14.7 \%$ ), leaf hoppers (Cicadellidae; 12.9\%) and long-legged flies (Dolichopodidae; 13.8\%). The remaining 23 frogs of the sample were combined as juvenile (males: 38-45 mm SVL, females: 38-62 mm SVL [Licht, 1971]) and adult (males: 46-64 mm SVL, females: 63-82 mm SVL [Licht, 1971]) frogs. Of this sample, 92.7\% of prey items were insects (45 families), $4.7 \%$ spiders (Arachnida), and 2.6\% mollusks (Mollusca). Relative to recently 
metamorphosed frogs, the older age classes had more diverse insect diets (45 families versus 25 ). However, only two insect groups were represented by $\geq 10 \%$ of the total food items: leaf beetles (Chrysomelidae; 13.6\%) and ground beetles (Carabidae; 9.9\%).

These differences in prey composition likely reflect gape limitations in the smaller (younger) frogs. However, inferences and generalizations of potential prey items for the species must be made cautiously. Ontogenetic and inter-population variation can potentially mask pertinent differences in potential and recognized prey items for many ranid species. For example, Licht (1986b) found diving beetles (Dytiscidae) to represent 1.6\% of prey items for the 41 frogs sampled (Hallock, in press), whereas at Conboy Lake, M. Hayes sampled 86 post-metamorphic OSFs and found 50\% of prey items to be diving beetles (Hallock, in press). Such significant differences in diet composition could be a result of diving beetle availability, but more likely reflect the differences in body size (and thus gape) between populations. Adult OSFs at Conboy Lake are on average 40 mm (SVL) larger in body size than the population sampled in Licht's (1986b) analysis (M. Hayes, personal communication), and therefore a greater portion of the Conboy Lake population are likely capable of taking relatively large diving beetles, an abundant group at Conboy.

Similarly, the potential vertebrate prey items of OSFs must be considered in light of the body size of the OSF population being discussed. Licht (1986b) provided field observations of adult OSFs eating recently metamorphosed Northern Red-legged Frogs (Rana aurora [23- 27mm SVL]), and Pacific Treefrogs (Pseudacris [formerly Hyla] regilla [30-35mm SVL]) in British Columbia. In other OSF populations, juvenile 
Western Toads (Anaxyrus boreas) have been documented prey (Pearl and Hayes, 2002) and consumption of recently metamorphosed conspecifics are infrequent. Given the diversity and size of documented prey items, populations of larger OSFs may take a greater variety of vertebrate prey.

All OSF life stages are vulnerable to predation, but tadpoles and metamorphosing OSFs (given their small size and reduced mobility) are susceptible to a greater number of predators including invertebrates such as dragonfly larvae (Odonata), giant water bugs (Belostoma spp.), water scorpions (Ranatra spp.), and backswimmers (Notonecta spp.). Metamorphosed frogs often have remnant scars and injuries as a result of failed invertebrate predation attempts. For example, I have documented giant water bugs capturing OSFs via envenomation, and consuming the viscera of recently metamorphosed (and metamorphosing) OSFs. I have also found frogs lacking a rear foot or digit, likely representing dragonfly larvae predation attempts (Caldwell et al., 1980).

Vertebrate predators of OSFs represent a diverse assemblage of animals. Confirmed predators include: bullfrogs (Pearl et al., 2004; Chapter 7, this dissertation), common garter snakes (Thamnophis sirtalis) (Licht 1974), great blue heron (Ardea herodias) (Licht 1974), mink (Neovison vison) (Hallock and Pearson, 2001; Hayes et al., 2001), northwestern salamanders (Ambystoma gracile) (larval and gilled stages documented to prey on tadpoles in laboratory experiments [Licht, 1974]), river otter (Lontra canadensis) (Hayes et al., 2005), and sandhill cranes (Antigone canadensis) (Hayes et al., 2006). 
Suspected predators include a suite of taxa for which strong evidence of predation exists, but documentation is lacking (Hallock, in press). For some taxa, it is due to issues with sampling; for others, it likely reflects insufficient effort to document. For instance, tadpole predation by finned fishes is incredibly likely (Hayes and Jennings, 1986;

Hallock, in press), however the rate of digestion is so fast that sampling has yet to positively identify an event (McAllister and Jennings, 1997; Hallock, in press). Introduced fish species are thought to impact OSF and other native anurans (Hayes and Jennings, 1986; McAllister and Leonard, 1997), such species include: smallmouth bass (Micropterus dolomieu), largemouth bass (Micropterus salmoides), pumpkinseed (Lepomis gibbosus), yellow perch (Perca flavescens), bluegill (Lepomis macrochirus), brown bullhead (Ameiurus nebulosus), brook trout (Salvelinus fontinalis), and rainbow trout (Oncorhynchus mykiss) (Hallock in press; USFWS 2009). Other suspected predators include: American bittern (Botaurus lentiginosus), belted kingfisher (Megaceryle alcyon), green frog (Lithobates clamitans), green herons (Butorides virescens), hooded mergansers (Lophodytes cucullatus), northern harrier (Circus cyaneus), red fox (Vulpes vulpes), raccoon (Procyon lotor), striped skunk (Mephitis mephitis), and feral domestic cats (Felis domesticus) (Licht, 1974; McAllister and Leonard, 1997)

\section{NATURAL HISTORY OF THE AMERICAN BULLFROG}

\section{(Rana (Aquarana) catesbeiana)}


Native to the southeastern United States, the bullfrog has been widely introduced across the world, and is now found in 29 countries (AmphibiaWeb, 2016). In the western United States, the bullfrog was widely introduced for food and aesthetic purposes starting in the 1890s (Moyle, 1973; Jennings and Hayes, 1985), and is now broadly distributed across western wetlands from Northern Canada to Mexico (Moyle, 1973; Bury and Whelan, 1984). As North America's largest native ranid (150-230 mm SVL), the bullfrog is a prominent inhabitant of invaded wetlands, where their size, breeding calls, and potential for high concentrations makes the species distinct among Pacific NW amphibians. In western Oregon, the bullfrog was introduced in 1915 for the nostalgic sounds of the male call, reminding many immigrants of their eastern homelands (Lampman, 1946; Nussbaum et al., 1983). Recent genetic analysis found bullfrogs in the Willamette Valley of Oregon to be of two distinct lineages, one from Louisiana and the other from the Great Lakes (Funk et al., 2010), illustrating that several introductions were likely responsible for the establishment of the populations observed today, a theme shared with many extant populations of bullfrogs (AmphibiaWeb, 2016).

As a warm water-adapted anuran, the distribution of bullfrogs in northern latitudes is thought to be limited by seasonal thermal profiles that limit the length of available active season so that the species cannot effectively breed and regain depleted energy stores to successfully overwinter (George, 1940; Bury and Whelan 1984). However, where survival and breeding occurs, the species occupies a wide range of suitable habitats including: lakes, ponds, reservoirs, irrigation ditches, golf course waters, and marshes. Being highly aquatic, these waters serve as sources for oviposition, active 
season, and overwintering sites with frequently little need for immigration or emigration (George, 1940). This diversity of suitable habitats has similarly diverse levels of submerged and emergent vegetation (Bury and Whelan, 1984). However, most sites invaded by the species have open water exposed to the sun, with a mixture of shallow margins and a deep permanent water body in the center (Skelly et al., 1999). As bullfrog tadpoles require 12 - 48 months for metamorphosis, permanent (or connections to) water is crucial to the species (Bury and Whelan, 1984) and is a unifying feature of most habitats used by the species.

The bullfrog displays different seasonal phenologies depending on the location of their site of introduction. The bullfrog does well in their native warm waters of eastern North America where populations in Louisiana can remain active year-round (George, 1940). However, in the Pacific Northwest and high (colder) latitude environments, the species survives by overwintering during the fall and winter months (Bury and Whelan, 1984). At sites where overwintering occurs, the bullfrog is the last anuran to emerge from overwintering in the late spring (Smith, 1934; Ryan, 1953). Emergence occurs once water temperatures rise above approximately $15^{\circ} \mathrm{C}$, after which adult frogs will begin establishing territories and breeding (Harding, 1997). The breeding season begins when water temperatures reach $20-25^{\circ} \mathrm{C}$, which can be constant for southern populations where year round reproduction is postulated, but unconfirmed (George, 1940; Kaefer et al., 2007). However, in northern latitude populations these temperatures (and thus breeding) are relegated to the middle and late summer months (Fitch, 1956). 
The sexually dimorphic males, with yellow throat patches, engorged nuptial pads, and large tympana, establish territories in active-season, permanent, still water habitat and vocalize to attract females. Gravid females allow amplexus and oviposit >20,000 eggs in a sheet-like mass (Schwalbe and Rosen, 1988). Concomitant with large egg masses, larger female bullfrogs are known to produce multiple clutches in a single breeding season and therein nearly double or even potentially triple their annual productivity (Emlen, 1977). Eggs develop and hatch in 3-5 days, after which, and depending on environmental conditions, tadpoles will mature over the next 1-4 years (Bury and Whelan 1984). Metamorphosis occurs in the summer months and juveniles become surface active. In areas of concentrated bullfrog numbers, juveniles will move over land and through water to colonize areas and thus avoid competition and predation by older bullfrogs (Merovich and Howard, 2000). In populations where over-wintering occurs, recently metamorphosed and adult bullfrogs remain in active-season waters until autumn temperatures begin to drop below $15^{\circ} \mathrm{C}$ (Harding, 1997), after which adults disappear below water to refugia of holes and woody debris for the winter months (Harding, 1997; Bury and Whelan, 1984). Recently metamorphosed frogs follow suite but later than adults and after freezing temperatures are present (Willis et al., 1956). As highly aquatic frogs, the ecology of bullfrog predatory and anti-predator actions are similar to the OSF; employing a sedentary strategy at least somewhat reliant on crypsis (though to a much lesser extent than OSF), the bullfrog takes surface-active prey items using a series of forward lunges propelled by the large and extensively webbed hind limbs. The tongue and mouth of the frog is used to capture and detain prey 
items, which are swallowed whole and often stuffed into the mouth using the forelimbs if the prey is large. Predation is avoided initially by reliance on crypsis at a distance, and when at perceived risk, escape occurs prior to close approach via a series of explosive leaps across the water surface prior to disappearing by diving.

Predators of bullfrogs are numerous and in the Pacific Northwest, not well documented, but likely include the same suite of predators listed for the OSF above with a few distinct additions (Rombough 2010). Two differences deserve comment: first, the large size of adult bullfrogs provides protection from predation by either out-growing the risk from smaller predators, or by increasing handling time ${ }^{2}$ (Kupferberg, 1994), thus enabling potential escape. Second, unlike OSFs, bullfrog tadpoles are largely unpalatable to many predatory fish species and therefore much less frequently targeted (Kruse and Francis, 1977; Seale, 1980; Werner and McPeek, 1994). This differential is thought to give the species an advantage over native northwestern amphibians, which are heavily preyed upon by fish and thus cannot co-exist with many exotic fishes (Jennings and Hayes, 1985; McAllister and Leonard, 1997).

Bullfrog prey in its introduced range in the Pacific NW is diverse and understudied (see Jancowski and Orchard, 2013 for a review). However, where studies have been conducted, a generalized theme emerges. Bullfrogs have diverse diets of

${ }^{2}$ I documented a 77-cm SVL female T. sirtalis preying on a 74-mm SVL bullfrog at Conboy Lake. Forty-seven minutes elapsed between initial capture and consumption of the frog, after which the snake was exhausted to a point that it did not resist capture nor make an attempt to flee when released. 
aquatic invertebrates similar to that described for the OSF. However, bullfrogs display an increase in the number, diversity, and size of vertebrate prey items, a trend that is likely related to the large size (and gape) of adult bullfrogs. Specifically, bullfrogs have been found to heavily prey on metamorphosed anurans including conspecifics where $>80 \%$ of the diets can be younger bullfrogs (Stuart and Painter 1993; Govindarajulu et al. 2006). Laboratory analysis of consumption trails confirms that recently metamorphosed OSFs are prey of bullfrogs, and may be more susceptible than Northern Red-legged frogs because of far greater seasonal overlap in habitat use and less effective escape behavior (Pearl et al. 2004). However, field studies confirming bullfrog impact on local anuran populations often lack either the sample size or morphometric details needed to assess such a relationship.

The largest study of bullfrog diet in the Pacific Northwest was conducted on Southeastern Vancouver Island, British Columbia: 60 sites were sampled and 5,075 bullfrogs were collected, of which 4,602 bullfrogs had prey contents (Jancowski and Orchard, 2013). Of the sample, 84\% of prey items were insects (Insecta), $4.60 \%$ spiders (Arachnida), 2.62\% vertebrates and the balance (8.78\%) comprised seven invertebrate orders. The contribution of invertebrate prey items (primarily insects) was apparent in all age classes, with the majority being Damselflies and Dragonflies (Odonata, 17.5\%) and social wasps (Hymenoptera, 14.0\%). Vertebrate prey items were found in the larger age classes and included 32 species including: fishes (Gasterosteiformes, Perciformes, Siluriformes, Salmoniformes, Scorpaeniformes), frogs (Anura), mammals (Rodentia), 
salamanders (Caudata), song birds (Passeriformes), lizards and snakes (Squamata), and turtles (Testudines).

Interestingly, and directly applicable to the present study, is the number of anurans consumed and the comparative size of the bullfrogs consuming them found by Jancowski and Orchard (2013). Bullfrogs consumed 51 metamorphosed conspecifics, 35 of which were consumed by the largest size bullfrog category in the study (i.e. $\geq 130 \mathrm{~mm}$ SVL). In contrast, only 10 Northern Red-legged Frogs were consumed, therefore bullfrogs consumed $1 / 5^{\text {th }}$ the number of Northern Red-legged frogs as conspecifics, potentially supporting previous work that bullfrog impact on Northwestern anurans may be highest for species with similar life histories (Pearl et al. 2004). Unfortunately, Jancowski and Orchard (2013) do not report the relative sizes of Northern Red-legged frogs or conspecifics consumed, nor the size of bullfrogs that consumed them. However, elsewhere in the bullfrogs introduced range, consumption of native ranids have been found to relate to habitat overlap (Stewart and Sandison, 1972; Wu et al., 2005; Silva et al., 2011, Silva et al., 2016) and bullfrog size (Stewart and Painter, 1994; Toledo et al., 2007; Leivas et al., 2012; Silva et al., 2016). These observational relationships are largely unexplored for OSF-bullfrog interactions.

To investigate the apparent relationship between bullfrog size and propensity for vertebrate prey, and, more specifically, to investigate the size of metamorphosed OSFs vulnerable to bullfrog predation, I examined the dietary contents of $>880$ bullfrogs from Conboy Lake. Chapter 7 of this dissertation reports the number of vertebrate prey contents consumed, their size and mass, and the size of bullfrogs which consumed them. 


\section{CHAPTER 1 FIGURES}

Figure 1.1. Historic and current distribution of Rana pretiosa (adapted from Hayes et al., 1997). Blue circles indicate recently described populations in Whatcom and Skagit counties, Washington State (Bohannon et al., 2016).

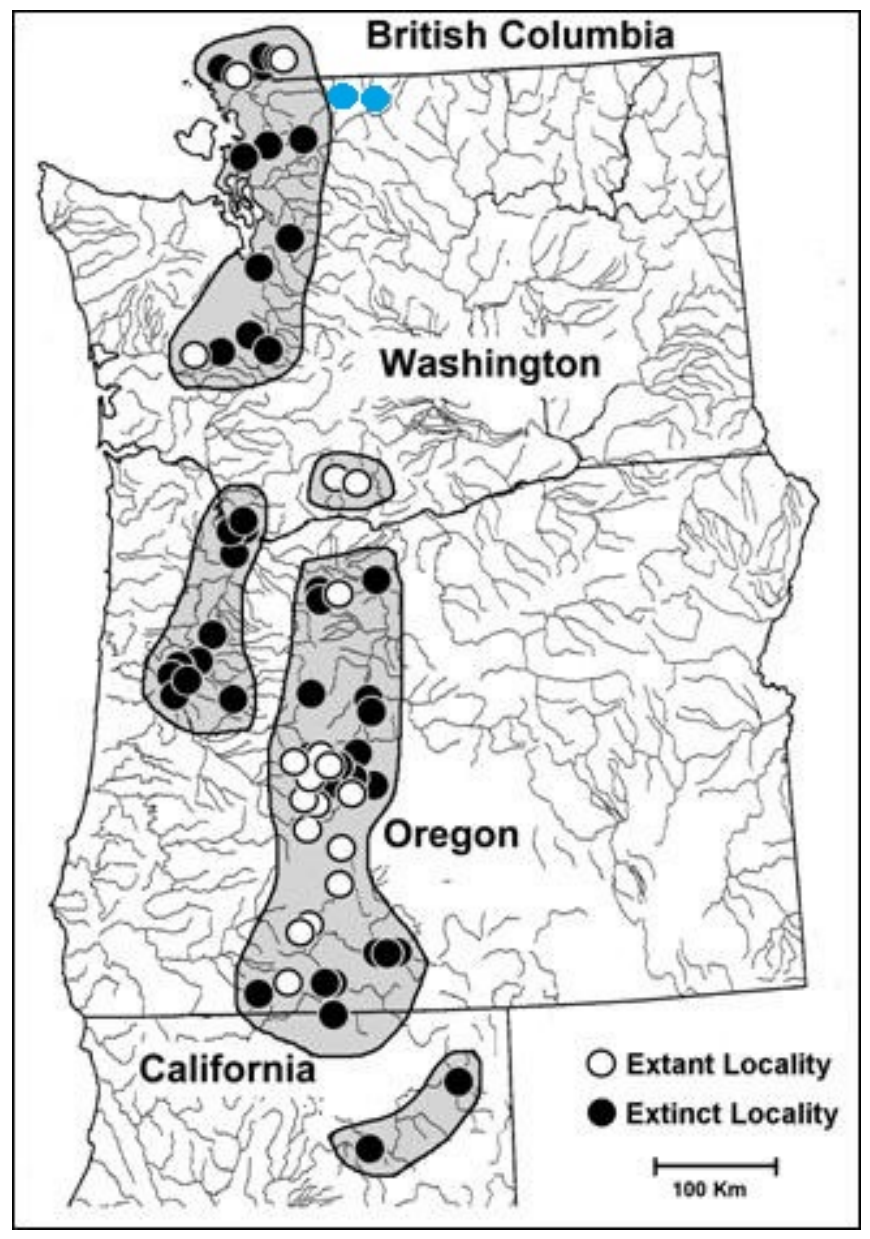




\title{
CHAPTER 2
}

\section{INTER-POPULATION VARIABILITY IN EVASIVE BEHAVIOR IN THE OREGON SPOTTED FROG (RANA PRETIOSA)}

\begin{abstract}
Few data exist that quantify evasive behavior in post-metamorphic anurans. Based on our casual observations that Oregon Spotted Frog (Rana pretiosa) from one of two different populations appeared to exhibit a more pronounced evasive response, we used a pseudo-predator stimulus to quantify the evasive response of juveniles from the two populations. We drew test animals from a pool of animals for each population that were captive-reared under identical conditions. Using latency to initial response, we compared the distribution of response times between the two populations at two sequential intervals over the rearing period. In both experiments, the Conboy Lake population had shorter latency-to-response times than the Black River population. However, we also found that latency-to-response times were shorter during the second test interval than during the first test interval for each population. The basis of population differences in response times may reside in differences in the predator set influencing each population, contaminants differentially influencing the Black River population in a negative manner, or some combination of both. Explanation for the faster latency-to-response times in the second experiment is unclear since both maturation and the length of the captive rearing interval may contribute to the effect but they are confounded in this study.
\end{abstract}




\section{INTRODUCTION}

Anti-predator responses represent behaviors basic to species survival. Moreover, understanding intraspecific variation in anti-predator behavior is basic to elucidating the functional significance of alternative behavioral patterns in specific ecological contexts (Dowdey and Brodie, 1989; Ingle and Hoff, 1990; Brodie et al., 1991; Gomes et al., 2002). Our casual observations that juveniles of the aquatic ranid frog, Rana pretiosa, from one of two populations seemed to have a more rapid evasive behavior than individuals from the second population led us to a systematic evaluation of evasive behavior in this species. These observations were made during captive-rearing of frogs for a pilot translocation program on Joint Base Lewis McChord (JBLM), Pierce County, Washington, for this federal candidate (USFWS, 2010), and Washington State endangered species (McAllister and Leonard, 1997). Our primary interest was to evaluate the hypothesis that captive-reared frogs from the Conboy population exhibited faster escape responses (reduced latency-to-respond) than those similarly reared from the Black River population. However, this exploratory investigation was also intended to: 1) move towards developing a system that could be used ultimately to evaluate whether captiverearing, because it is a predator-free environment, might dilute anti-predator responses; and 2) determine whether frogs from one source population are more likely to exhibit behaviors that improve survival than those from other populations and as a result, potentially be more successful in re-establishing a population.

\section{MATERIALS AND METHODS}




\section{Study Animals}

In 2009 and 2010, we drew study animals from pools of juvenile Oregon Spotted Frogs that were obtained from each of two populations (Conboy Lake National Wildlife Refuge [Klickitat County] and the upper Black River [Thurston County], Washington). These animals were being reared at the Oregon Zoo for translocation to JBLM. Frogs were collected as eggs (ca. 400/year) from their respective source populations in March of each year; reared in plastic containers $(34.3 \mathrm{~cm} \times 20.3 \mathrm{~cm} 12.7 \times \mathrm{cm})$ to an approximately 2-cm total larval length on a diet of kale, romaine lettuce and Spirulina; transferred to Rubbermaid C plastic cattle tanks (1136 L) for rearing to metamorphosis; and fed calcium and vitamin-dusted crickets during rearing as post-metamorphic juveniles. Frogs from each population were reared at the same densities in each year, but the sizes of the reared populations from which frogs were drawn in 2009 were less than one third the size of those in $2010(n=75)$.

\section{Behavioral Experiments}

We conducted all experiments using a ball-drop apparatus (Figure 2.1) in a climate-controlled room at the Oregon Zoo where the temperature was maintained at 24.0 to $26.6^{\circ} \mathrm{C}$. The presentation stage of this apparatus consisted of a white plastic container $61 \mathrm{~cm}$ long $\times 46 \mathrm{~cm}$ wide $\times 31 \mathrm{~cm}$ high filled with water to a depth of about $10 \mathrm{~cm}$. Water was aged, had a pH of 6.8 to 7.1 and a temperature of 21.1 to $23.3^{\circ} \mathrm{C}$. Aging water involved treating a separate 1136-L tank with AmQuel ${ }^{\circledR}$ (Kordon LLC, 2242 Davis Court, Hayward, California 94545), a dechlorinating and denitrifying agent, at the appropriate dosage (13.2 ml AmQuel per $100 \mathrm{~L}$ water) and letting it to stand for no less 
than $22 \mathrm{hr}$ before use. We used a water temperature range mimicking active-season daytime conditions for Rana pretiosa because suboptimal temperatures have the potential to impair both physiological performance (Pough et al., 1992a; Brodie and Russell, 1999) and influence anti-predator response (Gomes et al., 2002). Water was deep enough to allow frogs to float with their front limbs off the bottom, but shallow enough that their hind limbs could touch bottom, which limited unnecessary energy expenditure (Pough et al., 1992a). The pseudo-predator stimulus in this apparatus was an orange-colored 10.2 cm-diameter plastic ball tethered to a rope strung through pulleys attached to the ceiling above the presentation stage to permit an investigator to move the ball from a concealed location; an opaque visual barrier about $85 \mathrm{~cm}$ high surrounding the stage concealed investigators. The ball could be released from about $60 \mathrm{~cm}$ over the water surface and a knot in the tether made the released ball stop $\sim 1.3 \mathrm{~cm}$ above the water. We mounted a Canon@ Vixia HF 200 video-camera at an angle over the tank to enable recording test trials with a broad overhead view and produce an archive for subsequent scoring with a 30 frames/sec $(0.03 \mathrm{sec})$ resolution. We selected frogs randomly from each population for each experiment.

We conducted an initial test of this apparatus on 14 juveniles selected from each of the aforementioned populations in August 2009 and measured latency to initial response. We elected to measure latency to initial response as we anticipated that this was the measure most likely to correspond to our casual observations of responsiveness. This test revealed that frogs from Conboy Lake had faster average latency-to-initial-response times $(\bar{x}=0.50 \mathrm{sec}, s=0.11 \mathrm{sec}$, range: $0.33-0.70 \mathrm{sec})$ than those from Black River $(\bar{x}=0.70$ 
sec, $s=0.35$ sec, range: $0.43-1.80 \mathrm{sec}$; t-test: $\left.t_{d f=25,(1)}=1.970, P=0.0303\right)$. We used the same apparatus in 2010 with further refinements to the test protocol. First, similar to Pearl et al. (2004), we normalized metabolic output by withholding food from frogs in the selection pool for 12-18 hrs. Second, after selecting frogs, but prior to trials, we housed frogs for at least $20 \mathrm{~min}$. in closed but ventilated 0.95-L opaque plastic containers that contained water about $1 \mathrm{~cm}$ deep to minimize pre-trial disturbance. Third, selection of the first frog in an experiment (e.g., which source population the frog was from) was determined by coin flip. We alternated source population for all subsequent frogs in an experiment. Lastly, after placing a frog in the apparatus, we began the trial (dropping the ball) only after a frog became stationary with its eyes positioned above water to ensure the pseudo-predator stimulus would immediately be perceived (body position was not controlled for in the initial 2009 experiment). After placement in the apparatus, we left a frog undisturbed for $60 \mathrm{sec}$, after which it was monitored through peep holes in the barrier to determine whether it had achieved the desired position.

We conducted two sequential experiments in 2010, one on August 3, when frogs ranged from 2 to $6 \mathrm{~g}$ in mass, and one on September 4, when frogs ranged from 8 to $15 \mathrm{~g}$ in mass. For each experiment frogs were selected arbitrarily from the rearing tanks, some frogs used in the second experiment may also have been used in the first. As frogs were not marked, this was unavoidable.

In the second experiment, we obtained individual body size (snout-to-vent length), shank (fibulo-tibia), and mass measurements; in the first experiment, we had only an estimate of the range of body sizes and masses in each population sample. 


\section{Data Handling and Analyses}

We used Ulead Video@ software (Ulead Systems North America, 970 West $190^{\text {th }}$ Street, Suite 480, Torrance, California 90501) to review the video archive. We measured latency-to-response by counting video frames to determine the amount of time between the initial movement of the dropping ball and the initial frog evasive action. We defined initial evasive action as the first leg movement a frog made after the ball was dropped. Though the distribution of latency-to-response times was skewed in some cases (skewness values were $\leq|0.72|$ ), we considered these departures from normality within the range for which t-tests are robust (Zar, 1999). Because our preliminary experiment suggested that Conboy Lake frogs would have shorter latency-to-response times than Black River frogs, the 2010 tests examined the one-tailed null hypothesis that latency-toresponse time for Conboy Lake frogs would be greater than or equal to that for Black River frogs. We also used one-tailed tests to examine the differences implied by the mean latency-to-response times within each population between our early and late experiments in 2010. As noted above, early versus late experiments in 2010 were also constrained by differences in body size as a consequence of growth of the juvenile cohort, so we also examined whether a relationship existed between body size parameters (SVL and mass) and latency-to-response time using Pearson correlations. Lastly, our serial trial sequence resulted in frogs used later in an experiment being held progressively longer periods of time in the opaque containers, so we examined whether a relationship existed between the sequence of when a frog was tested and the latency-to-response time using a simple linear regression. 


\section{RESULTS}

Notwithstanding our more refined experimental approach in 2010, we obtained the same results in both 2010 experiments (Figure 2.2) as in our preliminary experiment in 2009. In all cases, Conboy Lake frogs had significantly shorter latency-to-response times than Black River frogs (Table 2.1), and the mean difference between populations in both 2010 experiments was about $0.1 \mathrm{sec}$. Four juveniles failed to respond to the pseudopredator stimulus in the early experiment; all four were from the Black River population. We had no practical way to include these animals when calculating the difference in latency-to-response time in the early experiment (Table 2.1). In contrast, all 25 frogs from each population responded in the late experiment.

The 2010 experiments also revealed significantly shorter latency-to-response times in the later experiment for both populations (Figure 2.2, Table 2.1). This difference was similar in magnitude to the difference between populations. In the 2 September experiment, we recorded no significant differences among the three measures of body size between the Conboy Lake and Black River frogs (SVL: $t=1.78, P=0.082$; mass: $t=$ $0.40, P=0.695$; shank length: $t=0.40, P=0.695$ ) and found no significant correlations between any of the three measures of body size and latency-to-response times $(r=$ $|0.290|, P \geq 0.161)$.

Regression of latency-to-response times on the sequence in which frogs were tested revealed no significant relationship for any population sample in the 2010 experiments (Table 2.1). 


\section{DISCUSSION}

The consistency of our results gives us confidence that our hypothesis is supported, juvenile R. pretiosa from the Conboy Lake population are on average faster than those from the Black River population. Rearing conditions between the two populations were identical, so we expect that the basis of the difference lies in some environmental difference to which the two populations are exposed in their natal habitat. One possible basis for the differences is in the predator set to which each population is exposed. Though details of the full predator set for both populations are not known, the Conboy Lake population is the only $R$. pretiosa population known that has been able to co-exist with American Bullfrogs (Rana (Aquarana) catesbeiana), and has done so for nearly 60 years (K. Tidwell, unpubl. data). However, it needs to be acknowledged that the dropping-ball stimulus exhibits little resemblance to $R$. catesbeiana or other frogs that might approach floating aquatic prey (Werner et al., 1995; Pearl and Hayes, 2002; Wu et al., 2005), and is closer to what one might anticipate from an approaching avian predator (Martin and Lopez, 1990; Poulin et al., 2001). Alternatively or in addition, the slower latency-to-response behavior in the Black River population could reflect some impairment in anti-predator response that reflects local conditions. Contaminants are known to impair anti-predator responses, and impairment can sometimes be manifest as either the level or speed of response (Bridges, 1999; Punzo, 2005; Boone et al., 2005; Relyea and Edwards, 2010). That four Black River juveniles in the earlier 2010 experiment, when the juveniles were smaller, did not respond was a concern to us precisely because of such a potential scenario; the Black River population occurs in a 
more urbanized location where the likelihood of contamination is increased (Sprague and Nowell, 2008; Whittmer et al., 2010). Clearly, investigation of the environmental conditions influencing these two populations is a prerequisite to understanding the difference in response behavior.

The reduced latency-to-response we observed in the second versus first experiment in both populations also has three potentially confounded explanations. A more rapid response linked to ontogeny may be the simplest. Documentation of a more rapid response time with growth and maturation is well known (Choi and Park, 1996; Gomes et al., 2002; Martin et al. 2005). Though the lack of relationship between metrics of body size and latency-to-response time might seem to contradict this possibility, the size range of frogs in the experiment was small and perhaps not large enough to show the correlation we might expect with an ontogenetic change in response. However, it is also possible that husbandry activities such as cleaning and feeding made the frogs progressively warier. Lastly, a more rapid response could also reflect a second exposure to the stimulus. Though we believe the latter two explanations less likely, disentangling these explanations is of paramount importance to the captive-rearing effort for frogs such as these, which are targeted for translocation and intended to establish a new population. If husbandry is shown to effect predator escape behavior in captivity it may be possible to manipulate husbandry protocols to increase post-release survival.

We envision rich opportunities in the study of post-metamorphic frog responses to predators or stimuli mimicking predators, a depauperate research area. Our finding of significant variability in such a simple behavioral parameter as latency-to-response in the 
first two R. pretiosa populations we examined leads us to believe that this general model has promise for evaluating anti-predator responses. Notably, we see it as valuable in distinguishing among rearing regimes where frogs are drawn from the same populations. It also has promise for comparing wild and captive-reared frogs for dilution (or augmentation) in anti-predator response. The dropping ball pseudo-predator stimulus is useful to evaluate rearing regimes or captive versus wild frog responses. However, an evaluation of how the pseudo-predator stimulus compares to the stimulus from actual predators from different $R$. pretiosa populations is a critical next step.

\section{ACKNOWLEDGEMENTS}

The Mid-Columbia National Wildlife Refuges complex provided the Special Use Permit to collect eggs on Conboy Lake National Wildlife Refuge. The Nisqually National Wildlife Refuges provided the Special Use Permit to collect eggs in the Black River system and Port Blakeley Tree Farm, LLP, gave permission to collect eggs on their ownership. Frogs were reared under the amphibian and reptile Animal Use and Care Guidelines promulgated by the Society for Amphibians and Reptiles, which is a feature of the programmatic permit under which personnel of the Washington Department of Fish and Wildlife and their partners must work. The Oregon Zoo provided the facilities and the funding to support Tidwell in this experimental effort. Thanks to S. Hash and G. Gomez for their responsibilities in rearing the frogs; and to E. Menche and E. Giles for conducting some of the review of the video archive for the preliminary experiment. 


\section{CHAPTER 2 TABLES}

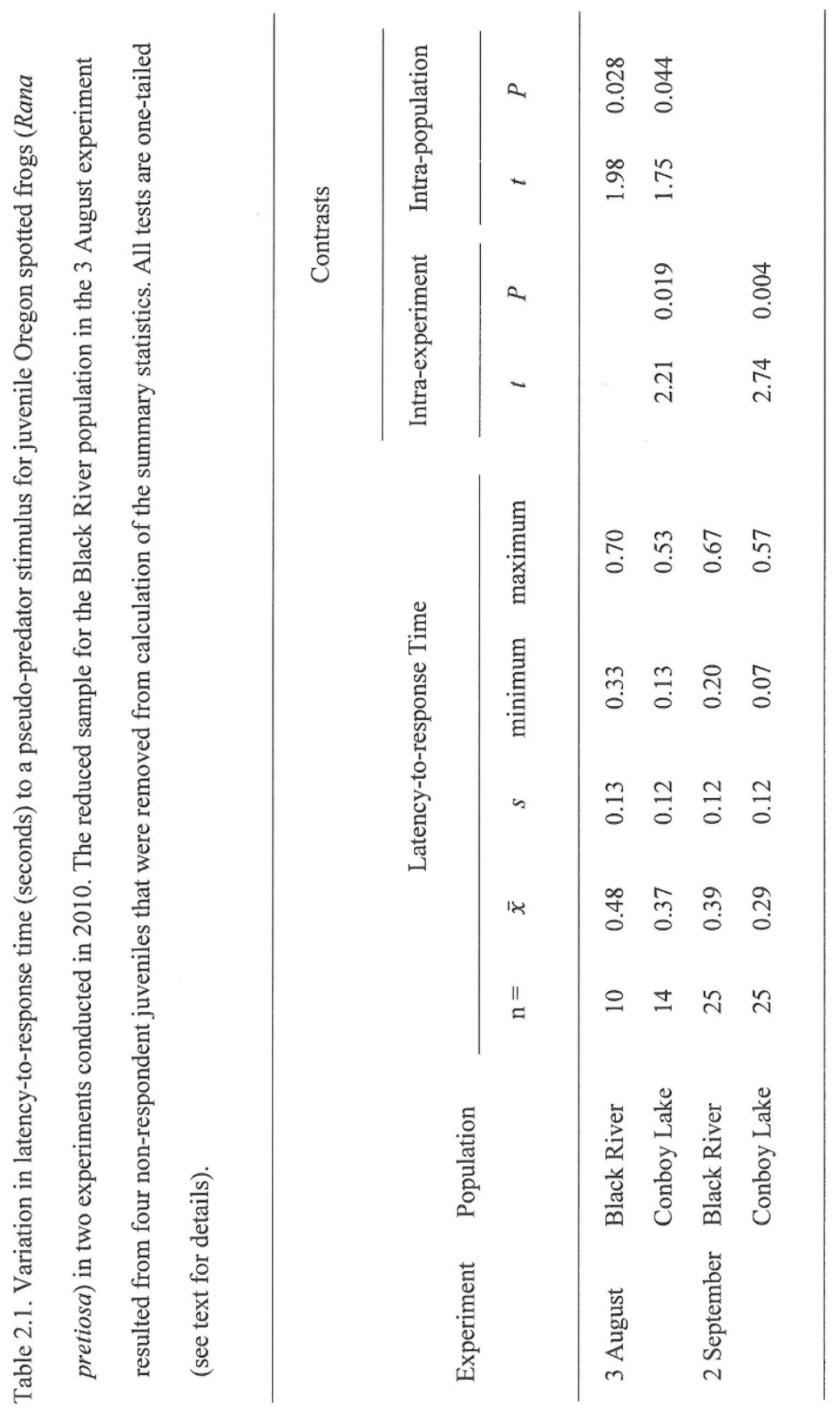




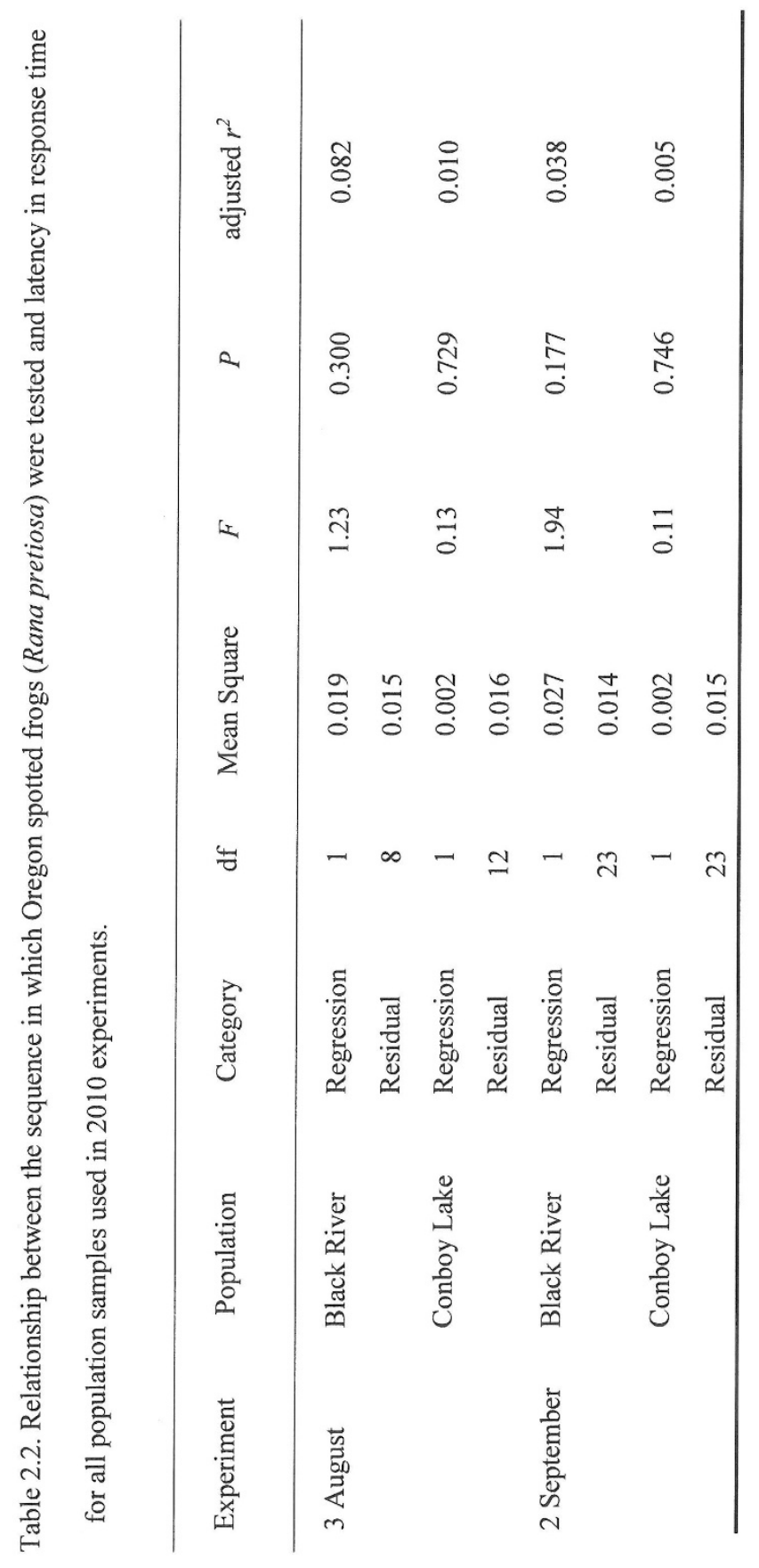




\section{CHAPTER 2 FIGURES}

Figure 2.1. Apparatus used in experiments in 2009-2010.

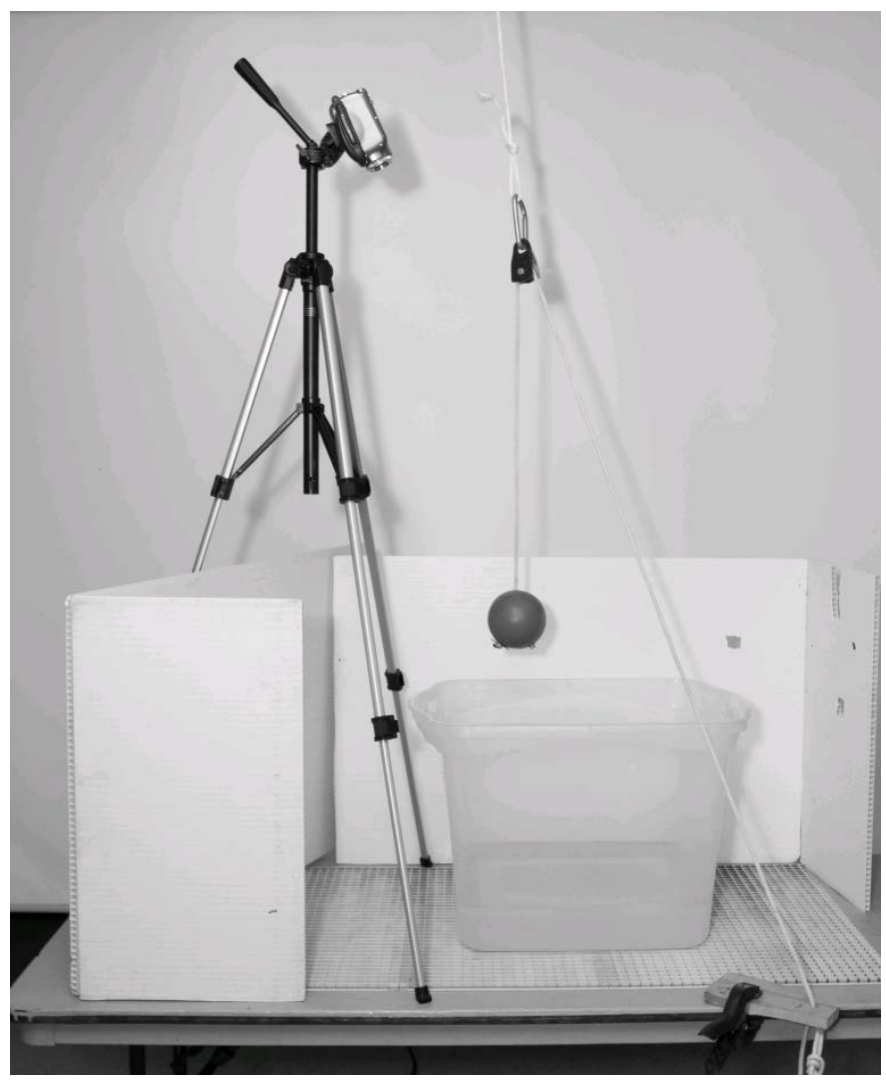


Figure 2.2. Latency-to-response results (in seconds) from early (3 August) and late (2 September) experiments in 2010. Boxes encompass the median, and are bounded by the 25th (lower) and 75th (upper) percentiles; whiskers denote the 10th (lower) and 90th (upper) percentiles; and dots are data points falling below the 10th or above the 90th percentiles. See Table 2.1 for the sample sizes in each experimental population.

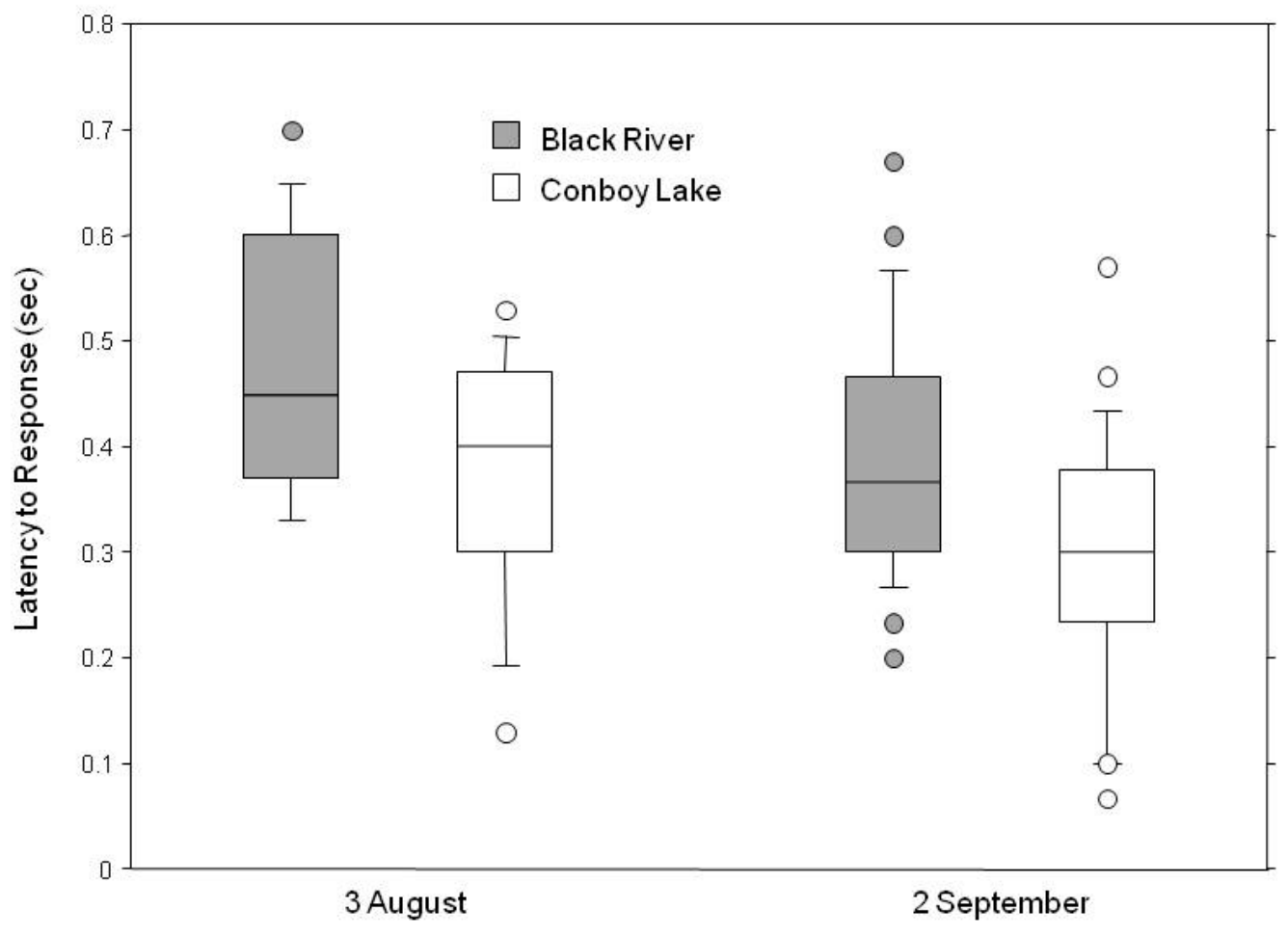




\title{
CHAPTER 3
}

\section{DIFFERENCE IN FLIGHT INITIATION DISTANCE BETWEEN RECENTLY METAMORPHOSED OREGON SPOTTED FROGS (RANA PRETIOSA) AND AMERICAN BULLFROGS (RANA (AQUARANA) CATESBEIANA)}

\begin{abstract}
Observations that recently metamorphosed Oregon Spotted Frogs (Rana pretiosa) appear to allow close approach before fleeing led us to contrast their flight initiation distances with those of introduced American Bullfrogs (Rana (Aquarana) catesbeiana) in order to determine whether this anti-predator variable had the potential to make $R$. pretiosa vulnerable to predation. Using a rangefinder radio-linked to a high-resolution global positioning system unit, we quantified flight initiation distance for recently metamorphosed juveniles of both species using a controlled approach at Conboy Lake National Wildlife Refuge, Washington State, USA. Recently metamorphosed R. pretiosa typically allowed extremely close approach (median flight initiation distance, $\tilde{x}=0.07 \mathrm{~m}$, range: 0-6.5 m) with over 30\% of frogs approached allowing themselves to be touched prior to fleeing. In contrast, recently metamorphosed $R$. catesbeiana typically did not allow close approach, always fleeing at distances $\geq 1.7 \mathrm{~m}$ (flight initiation distance, $\tilde{x}=$ $6.1 \mathrm{~m}$, range: $1.7-13.9 \mathrm{~m})$. The close approach tactic of $R$. pretiosa would be consistent with a crypsis-based anti-predator strategy, whereas $R$. catesbeiana uses a flight-oriented
\end{abstract}


method of avoiding predation. Permitting close approach may place recently metamorphosed $R$. pretiosa within the typical predatory strike range of $R$. catesbeiana, which may explain the disappearance of $R$. pretiosa in areas invaded by $R$. catesbeiana. Rana pretiosa at Conboy Lake represents a unique instance of long-term co-occurrence with $R$. catesbeiana, raising questions about the basis of this co-occurrence.

\section{INTRODUCTION}

Anti-predator behavior is basic for survival (Harvey and Greenwood 1978; Lass and Spaak 2003; Stankowich and Blumstein 2005). One important aspect of antipredator behavior is how close an organism will allow a predator to approach prior to taking evasive action, a distance termed the flight initiation distance (Ydenberg and Dill 1986; Cooper and Frederick 2007; Cooper 2009). Flight initiation distances or their equivalent have been examined in mammals (Altmann 1958; Dill and Houtman 1989; Bonenfant and Kramer 1996; Recarte et al. 1998), birds (Burger and Gochfeld 1991; Bednekoff 1996; Blumstein 2003), lizards (Rand 1964; Heatwole 1968; Cooper 1997b, 2003a, 2009), snakes (Mori and Burghardt 2001; Brown and Shine 2004), fishes (Dill 1990; Domenici 2002; Kiyoko et al. 2009), and invertebrates (Ydenberg and Dill 1986; Cooper 2006; Chan et al. 2010), but until recently, have remained relatively unstudied in amphibians (Martin et al. 2005; Cooper 2011a; McCallum 2011).

Our interest in flight initiation distances arose from the field observation that

Oregon Spotted Frogs (Rana pretiosa) appeared to allow closer approach than American Bullfrogs (Rana (Aquarana) catesbeiana). If close approach (short flight initiation 
distance) represents an anti-predator tactic (as discussed by Ydenberg and Dill 1986; Broom and Ruxton 2005; Cooper and Frederick 2007), it may signify a vulnerability for R. pretiosa, which is an endangered species in Washington State (McAllister and Leonard 1997), particularly in the face of the voracious and opportunistic introduced $R$. catesbeiana. For this reason, we conducted a study comparing flight initiation distance between these species to determine the extent to which their anti-predator tactics differ. We conducted the study at Conboy Lake National Wildlife Refuge, the only location where $R$. pretiosa has successfully co-existed long-term (nearly 60 years) with $R$. catesbeiana, in an effort to provide insight into the reason for their unique co-occurrence. We chose to use recently metamorphosed frogs for this comparison because we felt that behavioral inexperience resulting from entry into a new life stage and influenced by a different predator set (e.g., larval vs. frog predators) might best reveal where fundamental differences exist in the flight initiation distance of both species.

\section{MATERIALS AND METHODS}

\section{Study Area}

Our study area was located on Conboy Lake National Wildlife Refuge (NWR) in Klickitat County, Washington State, USA (Fig. 3.1). This refuge includes roughly twothirds of the large (4,046 ha) wetland complex in the Glenwood Valley, which is located $20 \mathrm{~km}$ southeast of Mount Adams at slightly over $550 \mathrm{~m}$ above mean sea level.

Construction of conveyance channels in the period 1911-1914 (Ladiges 1978) greatly altered drainage patterns across this wetland. These channels now provide permanent 
aquatic habitat in this system, habitat that is a basic life history requirement for both of the highly aquatic frog species in this study.

We performed this study in one $\geq 200 \mathrm{~m}$ reach in two of these conveyance channels, Cold Springs Ditch and Outlet Creek (Fig. 3.1). Vegetation in both reaches was a mosaic of floating mats and selected emergents. The Cold Springs Ditch reach had floating and emergent vegetation patches and was narrower (3-4 m wide) than the Outlet Creek reach (4-5 m wide), which had mostly floating vegetation.

\section{Reconnaissance surveys}

We performed reconnaissance surveys to obtain size distributions of the two target frog species to allow rapid identification of the recently metamorphosed cohort for both species based on size and to determine precisely where to locate our study reaches for flight initiation distance trials. These surveys were conducted between 0900 and $1700 \mathrm{~h}$ during the day and between 2030 and $0130 \mathrm{~h}$ at night over the two days immediately prior to our quantification of flight initiation distance. We used headlamps with a 60-200 lumen illumination range to conduct nighttime surveys.

\section{Quantification of Flight Initiation Distance}

We quantified flight initiation distance by performing controlled approaches to individual recently metamorphosed frogs of both species between 1000 and $1755 \mathrm{~h}$ on 2 and 3 September 2012. We modified the two-investigator approach that Martin et al. (2005) used on Rana perezi by using binoculars to assist locating frogs and recording distances with a rangefinder. During approaches, investigators moved in parallel, one in mid-channel, the other on the channel bank. We always moved in a direction back- or 
over-lit by the sun to ensure favorable illumination to detect frogs and to improve opportunities for approached frogs to clearly see the mid-channel investigator. Reconnaissance surveys had established that recently metamorphosed frogs of both target species were almost invariably in water, so the mid-channel investigator took on the pseudo-predator role to maintain greater uniformity in quantifying approaches. In each of the two study reaches used, we began at an arbitrary point in the channel and consistently moved slowly in the same direction until we finished that reach. Working in a uni-directional pattern and surveying each reach once ensured independence among approach observations. We stopped periodically at short-distance intervals (1-2 m) to completely scan the channel with binoculars up to $20 \mathrm{~m}$ in advance of our position, and initiated a controlled approach when one investigator located a frog of the target species. Upon locating a frog of the appropriate age cohort, we stopped and recorded the species. The on-bank investigator recorded data using a pull-down menu-enhanced personal digital assistant that was imbedded in a Trimble GeoExplorer 6000XT ${ }^{\mathrm{TM}}$ global positioning system (GPS) unit (Trimble Navigation Limited, Sunnyvale, California, USA). To maintain adequate precision, we recorded all locations in the GPS unit after logging at least 30 points for each location. After initial data were recorded, the on-bank investigator remained stationary while the in-channel investigator conducted the approach. Led by an extended arm and open palm hand similar to the method used by McCallum (2011), the in-channel investigator approached the target frog at a velocity of $0.5-0.75 \mathrm{~m} / \mathrm{s}$ on a direct line-of-sight vector. We verified the identification of the species during approach, and approach continued until the frog fled. As soon as fleeing occurred, 
the in-channel investigator stopped and obtained the flight initiation distance of the frog with a Trimble Laser Ace ${ }^{\mathrm{TM}} 1000$ digital range finder that was Bluetooth-linked to the GPS unit and recorded all flight initiation distances $\geq 0.5 \mathrm{~m}$ with decimeter accuracy. If the flight initiation distance was $<0.5 \mathrm{~m}$, we measured it with a steel tape to the nearest centimeter. Frogs that did not flee (allowed the investigator to touch them) were assigned a flight initiation distance of $0 \mathrm{~m}$. If the frog did not flee, it was repeatedly touched until it fled.

We were able to confidently visually assess the size of both species as representing recently metamorphosed animals during the trials based on having captured >200 individuals of both species measured over all body sizes (snout-to-vent length [SVL]) during mid-July-early September efforts in 2011-2012. Recently metamorphosed R. pretiosa averaged $39.3 \pm 2.1 \mathrm{~mm} \mathrm{SVL} \pm$ standard deviation (SD) (range: 36.0-46.0 $\mathrm{mm}$ SVL, $\mathrm{n}=29$ ) and one year after metamorphosis averaged $63.2 \pm 1.8 \mathrm{~mm} \mathrm{SVL} \pm \mathrm{SD}$ (range: 60.7-65.2 mm SVL, $\mathrm{n}=5$ ). Similarly, recently metamorphosed $R$. catesbeiana averaged $60.2 \pm 4.8 \mathrm{~mm}$ SVL \pm SD (range: 53.0-70.0 mm SVL, $\mathrm{n}=50$ ) and one year after metamorphosis averaged $93.2 \pm 9.5$ mm SVL \pm SD (range: 77.5-107.5 mm SVL, n = 20). Hence, the $>10 \mathrm{~mm}$ gap (measured as SVL) that existed between recently metamorphosed animals and the next year class after metamorphosis facilitated recognizing the cohort that had just metamorphosed.

\section{Measurement of Potential Co-factors}

We measured three factors that previous investigators had shown might influence flight initiation distance. Those co-factors were temperature at the location of the animal 
(Rand 1964; Rocha and Bergallo 1990; Smith 1997; Cooper 2003a), the orientation of the frog to the approaching investigator (Cooper 1997a; McCallum 2011) and the concealment level of approached animals (Heatwole 1968; Cooper 2003b; Martin et al. 2006). We recorded water temperature at the location from which a frog had fled within $30 \mathrm{~s}$ of the escape response with a digital Taylor thermometer (Taylor Precision Products, Oak Brook, Illinois, USA) to the nearest $0.1^{\circ} \mathrm{C}$. We estimated the frog's orientation on an axis relative to the in-channel investigator in 45 -degree increments on a $0-4$ scale. A frog estimated to be within 22.5 degrees of facing directly away from that investigator scored 0 , whereas a frog within 22.5 degrees of facing directly towards the investigator scored 4 and frogs facing to the right or left scored 1-3 depending on whether they had an orientation closer to or further from facing the investigator. Lastly, we estimated degree of cover around approached frogs categorically on a 0-3 scale. A zero score meant no emergent vegetation was present immediately around a frog, a score of 1 indicated that roughly one-third of the frog was cover-obstructed to the approaching investigator's visual field, a score of 2 indicated that about two-thirds of the frog was cover-obstructed, and a score of 3 indicated that nearly all the frog was cover-obstructed.

\section{Analyses}

Because the distribution of flight initiation distances for recently metamorphosed R. pretiosa was strong negatively skewed (Fig. 3.2), we compared the distributions of recently metamorphosed individuals between the two species with a KolmogorovSmirnov Goodness of Fit test and compared the medians of those distributions with a Mann-Whitney U test (Zar 2010). To ensure uniformity of conditions between the two 
species, we also compared cover, orientation, and water temperature for approached frogs between the two species using Mann-Whitney U tests. Finally, to determine whether any relationship existed between flight initiation distance and each of the co-factors measured for approached frogs (cover, orientation, and water temperature), we conducted Spearman Rank correlations $(\rho)$ for each species. For comparative purposes, we report means and standard errors in addition to medians and ranges for both the flight initiation distances and each co-factor. We describe effect size for flight initiation distance between the species with Hedges $g$, whereas effect size for co-factors on flight initiation distance was described with the aforementioned Spearman Rank correlations. All statistical analyses were performed using JMP version 9. For all analyses, we set $\alpha=$ 0.05; all tests were two-tailed.

\section{RESULTS}

\section{Comparison of Flight Initiation Distances}

We quantified flight initiation distance for 45 recently metamorphosed $R$. pretiosa and 27 recently metamorphosed $R$. catesbeiana. The distributions of flight initiation distance differed significantly between the species (Table 3.1; Fig. 3.2). Median flight initiation distance for $R$. pretiosa was less than $1 / 60^{\text {th }}$ that for $R$. catesbeiana (Mann-Whitney U: $P<0.0001$; Table 3.1). Fourteen of the R. pretiosa did not flee until after they were touched, and $87 \%(\mathrm{n}=39)$ of $R$. pretiosa allowed approach to within or equal to $0.25 \mathrm{~m}$ (Fig. 3.3). In contrast, none of the $27 R$. catesbeiana allowed closer approach than $1.7 \mathrm{~m}$. We found no significant differences among each of the cover, orientation, and temperature co-factors between the two species (Table 3.1). 


\section{Co-factors versus Flight Initiation Distances}

We found no clear relationship between flight initiation distance and either temperature or orientation for recently metamorphosed individuals for either $R$. pretiosa (orientation: $P=0.1061$; temperature: $P=0.7784$ ) or $R$. catesbeiana (orientation: $P=$ 0.1371; temperature: $P=0.7094$; Table 3.1). However, we found a significant inverse relationship between flight initiation distance and extent of cover for $R$. pretiosa $(P<0.0001)$, but not for $R$. catesbeiana $(P=0.5930)$.

\section{DISCUSSION}

Our hypothesis that $R$. pretiosa allow closer approach than $R$. catesbeiana, at least for recently metamorphosed individuals, was confirmed. The fact that flight initiation distance for $R$. pretiosa was typically so short that recently metamorphosed frogs frequently allowed themselves to be touched or almost touched by the investigator seemed counter-intuitive for predation avoidance. However, the highly cryptic litterdwelling frogs in the genus Craugastor exhibit behavior that is clearly more extreme; $>90 \%$ of individuals approached by a human observer did not flee until touched (Cooper et al. 2008). Further, where degree of crypsis has been quantified, more cryptic taxa or individuals generally have shorter flight initiation distances (Heatwole 1968; Cooper and Sherbrooke 2010; Camp et al. 2012). Hence, the longer flight initiation distances of $R$. catesbeiana appear to reflect a fundamentally different way to avoid capture.

The inverse relationship between cover and flight initiation distance in $R$. pretiosa, but not in $R$. catesbeiana supports the idea that $R$. pretiosa also uses a crypsis- 
based immobility tactic that differs fundamentally from the flight-based escape behavior we observed in $R$. catesbeiana. Such a tactic depends on crypsis until the risk of detection is high (Stankowich and Blumstein 2005; Cooper and Sherbrooke 2010), and since a greater level of cover is known to reduce the risk of detection (Cooper et al. 2008; Camp et al. 2012), flight initiation distances would indeed be expected to decrease with greater cover. Although we did not quantify the degree of crypsis that could help assess any difference between the two species, the color and pattern of recently metamorphosed R. pretiosa appeared to match to their background better than recently metamorphosed $R$. catesbeiana.

The differences we found in flight initiation behavior between recent metamorphs of the two species raise important questions about the basis of the differences, which may inform the unique long-term co-occurrence of the two species at Conboy Lake NWR. First, the flight initiation distances of recently metamorphosed $R$. pretiosa are very short, and this may put them at a disadvantage in the face of potential predation by $L$. catesbeianus. Vulnerability of recently metamorphosed $R$. pretiosa may be high if the predatory striking range of large $R$. catesbeiana encompasses the flight initiation distance of $R$. pretiosa. Secondly, although large (older) R. catesbeiana are known major predators (Werner et al. 1995; Pearl et al. 2004), details of how they take their prey remain unquantified. Third, our focus on recent metamorphs raises the question of whether older post-metamorphic life stages display similar differences in flight initiation behavior or whether shifts in those differences occur with size and experience. 


\section{ACKNOWLEDGMENTS}

We thank Shannon Ludwig, Heidi Newsome, and Lisa Wilson for help with

lodging and/or logistics at Conboy Lake National Wildlife Refuge, and David J. Shepherdson for help during reconnaissance surveys. Handling of amphibians followed the ASIH/HL/SSAR guidelines for use of live amphibians and reptiles in field research. Jason Deason (GeoLine, Inc., Tigard, Oregon, USA) assisted with GPS equipment and support. The Mid-Columbia National Wildlife Refuges complex provided the Special Use Permit to work on the refuge. Financial support was provided by Point Defiance Zoo and Aquarium Conservation Fund and Portland State University’s Forbes-Lea Endowment Fund. We thank Deborah Duffield and Tanya Cheeke for suggestions on the manuscript, and Jon Bowerman and The Oregon Community Foundation for their generous support of Tidwell. 


\section{CHAPTER 3 TABLES}

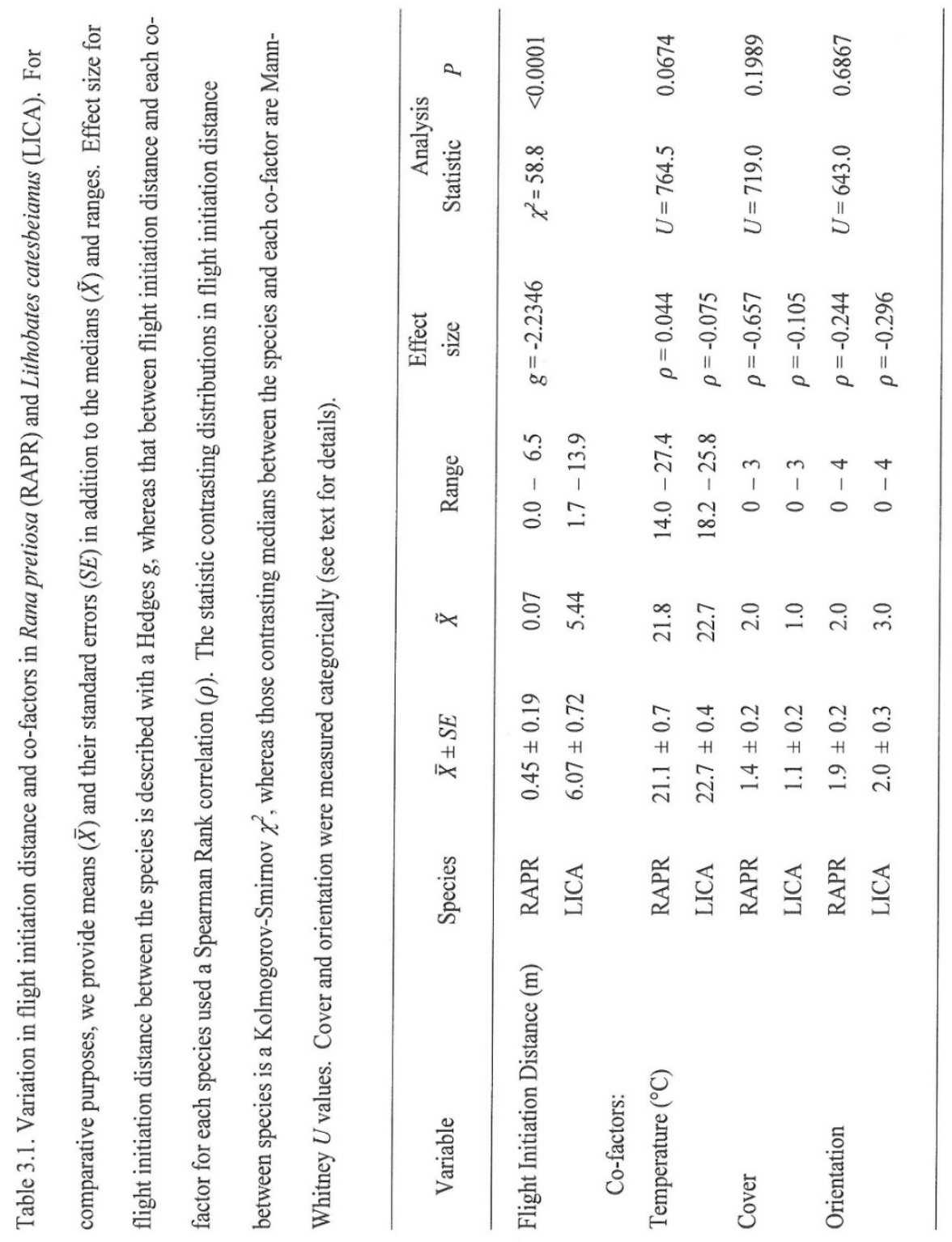




\section{CHAPTER 3 FIGURES}

Figure 3.1. Aerial photograph of the portion of Conboy Lake National Wildlife Refuge showing the Cold Springs Ditch and Outlet Creek conveyance channels and study reaches used in the flight initiation distance trials. The inset shows the location of Conboy Lake National Wildlife Refuge within Washington State.

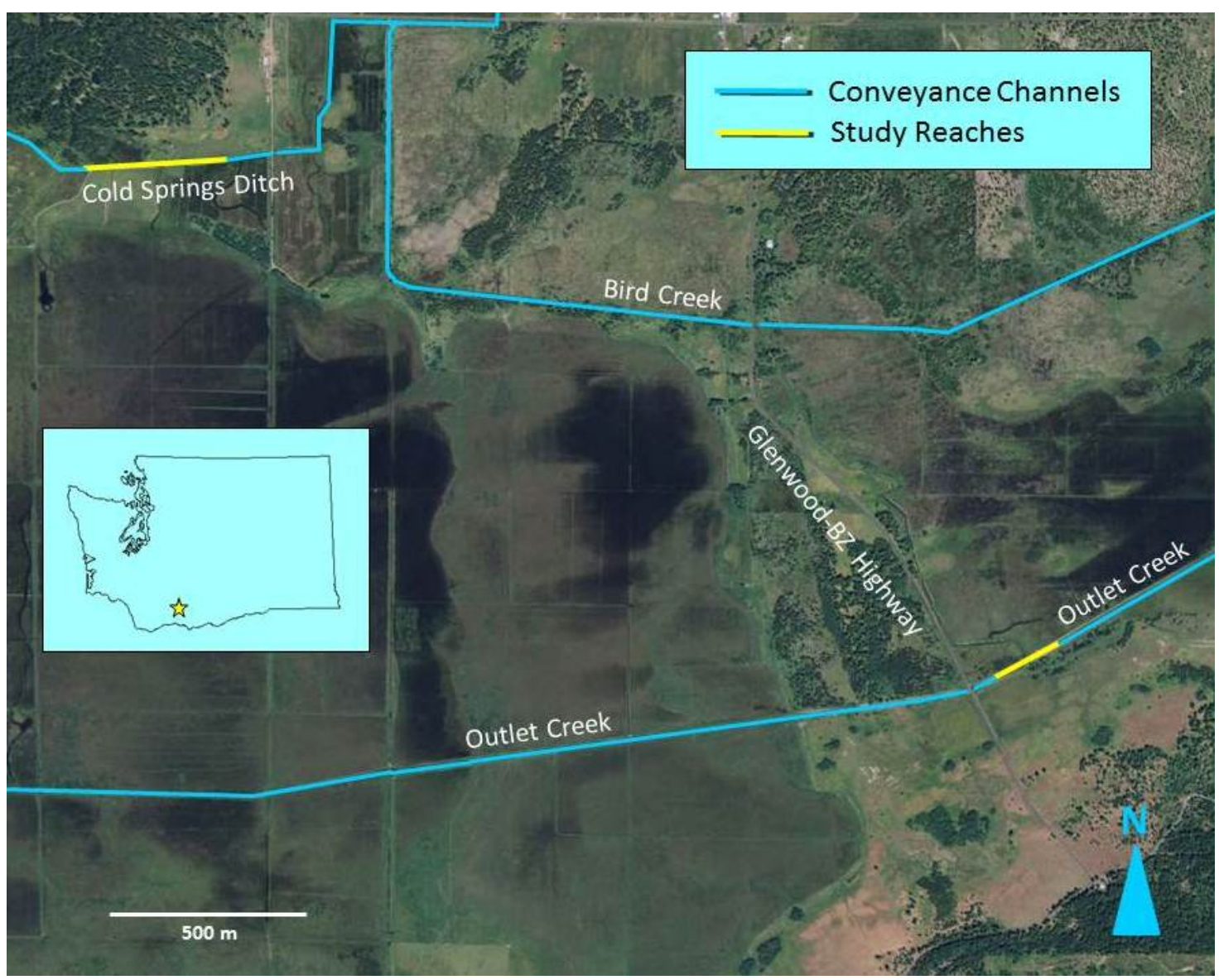


Figure 3.2. Distributions of flight initiation distances for recently metamorphosed individuals of Rana pretiosa (RAPR) and Rana (Aquarana) catesbeiana (RACT) at Conboy Lake National Wildlife Refuge on 2-3 September 2012.

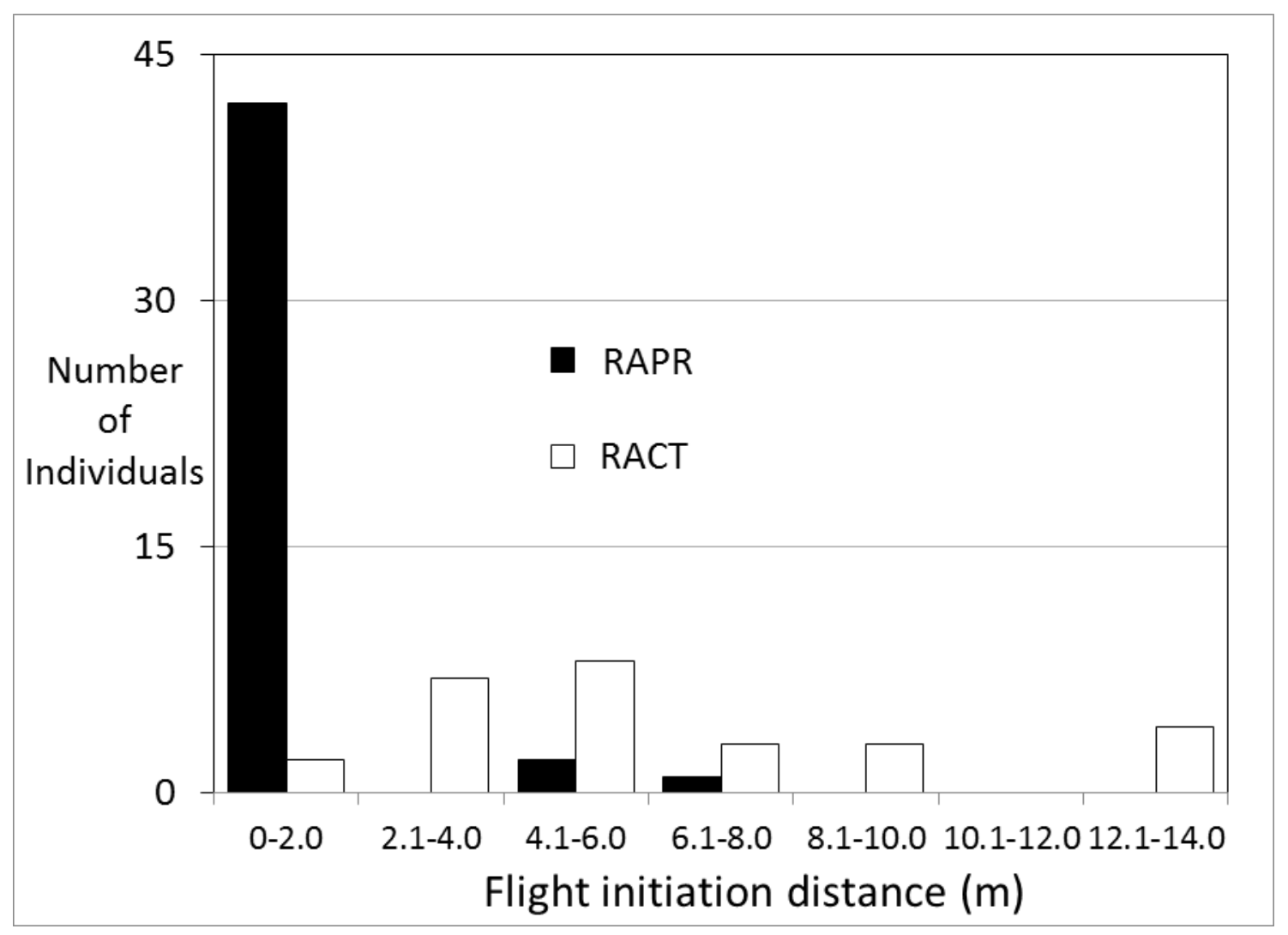


Figure 3.3. Distributions of flight initiation distance for recently metamorphosed individuals of Rana pretiosa (RAPR) and Rana (Aquarana) catesbeiana (RACT) at Conboy Lake National Wildlife Refuge on 2-3 September 2012 for those individuals that fled at distances $\leq 2 \mathrm{~m}$.

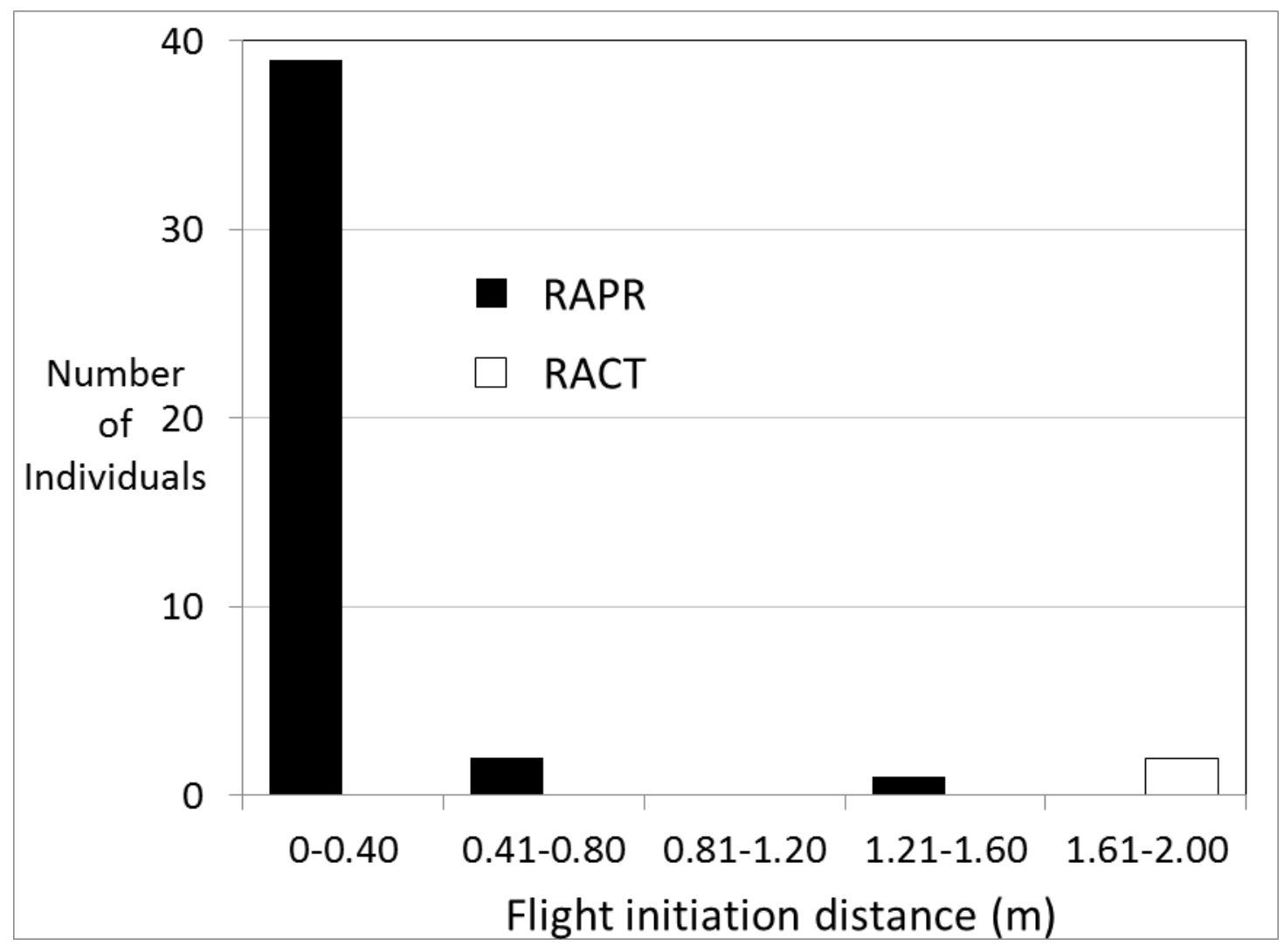




\title{
Chapter 4
}

\section{AGE-BASED SHIFT IN FLIGHT INITIATION DISTANCE FOR A CRYPSIS- DEPENDENT AQUATIC FROG}

\begin{abstract}
Recently metamorphosed Oregon Spotted Frogs (Rana pretiosa) are known to flee an approaching predator at extremely short distances, tactics thought to reflect crypsis-dependent anti-predator behavior. Our primary purpose here was to determine whether flee responses in Oregon Spotted Frogs change with age. We used controlled simulated predator approach trials to quantify flee responses for flight initiation distance among three frog age classes, and used "maximum-accuracy" optimal discriminant analysis to identify age-related differences in flight initiation and starting distances (distance from prey when predator begins approach). The youngest frogs allowed a closer approach than frogs in the two older age classes $\geq 88 \%$ of the time. Compared to the youngest frogs, flight initiation distance of older frogs was significantly greater and jackknife analysis suggested this effect is cross-generalizable. Similarly, compared to the youngest frogs starting distance of older frogs was significantly greater, however jackknife analysis suggested this effect is not cross-generalizable.
\end{abstract}




\section{INTRODUCTION}

Evasive behavior is a fundamental aspect of anti-predator tactics for diverse organisms, and flight initiation distance (FID), the distance between the predator and prey when the prey begins to flee, is a basic tool for its study (Samia et al., 2013, 2015; Cooper \& Blumstein, 2015). From a methodological perspective, a fortuitous aspect of FID is its ease and scope of application—human investigators simulating a predator can induce an organism to flee with relative ease. Although FID has been studied across a relatively broad range of organisms (see summary data in Stankowich \& Blumstein, 2005; Samia, et al., 2013, 2015; Cooper \& Blumstein, 2014, 2015), its study in frogs is largely a recent phenomenon (e.g., Martín et al. 2005, 2006; Cooper, 2011a; McCallum, 2011; Tidwell \& Hayes, 2013; Cloyed \& Eason, 2015; McKnight \& Howell, 2015).

Our overarching purpose in the work described herein is an outgrowth of previous investigations of FID in the Oregon Spotted Frog (Rana pretiosa), a species now listed as Threatened under the United States Endangered Species Act (USFWS, 2014), and the American bullfrog (Rana (Aquarana) catesbeiana), an introduced species widespread across the Oregon Spotted Frog's historic range. The American Bullfrog is thought to place the Oregon Spotted Frog at substantial risk from the direct effects of predation (Pearl et al., 2004). The striking finding of this work is that during controlled approaches using a human investigator as a simulated predator, recently metamorphosed Oregon Spotted Frogs allowed extremely close approach prior to fleeing-in many cases the investigator had to touch a frog before it took evasive action (Tidwell \& Hayes, 2013). 
This pattern is consistent with anti-predator behaviors found in anurans and other organisms that depend on crypsis (Broom \& Ruxton, 2005; Cooper et al., 2008; Cooper, 2011a).

Because this finding revealed a likely intrinsic condition that may place Oregon Spotted Frogs at risk of predation by American Bullfrogs, a larger and hence faster predatory species (Alexander, 2000), we were particularly interested in how FID might change with frog size — a surrogate measure reflecting their age and likely their experience (Lind \& Cresswell, 2005; Dagg, 2008). Furthermore, our earlier work revealed that young Oregon Spotted Frogs allowed closer approach when they had greater concealment (Tidwell \& Hayes, 2013), a pattern that also supports the notion of dependence on crypsis. For this reason, we also elected to evaluate the degree of concealment and orientation to determine whether their relationship to FID agreed with findings from prior research, and also to assess the relationship of the co-factors with age.

Our secondary purpose derives from recent refinements to escape theory arising from the concept of starting distance (SD), defined as the distance from which a predator first approaches its prey (Cooper \& Blumstein, 2014, 2015). Dumont and colleagues (2012) noted that in a controlled setting with a human investigator as the simulated predator, for each observation SD should be greater than FID in order to prevent truncating the upper tail of the distribution of FIDs obtained from the study sample. However, SD has also resulted in controversy due to its inconsistent fit between risk and cost factors, which has generated uncertainty regarding its ultimate importance in some taxa (Cooper, 2005; Cooper \& Blumstein, 2014; however see Blumstein, 2003; Samia et 
al., 2013). We thus evaluated SD in our analyses to confirm that the distribution of FIDs were not truncated, and also to explore the effect of ontogeny on SD in a frog, a taxonomic group for which additional study of these variables is needed.

\section{METHODS}

\section{Study organism}

The Oregon Spotted Frog is a moderate-sized ranid frog (adult size 50-105 mm SVL) that spends its entire life history in or immediately adjacent to aquatic habitats (Jones et al., 2005). During the active season, low emergent marsh is the focal habitat in which this species is observed (Pearl \& Hayes, 2004). The anti-predator tactics of postmetamorphic Oregon Spotted Frogs are consistent with their highly aquatic life style, where their refuge is the aquatic matrix (Licht, 1986). Videography reveals that when fleeing a predator, Oregon Spotted Frogs use their forelimbs to push backwards off aquatic vegetation at a slight downward angle to retreat rapidly from the water surface: this maneuver facilitates escape to deeper water because during the backwards push, the hindlimbs retract, enabling rapid swim toward a submerged refuge (KST, personal observation).

\section{Study area}

We studied Oregon Spotted Frogs at Conboy Lake National Wildlife Refuge

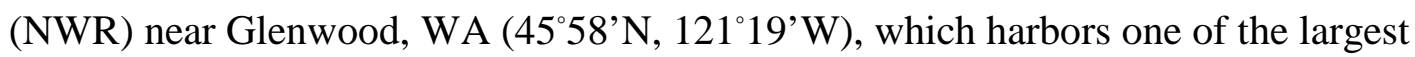
extant populations of this species. Used for the previous study of FID in Oregon Spotted Frogs (Tidwell \& Hayes, 2013), this site is composed of historic human-built conveyance 
channels that provide important active-season habitat for this frog. These channels are also utilized by many native bird, mammal, and snake predators, as well as by a substantial population of American Bullfrogs (Rana (Aquarana) catesbeiana) introduced to this site in 1958—and which elsewhere have been confirmed as predators of postmetamorphic Oregon Spotted Frogs (Pearl et al., 2004). The conveyance channels are 3$5 \mathrm{~m}$ wide, fed by a combination of surface flow from snow melt and permanent springs, and possess a patchwork of vegetation and open water. Vegetation in these channels is a mosaic (dominant species in parentheses) of floating and submerged beds (water buttercup [Ranunculus aquatilis] and common pondweed [Potamogeton natans]) and emergents of varying stature (narrow-leaved burreed [Sparganium angustifolium], cattail [Typha latifolia], creeping spike-rush [Eleocharis palustris], and reed canarygrass [Phalaris arundinacea]) that vary considerably in their local densities.

\section{FID trials}

We quantified FID for Oregon Spotted Frogs in the aquatic platform of previously described water-filled channels between 10 July and 1 September 2013, a date range selected to ensure young-of-the-year (YOY) frogs had completed metamorphosis. As in our previous study, FIDs were obtained using one investigator who simulated an approaching predator by walking towards the frogs (Tidwell \& Hayes, 2013). This is a widely accepted method for this sort of work (Stankowich \& Blumstein, 2005; Cooper, 2015) that was approved for this study by the Institutional Animal Care and Use Committee (IACUC; PSU13.01.19.1) at Portland State University. We employed most 
of the same methods used in the previous study of Oregon Spotted Frog FID (Tidwell \& Hayes, 2013), and describe the few differences for this study in the following narrative.

Over the interval 6-9 July 2013, we used daytime and nighttime surveys to locate channel reaches with large numbers of frogs in all age classes. We used 200-lumen headlamps during nighttime surveys to detect frogs via their eyeshine and binoculars during daytime surveys.

Once appropriate channel reaches were chosen, we conducted approach trials to quantify FID between 0700 and 1700 PST over seven different days within the interval 10 July-1 September 2013. In the channels, we used a two-person team to visually identify surface-active frogs for which we could quantify FID. Using binoculars to identify frogs at a distance, we worked in one direction with the sun at our backs in order to avoid resampling frogs and to ensure that frogs could clearly see the approaching investigator (see Tidwell \& Hayes, 2013). We limited our visual search range for frogs to $25 \mathrm{~m}$ because this was the furthest distance at which we could reliably detect frogs with binoculars and this distance encompassed the outer FID range we observed for the species in hundreds of hours of fieldwork. Upon identifying a frog, we immediately recorded its age class and measured the SD with the rangefinder, after which the in-channel investigator (KST) maintained visual contact with the frog while approaching it. Approach was made using a water route in a direct line-of-sight vector at a practiced moderately slow rate $(0.5-0.75 \mathrm{~m} / \mathrm{s})$, and the investigator maintained an outstretched open-palm hand during approach. Simultaneously, the on-bank observer (MPH) also maintained visual contact with the frog to identify the exact location from which evasive 
behavior occurred. As soon as a frog fled, invariably diving into the water column, the distance between the in-channel investigator's hand and the frog was recorded as the FID. We measured distances and recorded data with the same Laser Ace ${ }^{\mathrm{TM}} 1000$ digital range finder Bluetooth-linked to the Trimble $6000 \mathrm{XT}^{\mathrm{TM}}$ GPS unit that we used in the 2012 study. This system provided decimeter-level accuracy for FIDs $\geq 0.5 \mathrm{~m}$, and shorter FIDs were tape-measured to the nearest centimeter. If a frog allowed the investigator to touch it, the investigator would touch the frog until it took evasive action; touched frogs were assigned an FID of $0 \mathrm{~cm}$.

Similar to our visual separation of YOY from $2^{\text {nd }}$-year and older frogs in the 2012 study (Tidwell \& Hayes, 2013), we visually assigned frogs to age classes. In this study, we partitioned all post-metamorphic frogs into three classes (YOY, $2^{\text {nd }}$-year frogs, and adults [frogs $>2$ years old]). At the start of our 2013 study interval, the upper end of the $2^{\text {nd }}$-year age class and the lower end of the adult age class was 62 and $70 \mathrm{~mm}$, respectively, but by the end of our sampling interval, these class size limits had shifted upwards roughly $10 \mathrm{~mm}$ with seasonal growth. As a consequence of this size separation, these two older age classes were easy to distinguish visually. We emphasize that these year classes do not precisely reflect maturity patterns at this site; locally, Oregon Spotted Frog males can mature in their $2^{\text {nd }}$-year, whereas most females are not mature until they are $>2$ years old (MPH, unpublished data).

\section{Measurement of co-factors}

Our 2012 study of FID revealed that the level of concealment or cover influenced the FID of recently metamorphosed Oregon Spotted Frogs (Tidwell \& Hayes, 2013). The 
other co-factors measured, temperature and orientation, did not influence FID. Body temperature has been reported to influence the FID of a variety of ectothermic poikilotherms (Samia et al., 2015), but obtaining frog body temperatures in our FID trials was not feasible because most frogs escaped into water and were inaccessible. We obtained the water temperature where each frog fled, but in their recent review, Samia and colleagues (2015) showed that environmental temperature is a poor proxy for animal body temperatures and often is only weakly correlated with the FID of the animal. Accordingly, we elected to not address temperature as a potential co-factor in this study.

We did assess the previously evaluated co-factors of cover and orientation. Cover was measured using a graded scale similar to that used previously (Tidwell \& Hayes, 2013), however to simplify data collection and facilitate rapid, accurate data recording the new scale had three categories (rather than four) quantifying the degree to which the target frog was visible to the approaching observer. Cover was scored as 1 to 3 based on whether, respectively, cover obscured up to one third, more than one third and up to twothirds, or more than two-thirds of the target frog. We also elected to re-investigate orientation as a co-factor despite our previous finding that it had no influence of FID, due to the paucity of information available on amphibian FID. Moreover, escape behavior of ranid frogs has been found elsewhere to be influenced by their own orientation and also by the orientation of approaching stimuli (Ingle \& Hoff, 1990). Orientation was assessed via the same five-category qualitative scale used in prior research (see Tidwell \& Hayes, 2013 for scoring criteria). 
We also included measurement of SD because of recent work on other taxa that suggests SD may impact behavioral decision-making (Cooper, 2005; Samia et al., 2013; Nishiumi \& Mori, 2014). Oregon Spotted Frog natural history characteristics (Pearl \& Hayes, 2002) suggest that it uses an ambush and escape strategy, as defined by Cooper (2005). Hence, here we elected to quantify the potential association between ontogeny and SD as these variables are understudied among taxa using ambush and escape strategies (Samia et al., 2013).

\section{ANALYTICAL PROCEDURE}

In typical field-observational research (true presently), data fail to satisfy distributional assumptions underlying parametric tests, and variables having many tied values yield low statistical power for non-parametric tests. In this case, for each hypothesis tested the typical analytic approach is: (a) conduct various parametric and non-parametric analyses using both raw and transformed data, with and without outliers excluded; (b) exclude all combinations of analysis method and (adjusted) data that violate assumptions underlying the validity of statistical conclusions; and (c) select among any surviving combinations. Typically, this approach results in the reporting of a variety of different statistical tests (used to evaluate different hypotheses) that compare different "objective functions" such as means, medians or percentages. For the different tests, some associated measures of strength of effect (not available for all tests) are maximumcorrected, but few are chance-corrected. The combination of different objective 
functions, sample constitution, effect strength indexes, and uncertain validity of estimated $P$ values make a unified conceptual understanding of the omnibus findings within and across studies impossible. What is needed to remedy this ubiquitous analytical complexity is a universal statistical method that can test all statistical hypotheses using a standardized sample (e.g., all eligible observations in the sample without imputing or excluding data); maximizes a standardized objective function (e.g., model predictive accuracy); provides a chance- and maximum-corrected measure of effect strength as well as exact $P$ values that require no distributional assumptions; and provides an estimate of the potential cross-generalizability of the model if it is applied to an independent random sample (Samia \& Blumstein, 2014; Cooper \& Blumstein, 2015: Yarnold \& Soltysik, 2016).

\section{Strategy}

We used optimal discriminant analysis (ODA), which is novel in its application to the study of FID, to evaluate all statistical hypotheses investigated in this study (Yarnold \& Soltysik, 2016). ODA is an exact machine-learning algorithm developed more than 25 years ago, that explicitly maximizes the predictive accuracy of a statistical model for a given hypothesis (Linden \& Yarnold, 2016). For example, imagine an analysis comparing two age class categories: YOY versus Adult frogs. An example of an ODA model comparing these two age categories on an ordered attribute (FID) might be: if FID $\leq 1.16 \mathrm{~m}$ then predict that age $=$ YOY, otherwise predict that age $=$ Adult. If the model predicts that a given frog is a member of the YOY category and the frog indeed is a 
member of the YOY category, then the prediction is correct; an incorrect prediction occurs when the predicted and true class category status of a given frog differ.

Accuracy is measured by the effect strength for sensitivity (ESS) statistic (Yarnold \& Soltysik, 2005, 2016), a normed index that is both chance-corrected $(0=$ the level of predictive accuracy for the application that is expected by chance) and maximum-corrected $(100=$ perfect prediction $)$. The accuracy with which the ODA model predicts the true class category status of observations in the sample is measured using the ESS statistic. The ability of the model to accurately classify the YOY frogs (as being members of the YOY class category) is called the sensitivity of the model for the YOY class, and the ability of the model to accurately classify the Adult frogs (as being members of the Adult class category) is called the sensitivity of the model for the Adult class. For an application having $\mathrm{C} \geq 2$ class categories, sensitivity $=(1 / \mathrm{C}) \times 100 \%$ is expected by chance under the null hypothesis that the attribute is uniform random (Yarnold \& Soltysik, 2005, 2016). To calculate ESS, first compute C* $=100$ / C (this is the mean sensitivity expected by chance). Then, ESS $=\left(\right.$ mean sensitivity $\left.-C^{*}\right) /(100-$ C*) x 100\% (Yarnold \& Soltysik, 2005, 2016).

For example, imagine a model correctly classified 70\% of the YOY frogs (as being members of the YOY class category), and $80 \%$ of the Adult frogs (as being members of the Adult class category). Here, $C^{*}=100 / 2=50$; mean sensitivity $=(70+$ 80) $/ 2=75$; and ESS $=(75-50) /(100-50) \times 100 \%=25 / 50 \times 100 \%=50 \%$. In this example the ODA model achieved 50\% of the theoretical possible improvement in predictive accuracy beyond what is expected by chance. The ODA algorithm identifies 
the specific assignment rule (the ordering of the predicted class categories in the model, and the specific cut-points that separate predicted categories) that explicitly maximizes ESS for the application (Yarnold \& Soltysik, 2005, 2016). Based on simulation research, ESS $<25$ is a weak effect, $25 \leq$ ESS $<50$ is a moderate effect, and ESS $\geq 50$ depicts varying degrees of a strong effect (Yarnold \& Soltysik, 2005, 2016).

Permutation probability is used to compute statistical significance ( $P$ value) for ODA analyses: no distributional assumptions are required of the data so $P$ values are exact (Yarnold \& Soltysik, 1991; Soltysik \& Yarnold, 1994; Carmony et al., 1998; Yarnold \& Soltysik, 2016). Multiple tests of statistical hypotheses are reported in this study, so the Šidák multiple comparisons methodology ensured the desired experimentwise rejection criterion: effects are described as being statistically significant at the experimentwise ( $p \leq$ Šidák criterion) or the generalized (per-comparison $p \leq 0.05$ ) criterion (Yarnold \& Soltysik, 2005, 2016).

Finally, we validated the potential cross-generalizability of statistically significant ODA models using one-sample jackknife analysis, also called leave-one-out (LOO) validity analysis (Lachenbruch \& Mickey, 1968; Yarnold \& Soltysik, 2005, 2016). Failure to account for cross-generalizability of classification performance is critical because training (total sample) results can produce models that achieve superior performance but yield chance (or worse) levels of reproducibility (Yarnold \& Soltysik, 2016). For LOO analyses, each observation is in turn held out, a model is obtained for the rest of the sample and used to classify the held-out observation, accuracy is determined as success or failure in predicting the actual class membership of that 
observation, and the combined results of all $n$ such classifications are used to compute the LOO (validity) ESS (Yarnold \& Soltysik, 2005). The ESS that is obtained in such LOO analysis is considered an upper-bound estimate of potential cross-sample reproducibility: identical ESS values for both training and LOO analyses suggests the ODA model may cross-generalize with comparable predictive accuracy were it to be applied to classify independent samples (Yarnold \& Soltysik, 2005, 2016).

\section{Analyses}

We used ODA to: (a) evaluate whether the YOY Oregon Spotted Frog age class behaved similarly to the YOY frogs measured in our earlier work (Tidwell \& Hayes, 2013), by assessing if the proportion of frogs that did not flee until touched (i.e., FID = 0) differed between the two studies; (b) compare the FID distributions of YOY in 2012 versus 2013; and (c) determine whether frogs having FIDs = 0 were disproportionately distributed among the three age classes in the current study. The relationship (if any) between frog age and each study variable (FID, SD, orientation, cover) was identified using ODA.

We also assessed the multivariable relationship between frog age and the cofactors via classification tree analysis (CTA), a data mining algorithm that chains multiple ODA analyses together in order to explicitly maximize ESS (Linden \& Yarnold, 2016; Yarnold \& Soltysik, 2016). Like ODA, CTA requires no distributional assumptions, so Type I error rates are exact. Modest sample sizes among frog age class resulting in low statistical power prevented using CTA to discriminate all frog age groups simultaneously (Yarnold \& Soltysik, 2016). Accordingly, we used ODA and (when 
possible) CTA models to conduct pairwise comparisons among age groups, as was appropriate for the hypothesis, metrics, and strata in an analysis (Yarnold \& Soltysik, 2016).

Finally, for descriptive purposes and to enable contrasts with other work, we report variability in FID and starting distance using means $(\bar{x})$, standard errors of the means (SE), medians ( $\tilde{x})$, interquartile ranges (IQR), and coefficients of variation (CV).

\section{RESULTS}

Table 4.1 presents summary descriptive statistics for FID and SD, separately by age class, for data collected in 2012 and 2013.

\section{Comparison of FID among YOY for 2012 versus 2013}

The FID among YOY Oregon Spotted Frogs was significantly greater (at the generalized criterion) in 2013 than in 2012 ( $P<0.0084)$ : 80\% of YOY from 2012 had FIDs of 0.154 m or less, whereas 56\% of YOY from 2013 had FIDs greater than $0.154 \mathrm{~m}$ (ESS $=36.25$, indicating an effect of moderate strength). The LOO validation analysis indicated this model had relatively weak cross-generalization (ESS $=22.43)$, that also was statistically significant at the generalized criterion $(P<0.0357)$. Thus, if conceptualized as reflecting an independent planned comparison with LOO validation (requiring two tests of statistical hypotheses), this analysis revealed a statistically reliable difference of moderate strength between the FID distributions of 2012 and 2013 frogs 
that is expected to reliably cross-generalize with relatively weak strength if assessed for an independent random sample of 2012 and 2013 frogs.

A substantial proportion of individual frogs did not flee until touched by an investigator (i.e., FID $=0 \mathrm{~m}$ ) in both years. The proportion of YOY that were touched in 2013 (28\%) did not differ significantly from the proportion of YOY touched in 2012 (31\%, Tidwell \& Hayes, 2013; weak ESS = 2.99, $P<0.8064$; Table 4.2).

\section{Variation in FID with age}

We measured FID of 100 frogs roughly equally distributed across the three age classes (Table 4.1). We found FID to be variable ( $\mathrm{CV} \geq 1.2$; Table 4.1) and positively skewed across all three age classes (Figures 4.1 and 4.2), and visual examination suggested progressively larger mean and median values with increasing age (Table 4.1). Pairwise ODA analyses comparing FID distributions between frog age classes revealed a generalized significant difference between YOY and $2^{\text {nd }}$-year frogs (moderate ESS $=$ 40.63, $P<0.0096$ ), and an experimentwise significant difference between YOY and adult frogs (relatively strong ESS $=52.43, P<0.0001$; Table 4.5 ). The model between $2^{\text {nd }}-$ year and adult frogs was not statistically reliable (relatively weak ESS = 20.14, $P<0.4139$;

Table 4.5). In LOO validation analyses, the models comparing YOY to $2^{\text {nd }}$-year and adult frogs retained moderate strength and were statistically reliable: respectively, ESS = 37.50, $P<0.0017$ and ESS $=40.28, P<0.0004$ (Table 4.5).

In 2013, the proportion of frogs that did not flee until touched varied from $16 \%$ ( $2^{\text {nd }}$-year frogs) to $28 \%$ (for both YOY and adults; Table 4.2), but ODA revealed no 
significant difference in the ratio of fleeing versus non-fleeing frogs among age classes (relatively weak ESS = 14.69, $P<0.3927$; Table 4.2).

\section{Variation in SD with age}

The SD sample was nine fewer $(\mathrm{n}=91)$ than for FID because of unrecorded values. We found $\mathrm{SD}$ was moderately variable (CV $\geq 0.53$; Table 4.1$)$ and generally positively skewed across all three age classes, and visual inspection indicated that mean and median values for SD were greatest for $2^{\text {nd }}$-year frogs—rather than increasing with age (Table 4.1). Pairwise ODA analyses of SD between frog age classes revealed an experimentwise significant difference between YOY and $2^{\text {nd }}$-year frogs (moderate, borderline relatively strong ESS $=49.65, P<0.0008$ ), and a generalized significant difference between YOY and adult frogs (moderate ESS $=37.50, P<0.0165$ ). Consistent

with the finding for FID, the comparison of SD between $2^{\text {nd }}$-year and adult frogs was not statistically reliable (moderate ESS $=31.13, P<0.0751$; Table 4.6). In contrast to findings for FID, neither of the two SD models found reliable in the training analysis were confirmed in LOO validation analyses (respectively, relatively weak ESS $=11.23, P$ $<0.2743$ and relatively weak ESS $=21.88, P<0.0656$; Table 4.6).

\section{Variation in cover and orientation with age}

Analysis of the relationship between FID and the cover and orientation cofactors, separately examined by frog age, was unrevealing. Only one ODA model was identified that yielded a statistically significant, moderate (LOO analysis) to relatively strong (total sample analysis) ESS (Table 4.3)—FID progressively increased with cover for adult frogs. 


\section{DISCUSSION}

We found that YOY Oregon Spotted Frogs from Conboy Lake NWR clearly exhibited a shorter FID than adult frogs (evaluated based on relative body sizes). The finding of an increase in FID accompanying a larger body size is consistent among the four anuran species studied to date (all are ranid frogs), and it also represents a majority pattern (61\%: 20 of 33 species) over the suite of 26 field studies of FID of lower vertebrates (Table 4.4). For 17 of these 20 consistent species, an increase in FID with body size/age was the only pattern observed, but in the other three species the FID increase was recorded only under select circumstances. For the spiny chuckwalla (Sauromalus hispidus) FID increased with age in the proximity of the refuge, but not when the species was on foraging grounds (Shallenberger, 1970). For the western fence lizard (Sceloporus occidentalis), FID was greater in adult males versus juveniles, but did not differ between adult females and juveniles (Johnson, 1970). And for the common water snake (Nerodia sipedon), FID was greater in adult females (but not males) versus juveniles (Cooper et al., 2008).

For all except one of the remaining species no relationship between FID and size or age was identified. However, low statistical power resulting from small sample sizes in either the juvenile or adult size classes (Sauromalus varius, S. ater [formerly obesus] Shallenberger, 1970; Sceloporus virgatus, Smith, 1996; G. Smith, pers. comm.; Microlophus albemarlensis, Watkins-Colwell, 1997; Liolaemus nigromaculatus, Kelt et al., 2002), and size restriction resulting from a small body size range that in some cases 
excluded the juvenile size class (Iberolacerta horvathi, Zootoca vivipara, Capizzi et al., 2007; Podarcis muralis, Rugiero, 1997), or included only one age class (Tropidurus hispidus, T. semitaeniatus, Maia-Carneiro 2015; Gambelia wislizenii, Jacobson et al. 2016; Regina septemvittata, Layne \& Ford, 1984), call into question the conclusion that no pattern exists.

The remaining exception is the Galapagos marine iguana (Amblyrhynchus cristatus), and is distinctive because it exhibits the reverse pattern: FIDs in adults are equal to or shorter than FIDs in juveniles (Berger et al., 2007), and because it appears to contradict earlier work with the same species (Shallenberger, 1970). However, these studies differ markedly in the predators to which marine iguanas were exposed. Shallenberger (1970) worked on Narborough (= Fernandina) Island, which had a limited predator set of only native species, mostly the Galapagos hawk (Buteo galapagoensis). In contrast, Berger and colleagues (2007) worked on the islands of Isabella, San Cristobal, and Santa Cruz, where various levels of introduced exotic species (feral cats and dogs) occurred and the native predator set was largely depleted. Based on a review of FID in predator-limited island populations (Cooper et al., 2013), the age class-based differences in FID between these two studies likely reflect a complex relationship that involves their respective predators and body sizes associated with their age class. For example, adult marine iguanas eventually reach large body sizes that make them essentially invulnerable to the introduced domestic cats that place young marine iguanas at risk (Berger et al., 2007). 
Besides the present study, five other studies of lower vertebrates involving nine different species (Shallenberger [1970], Kelt et al. [2002], Berger et al. [2007], Gotanda et al. [2009], and Cloyed \& Eason [2015]) have compared FID over three age classes (Table 4.4). All of these studies except those of Berger and colleagues (2007) and Kelt and colleagues (2002) revealed that when differences exist between age groups, the greatest change in FID occurred between the YOY and the next older age class, whereas little change was observed between older age classes. This finding appears robust across analytic methods, whether derived by comparing means and partitioning variance using ANOVA (Shallenberger, 1970) or general linear mixed models (Gotanda et al., 2009, Cloyed \& Eason, 2015), or by comparing distributions and maximizing predictive accuracy via ODA as done presently. This pattern is also consistent with findings of several lizard FID studies that partitioned YOY from other age groups and recorded markedly shorter FIDs among the YOY (e.g., Cooper, 2015). Collectively these studies emphasize how crucial it is to sample at the highest age resolution possible to elucidate differences in FID that occur as the animals mature.

In this study, the statistically significant differences in FID observed between YOY and the older frogs were attributable to the homogeneous YOY response. That is, YOY frogs had a shorter FID (i.e., a FID as long as or shorter than the value of the cutpoint identified by ODA in the model for FID) versus the $2^{\text {nd }}$-year ( $87.5 \%$ of the time), and adult (96.9\% of the time) frogs (Table 4.5). The underlying basis of the age-related increase in FID observed in Oregon Spotted Frogs and the majority of lower vertebrates listed in Table 4.4 remains unknown, but three plausible, not necessarily mutually 
exclusive, not yet tested possibilities exist: predator depletion of individuals that allow the closest approach; individuals accruing non-lethal predator experiences that progressively increase their FIDs; or reduced reliance on crypsis with age (Cooper, 2011b; Cooper et al., 2013). The latter possibility may reflect an intrinsic tendency to be cryptic simply related to size (Cooper, 2011b), color or pattern crypsis independent of size, or both.

Interestingly, FID and SD generated different statistically reliable models in training (total sample) analysis for the same two age group comparisons: YOY versus $2^{\text {nd }}$-year and versus adult frogs. However, LOO validation analyses revealed that while the FID models did cross-generalize, the SD models did not cross-generalize. Alternatively stated, whereas the SD models lack explanatory power outside the conditions of the dataset with which they were developed, the FID models remained robust in $\mathrm{LOO}$ validation analysis. The finding that $\mathrm{SD}$ is not cross-generalizable produces uncertainty concerning the role of SD as a metric in escape theory for this frog species. However, SD is used as a surrogate for alert distance (AD)-the predator-prey distance when the prey becomes alert to the presence of a predator (Cooper \& Blumstein, 2014), which may exhibit important taxon-specific differences. In ranid frogs such as the Oregon Spotted Frog, AD is typically indistinguishable from SD because ranid frogs very rarely provide visual cues that they are alert to an approaching predator, for example an approaching human observer. Accordingly, model validation analyses such as conducted presently are needed for taxa that readily display visual or auditory cues that signal 
recognition of predator presence and allow clear separation of SD from AD (i.e., selected squamates and mammals).

Neither the cover or orientation co-factors provided clear results. Concerning cover, we found non-parallel results among age classes and cover between the 2012 data—analyzed comparing medians (Tidwell \& Hayes, 2013), and the 2013 data in this study —analyzed comparing distributions. Furthermore, our use of different scales for measuring cover in 2012 and 2013 makes conducting a direct replication analysis impossible. Concerning orientation, consistent with our 2012 results for YOY, we found no relationship between FID and orientation. Of note, the strongly dorsally rotated eyes of Oregon Spotted Frogs in comparison to other frogs (Jones et al. 2005) implies they possess a circumdirectional field of vision extending through 360 degrees. Therefore, it may not make any difference how an Oregon Spotted Frog is oriented to enable its detection of an approaching predator.

In conclusion, our work on age-specific patterns in FID in the Oregon Spotted Frog contributes to the body of literature indicating that FID reliably and reproducibly increases with age. Whether the mechanism for this pattern reflects predation-depletion of young frogs with the shortest FIDs, accrual of non-lethal predator experience over time, reduced reliance on crypsis with increased size, or some combination thereof represents clear opportunity for future study.

Contextual and analytical aspects of our study deserve comment because they contribute significantly beyond simply expanding and refining FID literature. Considering contextual implications first, regardless of the precise mechanism, the 
increase in FID we observed with age indicates that a segment of the Oregon Spotted Frog predator set drives the pattern. Conboy Lake NWR is the only location where Oregon Spotted Frogs and American bullfrogs have co-existed for decades, and the predator with the greatest likelihood of driving the pattern is the American bullfrog. Hence, one might surmise that in the absence of American bullfrogs, based on its crypsisdependent anti-predator strategy, FID might not change as Oregon Spotted Frogs age.

The analytical context is the inaugural use of ODA to explore patterns in FID. The ODA algorithm is well-suited to the diverse geometry associated with various metrics, hypotheses, and constraints associated with observational studies (Yarnold \& Soltysik, 2005, 2016). This study utilized ODA to test all statistical hypotheses using all eligible observations (frogs) in the sample-data were neither imputed nor excluded. For each analysis, the statistical model that maximized the chance- and maximum-corrected ESS accuracy statistic was identified; the corresponding exact, assumption-free permutation probability was computed; and LOO validity analysis was conducted to obtain an upper-bound estimate of potential reproducibility (cross-generalizability) of the finding. As seen herein, the use of ODA as a unified statistical analysis framework simplifies and standardizes the presentation and interpretation of statistical findings; maximizes the accuracy of resulting models and validity of statistical conclusions reached for each hypothesis tested; and resolves the pervasive statistical conclusion validity ambiguities that otherwise inescapably arise when using conventional statistical methods to analyze data that have been sampled from real-world applications. 


\section{ACKNOWLEDGMENTS}

This work was supported by the Dr. Holly Reed Conservation Fund of the Point Defiance Zoo and Aquarium through Dr. Karen Goodrowe-Beck; the Sophie Danforth Conservation Biology Fund of the Roger Williams Park Zoo; the Rhode Island Zoological Society; and the Washington Department of Fish and Wildlife. Geoline, Inc.

(Tigard, OR) provided a discount on the rental of both the Laser Ace ${ }^{\mathrm{TM}} 1000$ digital range finder and the Trimble $6000 \mathrm{XT}^{\mathrm{TM}}$ GPS units used in the field. Fieldwork was conducted under a Washington State programmatic permit; this permit allows Washington Department of Fish and Wildlife personnel to handle state-listed species in the course of their work. This permit requires personnel and their cooperators to follow the guidelines for handling of amphibians and reptiles in the field as specified by the Herpetological Animal Use and Care Committee of the American Society of Ichthyologist and Herpetologists (Beaupre et al., 2004). This work was conducted prior to the federal listing of this species. The Mid-Columbia National Wildlife Refuge (NWR) Complex provided a Special Use Permit for fieldwork at Conboy Lake NWR. Lisa Wilson, Assistant Refuge Manager at Conboy Lake NWR, and Heidi Newsome, Supervisory Wildlife Biologist for the Mid-Columbia NWR Complex, assisted with logistics at Conboy Lake National Wildlife Refuge. Andre Garrett and Katey Bonn assisted in the field. Randy Zelick provided suggestions on the manuscript. 


\section{CHAPTER 4 TABLES}

Table 4.1. Flight initiation distance and starting distance metrics (in meters) by age class for Oregon Spotted Frogs. Abbreviated statistics are coefficient of variation (CV), interquartile range (IQR), and standard error (SE).

\begin{tabular}{|c|c|c|c|c|c|c|c|}
\hline Year & Age Class & $\mathrm{n}=$ & Mean \pm SE & $\mathrm{CV}$ & Median & IQR & Range \\
\hline \multicolumn{8}{|c|}{ Flight Initiation Distance } \\
\hline 2012 & YOY & 45 & $0.45 \pm 0.19$ & 2.86 & 0.07 & 0.14 & $0.0-6.5$ \\
\hline \multirow[t]{3}{*}{2013} & YOY & 32 & $0.41 \pm 0.90$ & 1.23 & 0.21 & 0.63 & $0.0-2.0$ \\
\hline & $2^{\text {nd }}-$ Year & 32 & $1.59 \pm 2.28$ & 1.28 & 0.96 & 2.24 & $0.0-11.3$ \\
\hline & Adults & 36 & $2.28 \pm 2.73$ & 1.18 & 1.63 & 3.00 & $0.0-11.3$ \\
\hline \multicolumn{8}{|c|}{ Starting Distance } \\
\hline \multirow[t]{3}{*}{2013} & YOY & 32 & $3.41 \pm 0.32$ & 0.53 & 2.85 & 2.90 & $1.3-7.4$ \\
\hline & $2^{\text {nd }}-$ Year & 27 & $7.78 \pm 0.92$ & 0.61 & 7.00 & 6.00 & $2.7-22.9$ \\
\hline & Adults & 32 & $5.19 \pm 0.50$ & 0.54 & 1.63 & 3.85 & $1.6-11.1$ \\
\hline
\end{tabular}


Table 4.2. ODA analysis of the frequency of zero versus non-zero flight initiation distances (FID) among Oregon Spotted Frogs by age class. Effect strength for sensitivity (ESS) statistic and probability $(P)$ are reported for each analysis.

\begin{tabular}{|c|c|c|c|c|c|c|}
\hline Year & Age Class & $\mathrm{n}=$ & $F I D=0$ & FID $\neq 0$ & ESS & $P$ \\
\hline 2012 & YOY & 45 & 14 & 31 & 2.99 & $<0.8064$ \\
\hline \multirow[t]{3}{*}{2013} & YOY & 32 & 9 & 23 & & \\
\hline & $2^{\text {nd }}-Y e a r$ & 32 & 5 & 27 & 14.69 & $<0.3927$ \\
\hline & Adults & 36 & 10 & 26 & & \\
\hline
\end{tabular}




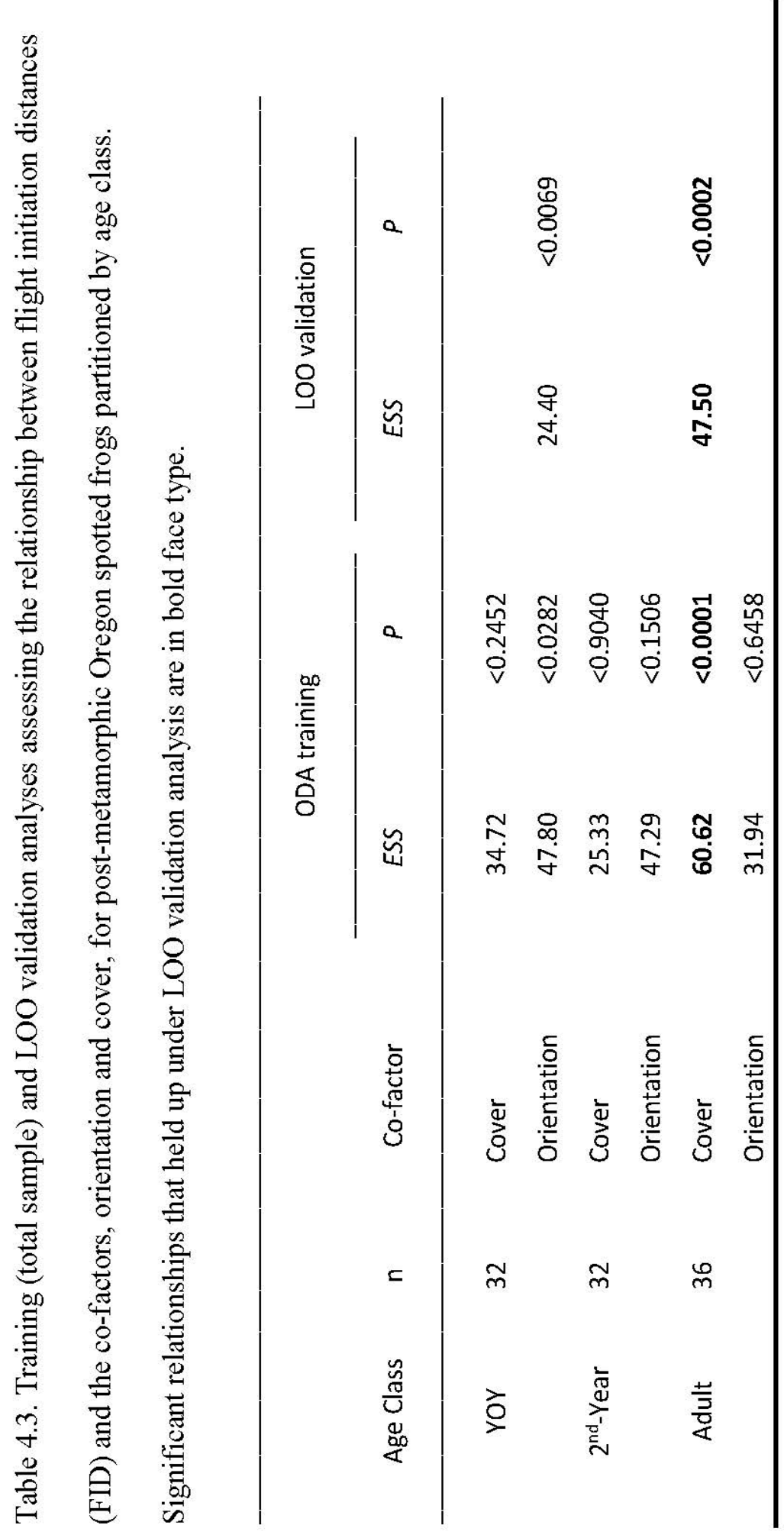




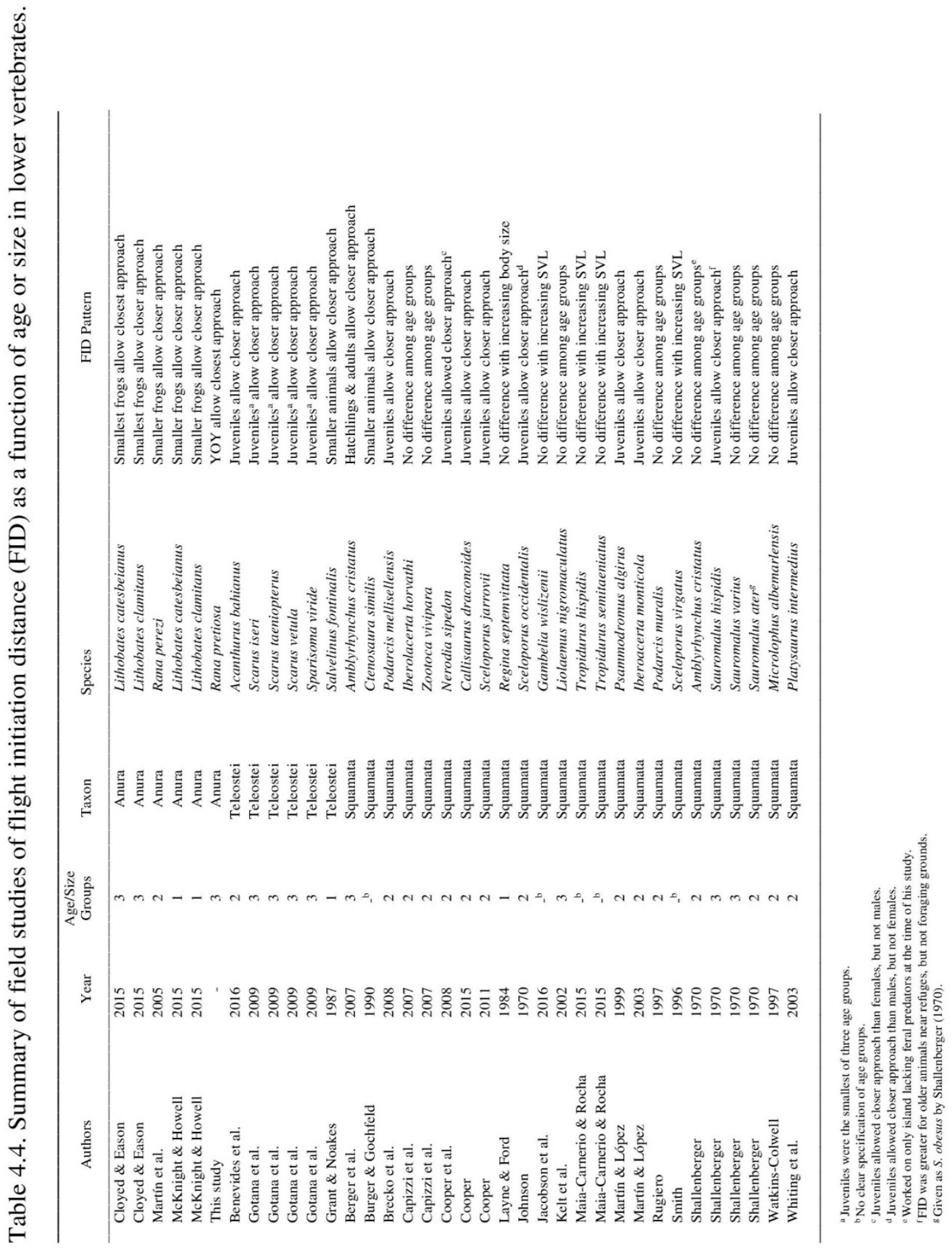




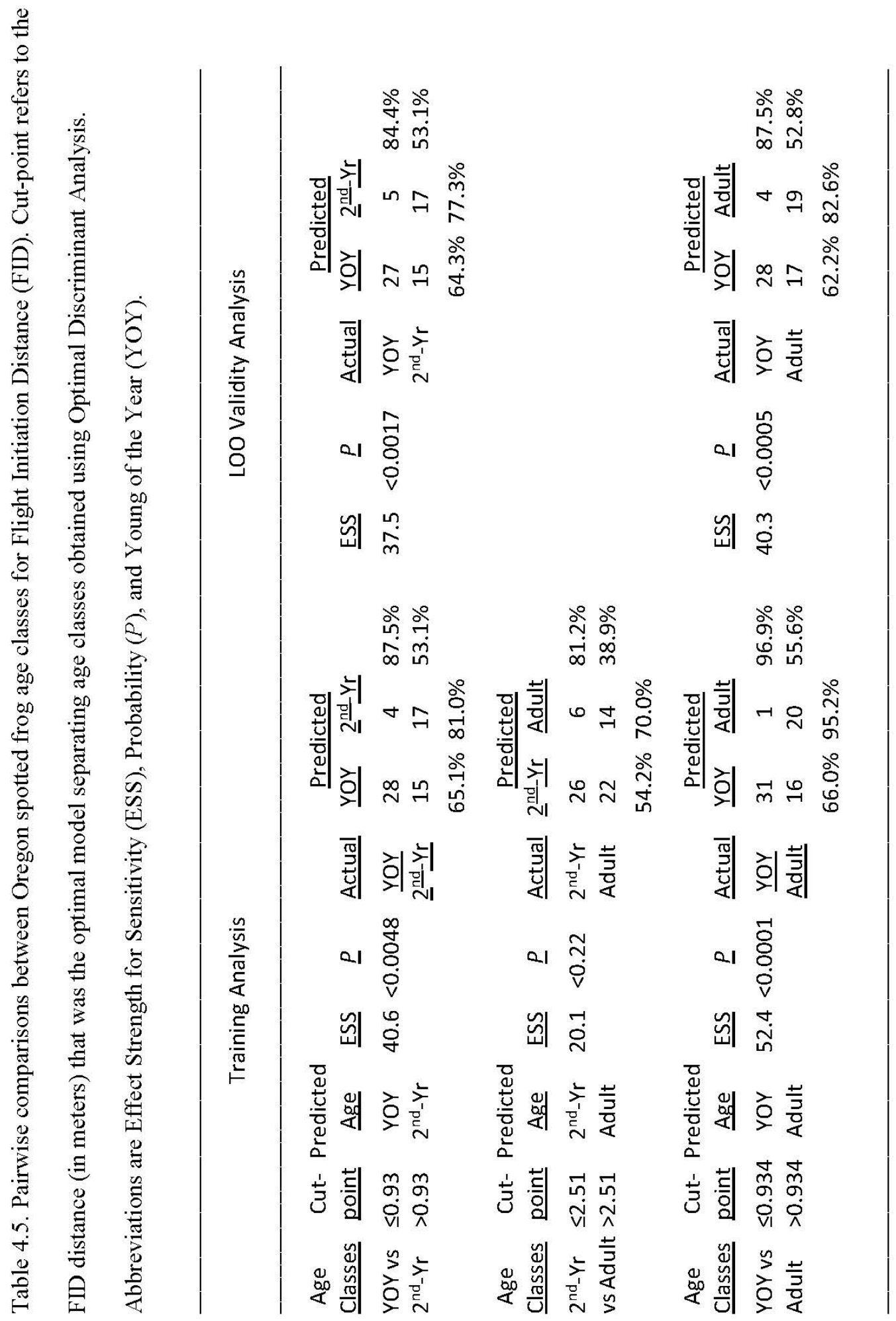




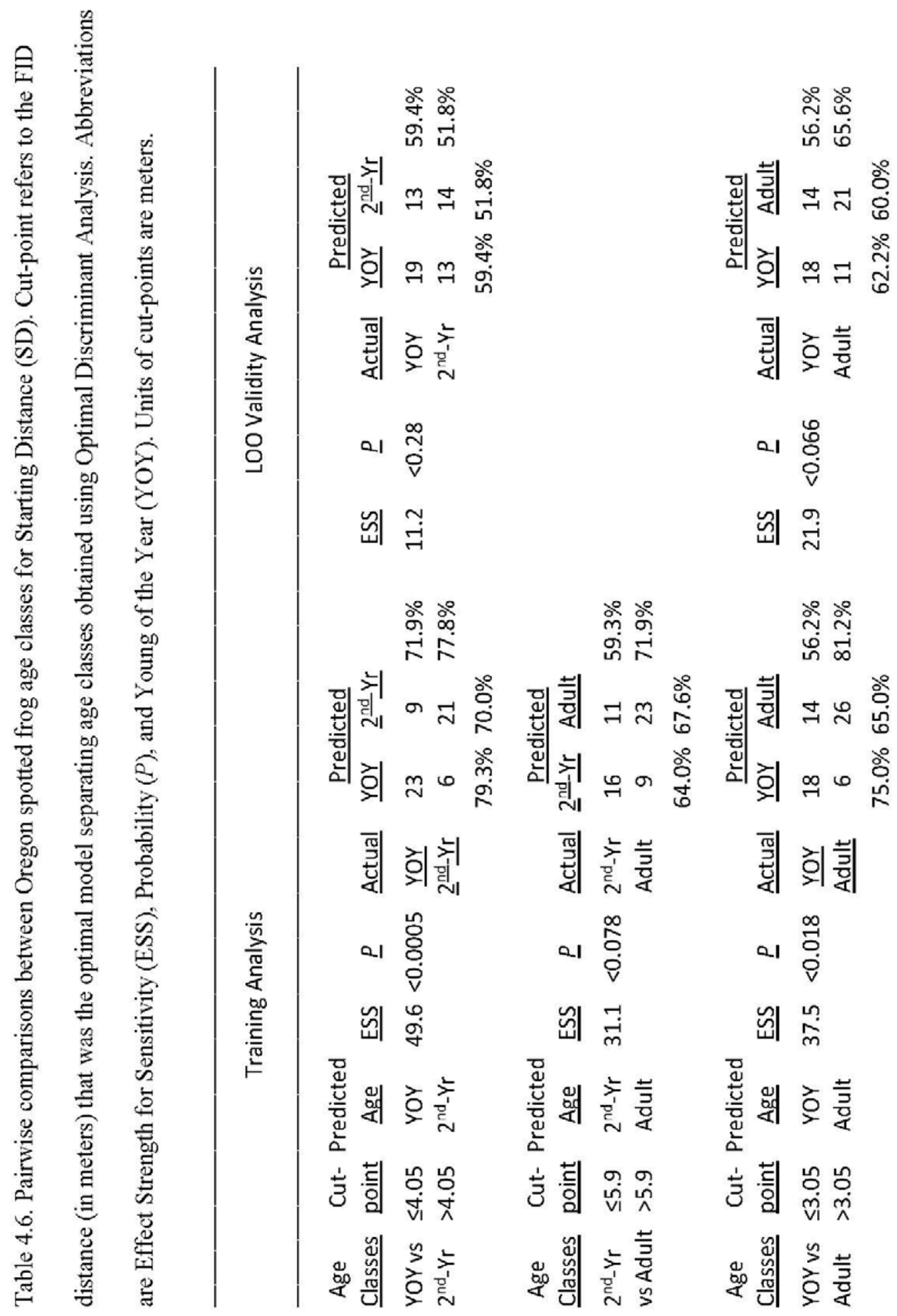




\section{CHAPTER 4 FIGURES}

Figure 4.1. Distribution of flight initiation distances for YOY, $2^{\text {nd }}$-year, and adult Oregon spotted frogs sampled at Conboy Lake National Wildlife Refuge in 2013.

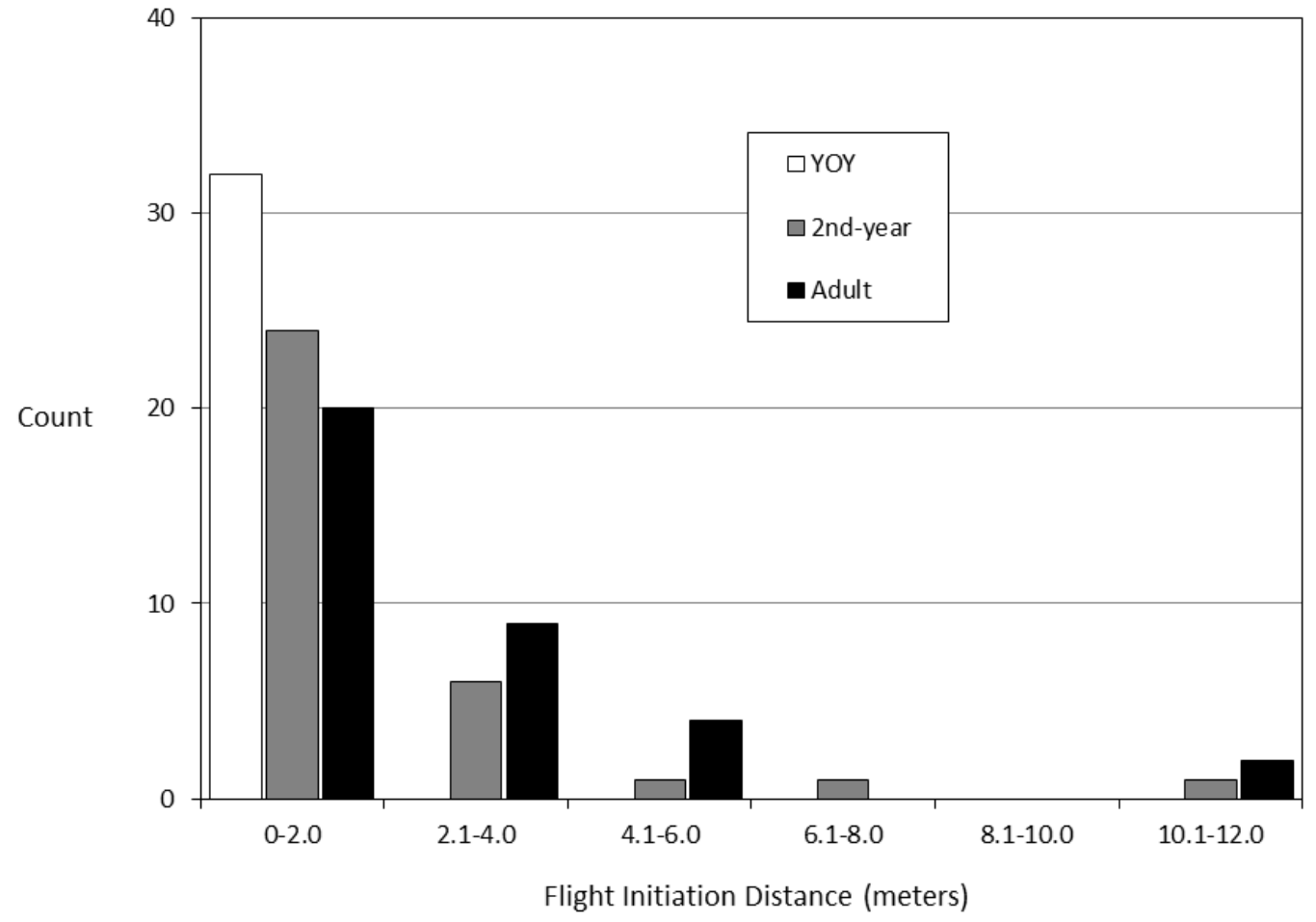


Figure 4.2. Distribution of flight initiation distances for YOY, $2^{\text {nd }}-$ year, and adult Oregon Spotted Frogs sampled at Conboy Lake National Wildlife Refuge in 2013 that allowed approach $\leq 2 \mathrm{~m}$.

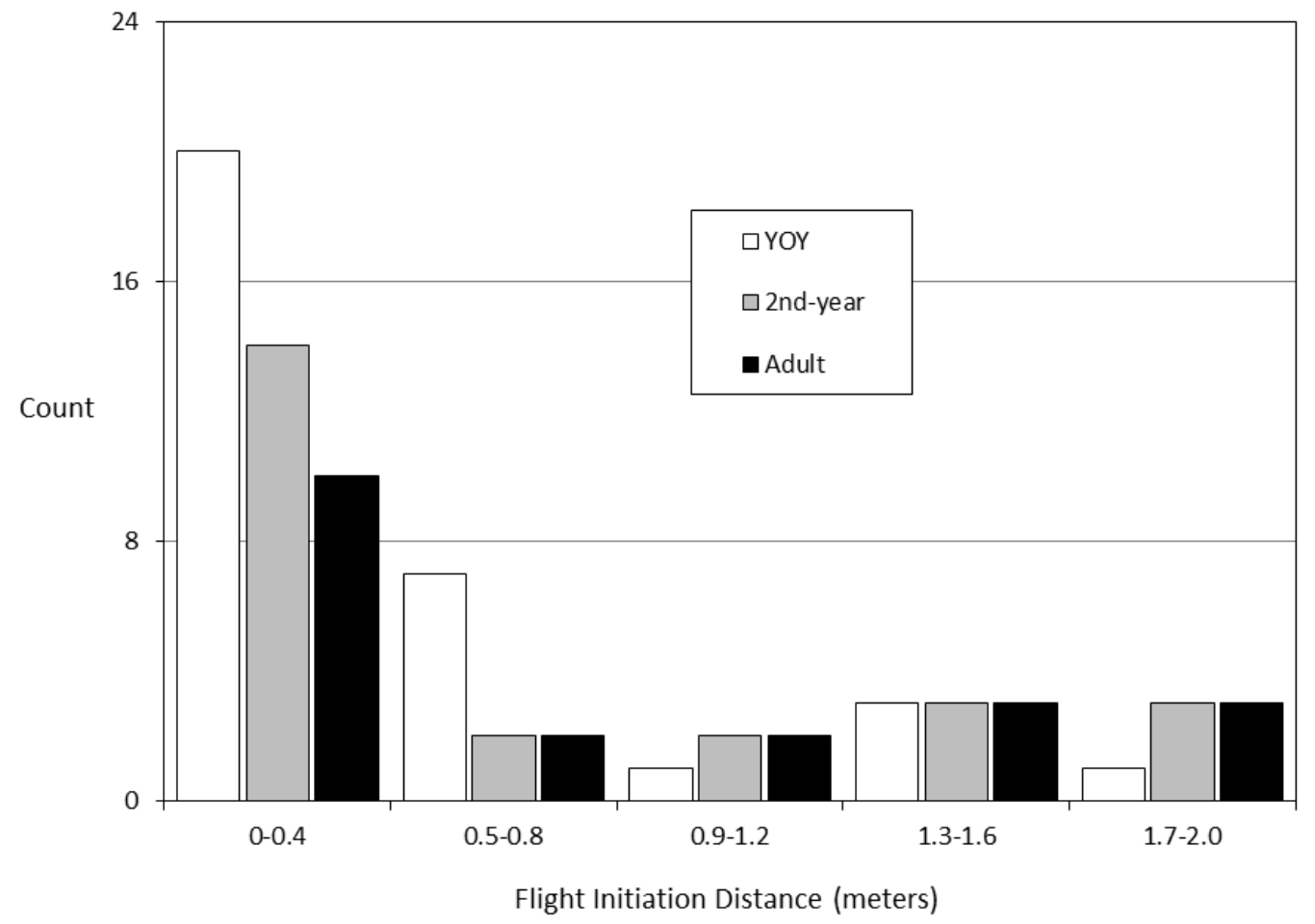




\title{
Chapter 5
}

\section{DIFFERENCES IN ESCAPE BEHAVIOR BETWEEN TWO POPULATIONS OF OREGON SPOTTED FROGS (RANA PRETIOSA) IDENTIFY AMERICAN BULLFROGS (RANA (AQUARANA) CATESBEIANA) AS A BEHAVIOR- MODIFYING AGENT}

\begin{abstract}
The process whereby introduced predators alter the behavior of native prey populations is rarely examined among lower vertebrates and remains unevaluated among anurans. Established populations of introduced American Bullfrogs (Rana (Aquarana) catesbeiana ) in the Pacific Northwest are presumed responsible for the decline and widespread local extirpation of the federally endangered Oregon Spotted Frog (Rana pretiosa). Recent studies at the only site of long-term co-occurrence of these two species revealed that the distance at which flight from an approaching predator (termed the Flight Initiation Distance [FID]) for first-year Oregon Spotted Frogs was typically shorter than in older frogs. To determine whether this age-based pattern is associated with bullfrog presence, we evaluated Oregon Spotted Frogs from another site where the predator set differs exclusively in lacking bullfrogs. We replicated the identical approach-trial procedure and analytic techniques used in our initial study. The Oregon Spotted Frogs from the bullfrog-absent site displayed no age-linked increase in FID. Moreover, the
\end{abstract}


distribution of FIDs for first-year Oregon Spotted Frogs from the site with bullfrogs present did not differ from those with bullfrogs absent. For the first year frogs from the bullfrog site we also evaluated whether approach-trial starting distance varied with age and whether vegetative cover influenced FID. Consistent with our previous study, we found no relationship between starting distance and age. We identified a positive relationship between cover and FID only for the $2^{\text {nd }}$-year (middle) age class—a pattern not previously observed. The distinctive contrast between the ontogenetic increase in FID when bullfrogs are present and the lack of ontogenetic change in the absence of bullfrogs collectively indicates potential differential selection focused on Oregon Spotted Frogs that survive the year after metamorphosis, a pattern that appears bullfrog driven.

\section{INTRODUCTION}

Systems where novel predators impact prey populations offer unique insights to evolutionary processes, among them how selection operates (Strauss et al., 2006). Coevolution of predator-prey behaviors have long been a focus in ecology (Dawkins \& Krebs, 1979; Lima, 2002), but the effects of introduced predators, often dramatically visible but frequently unrecognized at their onset, can be difficult to study due to accelerating change of the indigenous ecosystem (Fritts \& Rodda, 1998; Schlaepfer et al., 2005; Estes et al., 2011). Prior research documents behavioral adaptations to introduced predators in diverse taxa (Cox, 2004; Cox \& Lima, 2006; Grosholz \& Wells, 2016), but relatively little is known about escape behavior representing response to an introduced predator among mobile lower vertebrates. Such investigations are crucial to clarify the 
etiology and evolution of invasive species impacts, and to advance the study of antipredator behavior, specifically, of escape theory (Lima \& Dill, 1990; Stankowitch \& Coss, 2007).

Escape theory hypothesizes that prey species respond to predator cues in an optimal fashion whereby prey fitness, and thereby the likelihood of survival, is maximized (see Cooper \& Blumstein, 2015 for a review). A prominent behavioral metric used to evaluate escape theory for mobile organisms is the distance at which a prey organism allows a predator to approach before taking evasive action termed Flight Initiation Distance or FID. An ethological construct applied in more than 400 studies to date, FID has proven instrumental in exploring a wide range of escape theory hypotheses (Cooper \& Blumstein, 2015), and valuable in addressing questions concerning inter- and intra-population variation (Samia et al., 2013, 2015). Herein, we use FID to investigate inter-population variation attributable to ontogeny in the Oregon Spotted Frog (Rana pretiosa) to evaluate the potential impact of an introduced predator-the American bullfrog (Rana (Aquarana) catesbeiana; hereafter "bullfrog”).

Recently listed as threatened under the United States Endangered Species Act (USFWS, 2014), the Oregon Spotted Frog is a medium-sized (50-105 mm Snout-Vent Length [SVL]) aquatic ranid frog that survives in remnant populations scattered from south-central Oregon to extreme southwestern British Columbia. A marsh specialist, Oregon Spotted Frogs have been extirpated from an estimated 90\% of their historic range, presumably because of habitat alteration and introduced predators (Hayes, 1984, 1997; Watson, 2003, Pearl et al., 2004). Unfortunately, because historic range 
contraction was never monitored the details concerning its timing, development, and consequences are speculative. However, bullfrogs are strongly suspect in the decline of Oregon Spotted Frogs because of extensive overlap in habitat use arising from their similar aquatic life histories; large bullfrog body size facilitating predation on Oregon Spotted Frogs, juvenile and small adult Oregon Spotted Frogs being known bullfrog prey (Pearl et al., 2004; KST unpublished data), and bullfrogs occurring at nearly all sites of Oregon Spotted Frog extirpation (Hayes, 1994, USFWS, 2014). These reinforcing indications motivated our investigation of Oregon Spotted Frogs at their unique location of long-term co-occurrence with bullfrogs, Conboy Lake National Wildlife Refuge (hereafter Conboy).

Prior study of Oregon Spotted Frogs at Conboy revealed extremely short FIDs among $1^{\text {st }}$-year frogs (Tidwell and Hayes 2013), as well as an increase in FID with frog age (Hayes et al., in press). The age-associated increase in Oregon Spotted Frog FID at a site where bullfrogs are known to prey on Oregon Spotted Frogs led us to surmise that bullfrogs might be the genesis of this pattern. Hence, we speculated that based on the crypsis-dependent anti-predator strategy of Oregon Spotted Frogs, their FID might not change to the degree observed at Conboy with age at sites where bullfrogs are not present.

In order to test this hypothesis, we investigated Oregon Spotted Frog FID data at Big Marsh, a wetland system ecologically similar to Conboy that possesses an identical predator set, minus bullfrogs. Accordingly, we compared the ontogeny of FID in Oregon Spotted Frogs at bullfrog-free Big Marsh to the ontogeny of FID in Oregon Spotted Frogs 
at bullfrog-established Conboy. The original finding that Oregon Spotted Frog FID increased with age at Conboy suggests two different hypotheses. The null hypothesis presently is that the age-based shift in Oregon Spotted Frog FID does not differ between the two sites; this result would imply that the increase in FID after the first year is consistent for the species, regardless of site, and does not reflect introduced bullfrog predation. The a priori hypothesis is that little age-based change exists in the FID of Oregon Spotted Frogs from the Big Marsh population, which would support the theory that the longer FIDs observed in older frogs at Conboy reflect the impact of bullfrogs. We did not consider the theoretical possibility that FID in Oregon Spotted Frogs at Big Marsh would decline with ontogeny as reasonable because FID in young-of-the-year (YOY) Oregon Spotted Frogs at Conboy is already very short, such that a further decline in FID would likely not produce a reliably measurable difference. To evaluate the reproducibility of findings of our previous findings at Conboy, we also included analyses of the relationships of FID to cover and to starting distance (SD), i.e. the distance separating prey and investigator when the approach begins.

\section{METHODS}

\section{Study Sites}

The novel site used in this study was Big Marsh, a large (911 ha), complex in a moderately high elevation (1332 m) wetland system located in the upper Deschutes Watershed of central Oregon ( $\left.43^{\circ} 23^{\prime} \mathrm{N}, 121^{\circ} 56^{\prime} \mathrm{W}\right)$ and managed by the Deschutes National Forest (USDA, 1997). We selected this site expressly because it lacks bullfrogs; and it has the identical assemblage of known predators of post-metamorphic Oregon 
Spotted Frogs, and is similar in structure, vegetation, historical alteration, and hydrology to the bullfrog-occupied site, Conboy, that we used for contrast. The set of native predators on Oregon Spotted Frogs at Big Marsh includes: three wading birds (i.e., Sandhill crane [Antigone canadensis], Great blue heron [Ardea herodias], American bittern [Botaurus lentiginosus]), three mammals (i.e., River otter [Lontra canadensis], American mink [Neovison vison], raccoon [Procyon lotor]) and the Common garter snake (Thamnophis sirtalis). Similar to Conboy, Big Marsh has a series of human-built waterfilled conveyance channels that historically drained the system to allow livestock grazing. These spring- and snow-melt-fed channels are now grown to a mix of submerged, floating and emergent vegetation that form an extensive area of suitable habitat for Oregon Spotted Frogs lending itself to the same kind of approach trials to evaluate escape behavior that we conducted at Conboy. Details about Conboy, the large wetland complex located just south of Glenwood, Washington State $\left(45^{\circ} 58^{\prime} \mathrm{N}, 121^{\circ} 19^{\prime} \mathrm{W}\right)$ that is the unique site of long-term co-occurrence between Oregon Spotted Frog and bullfrogs that was the focus of the earlier comparative work used in this study, are presented elsewhere (Tidwell \& Hayes, 2013; Hayes et al., in press).

\section{FID Trials}

We used methods identical to those used in our prior study of the ontogeny of Oregon Spotted Frog FID at Conboy (Hayes et al., in press) to study the ontogeny of Oregon Spotted Frog FID at Big Marsh. Prior to the trials, we conducted reconnaissance surveys at night using 200-lumen headlamps to identify sections of the ditch system that contained frog numbers sufficient to conduct approach trials. At Big Marsh, 
reconnaissance surveys were conducted on 3-4 August 2013, and FID approach trials were conducted over 5-7 and 12 August 2013. At Conboy, we conducted reconnaissance surveys on 6-9 July 2013, and approach trials over seven days in the interval 10 July-1 September 2013.

Collection of FID data was conducted between 0700 and 1700 PST, with an onbank observer and an in-channel investigator working in tandem to identify surfaceactive frogs to a maximum distance of $25 \mathrm{~m}$ using field glasses (a distance determined through many hours of field work to lie substantially beyond the FID observed for any age of Oregon Spotted Frog). This ensured that every frog observed could be identified and accurately categorized for size. Once identified, a frog was visually assigned to one of three age classes —young-of-the-year (YOY), $2^{\text {nd }}$-year, and adult—based on size (see Hayes et al., in press for details), and its starting distance (SD) was measured. Working in a unidirectional pattern so as to avoid resampling frogs (i.e., pseudo-replication), the in-channel investigator (KST) then approached the focal frog, maintaining eye contact, at a constant rate with an outstretched open-palm arm until the frog took evasive action. We always worked with the sun at our back so the frogs could easily visualize the approaching investigator. As soon as an escape maneuver occurred, the in-channel investigator would stop and measure the distance between the frog's location and the outstretched hand (the FID), and the level of cover between the approaching investigator and the frog. If a frog allowed itself to be touched by the investigator then the frog was repeatedly contacted until it took evasive action. As in prior research, frogs allowing investigator contact were assigned an FID measurement of 0 . 
Measurements of SD and FID were made using the same combination of digital range finder Bluetooth-linked to a high resolution GPS system and a metric tape measure developed for previous studies of Oregon Spotted Frog FIDs (Tidwell \& Hayes, 2013). Cover was measured using the same three-category scheme used in the Conboy ontogeny work (Hayes et al., in press). Frogs with one-third or less of their body covered received a score of one; frogs with greater than one-third, and two-thirds or less of their body covered received a score of two; and frogs with more than two-thirds of their bodies covered received a score of three.

\section{Analytical Procedure}

Replicating our prior research for the Conboy sample (Hayes et. al, in press), optimal discriminant analysis (ODA) was used to evaluate the statistical hypotheses investigated here (Yarnold \& Soltysik, 2005, 2016). Accordingly and separately for every statistically significant finding that was identified for the Conboy sample, we tested the confirmatory alternative hypothesis that the prior finding replicates for the Big Marsh sample. In situations in which the confirmatory test was not supported for the Big Marsh sample, or if no prior effect was identified for the Conboy sample, we conducted analyses testing an exploratory alternative hypothesis that an association exists between the class variable and attribute. In all cases, the null hypothesis was that no statistically reliable difference or association exists.

An exact machine-learning algorithm developed over a quarter century ago, the ODA algorithm is well-suited to the diverse geometry associated with the various metrics, constraints, and hypotheses emblematic of observational research (Yarnold \& 
Soltysik, 2016). The use of ODA as a unified statistical analysis framework simplifies and standardizes presentation and interpretation of statistical findings, maximizes predictive accuracy of identified models and validity of statistical conclusions for each hypothesis tested, and resolves statistical conclusion validity ambiguities invariably arising when using conventional statistical methods to analyze data sampled from realworld applications (Grimm \& Yarnold, 1995, 2000).

ODA explicitly maximizes the predictive accuracy of a statistical model developed to test any given hypothesis (Linden \& Yarnold, 2016). For example, for an analysis comparing two age class categories (YOY versus Adult frogs), an ODA model comparing these two age categories on an ordered attribute such as FID might be: if FID $\leq 0.86 \mathrm{~m}$ then predict age $=$ YOY, otherwise predict age $=$ Adult. If this model predicts a given frog is a member of the YOY category and the frog actually is a member of the YOY category then the prediction is correct: an incorrect prediction occurs when a frog's predicted and true class category status differs. Model predictive accuracy is summarized using the chance- and maximum-corrected $(0$ = predictive accuracy expected by chance; $100=$ perfect accuracy) effect strength for sensitivity (ESS) index (Yarnold \& Soltysik, 2005, 2016). For an application having $C \geq 2$ class categories, sensitivity $=(1 / C) x$ $100 \%$ is expected by chance under the null hypothesis that the attribute is uniform random. To calculate ESS, first compute the mean sensitivity expected by chance: $\mathrm{C}^{*}=$ $100 /$ C. Then, ESS $=\left(\right.$ mean sensitivity $\left.-C^{*}\right) /\left(100-C^{*}\right) \times 100 \%$. The ODA algorithm identifies the specific assignment rule (the ordering of the predicted class categories in the model, and the specific cut-points that separate predicted categories) that explicitly 
maximizes ESS for the application. Simulation research indicated that ESS $<25$ is a weak effect, $25 \leq$ ESS $<50$ is a moderate effect, and ESS $\geq 50$ depicts varying degrees of a strong effect (Yarnold \& Soltysik, 2005, 2016).

Permutation probability is used to compute statistical significance ( $P$ value) for ODA analyses: because no distributional assumptions are required of the data the $P$ values are exact (Yarnold \& Soltysik, 1991; Carmony et al., 1998). If multiple tests of statistical hypotheses are reported in a study, the Šidák multiple comparisons methodology is used to ensure the desired experimentwise rejection criterion: effects are described as being statistically reliable at the experimentwise ( $p \leq$ Šidák criterion) or the generalized (per-comparison $p \leq 0.05$ ) criterion (Yarnold and Soltysik 2005, 2016). Effects having associated $P<0.05$ herein are statistically significant at the generalized criterion unless noted as having “experimentwise $P<$ ”.

The potential cross-generalizability of statistically significant ODA models was assessed using one-sample jackknife analysis, also called leave-one-out (LOO) validity analysis (Lachenbruch \& Mickey, 1968). Failure to account for cross-generalizability of classification performance is critical because training (total sample) results can produce models that achieve superior performance but yield chance (or worse) levels of reproducibility (Yarnold \& Soltysik, 2016). For LOO analyses, each observation is in turn held out, a model is obtained for the rest of the sample and used to classify the heldout observation, accuracy is determined as success or failure in predicting the actual class membership of that observation, and the combined results of all $n$ such classifications are used to compute the LOO (validity) ESS (Yarnold \& Soltysik, 2005). The ESS that is 
obtained in such LOO analysis is considered an upper-bound estimate of potential crosssample reproducibility: identical ESS values for both training and LOO analyses suggests the ODA model may cross-generalize with comparable predictive accuracy if it was applied to classify independent samples (Yarnold \& Soltysik, 2005, 2016).

\section{RESULTS}

We sampled 116 frogs at Big Marsh and 100 at Conboy Lake across all age classes combined. For both sites, summary descriptive statistics for FID and SD, partitioned by age class, are presented in Table 5.1.

Statistical analysis began with an exploratory comparison (first aggregated over age, then separately by age) of the proportion of frogs that did not flee until touched (i.e., having FID $=0 \mathrm{~m}$ ) between Conboy and Big Marsh. Exploratory hypotheses were tested since no statistically reliable differences in the proportion of touched frogs were observed between age groups in the prior analysis for Conboy Lake. Confirmatory analysis was then used to assess generalizability of prior findings on the relationship of age and FID identified at Conboy applied to the Big Marsh data. Because the hypothesized differences between YOY and the $2^{\text {nd }}$-year and adult frogs were not confirmed, the pairwise analyses were repeated testing as non-directional hypotheses. Planned between-site comparisons of FID distributions for different age groups were conducted next, including a nondirectional comparison of YOY frogs between sites, and two directional comparisons hypothesizing that the FID distributions of $2^{\text {nd }}$-year and adult frogs at Conboy were greater than the corresponding distributions at Big Marsh. Exploratory paired 
comparisons were contrasted to start distance distributions between YOY, $2^{\text {nd }}$-year, and adult frogs at Big Marsh. Finally, failing an attempted replication of our original finding regarding the relationship between cover and FID for adult frogs, exploratory ODA was used to assess this relationship separately by age class for Big Marsh frogs.

\section{Between-Site Comparisons of the Proportion of Frogs Allowing Touch}

An omnibus exploratory comparison of the proportion of frogs with FID $=0 \mathrm{~m}$, aggregated over age, between Conboy and Big Marsh (24.0\% versus 32.4\%, respectively) revealed a weak $($ ESS $=8.72)$, statistically unreliable $(P<0.2583)$ difference.

Furthermore, exploratory comparisons of the proportion of frogs with FID $=0 \mathrm{~m}$ between sites revealed weak, statistically unreliable differences for YOY (ESS $=16.4, P<0.3740)$, $2^{\text {nd }}$-year $($ ESS $=24.0, P<0.0745)$, and adult $($ ESS $=9.6, P<0.6125)$ frogs $($ Table 5.2$)$.

\section{Descriptive Statistics for FID and SD}

Table 5.1 summarizes descriptive statistics for FID and SD for data collected presently at Big Marsh, and also for data collected in our prior research at Conboy (Hayes et al., in press). Visual inspection indicate that mean FID and SD values were highest at Conboy, that the coefficient of variability was comparable between sites, and is greater for FID than for SD, and that numerous within- and between-site differences exist in the median, IQR and range statistics for FID and SD data among the different age groups.

\section{The Relationship of Age and FID at Big Marsh}

Pairwise ODA analyses tested the a priori hypotheses (Hayes et al., in press) that Big Marsh YOY frogs would have shorter FIDs compared to both $2^{\text {nd }}$-year (weak ESS = 
11.33, $P<0.5049$ ) and adult (weak ESS $=22.22, P<0.1547$ ) frogs (Fig. 5.1). Neither effect identified at Conboy involving YOY versus older frogs was found at Big Marsh. However, the finding of the test of the non-directional hypothesis comparing $2^{\text {nd }}$-year and adult frogs (weak ESS $=11.89, P<0.7899$ ) was consistent with the Conboy result of no reliable difference between these age groups (Table 5.4).

\section{Between-Site Comparisons of FID by Age Group}

A non-directional comparison of FID distributions between YOY frogs of Conboy and Big Marsh failed to identify a reliable difference (weak ESS $=20.83, P<0.3819$ ) (Table 5.5).

Consistent with the a priori hypothesis, FID values for $2^{\text {nd }}-$ year frogs at Big Marsh were significantly shorter than FID values for $2^{\text {nd }}$-year frogs at Conboy (moderate ESS $=31.25, P<0.0161)$. LOO analysis indicated this finding is expected to crossgeneralize for independent samples of frogs (moderate ESS $=26.12, P<0.0148$ ). The training and LOO models correctly classified approximately 50\% of Big Marsh frogs ( $50 \%$ accuracy is expected by chance), versus $81.3 \%$ and $78.1 \%$, respectively, of Conboy frogs. Thus, the effect is primarily attributable to the relatively large proportion of Conboy frogs having comparatively long FIDs (Table 5.5).

Likewise consistent with the a priori hypothesis, FID values for adult frogs at Big Marsh were significantly shorter than FID values for adult frogs at Conboy (moderate ESS $=30.56, P<0.0322) . \mathrm{LOO}$ analysis indicated this finding is expected to crossgeneralize for independent samples of frogs (moderate ESS $=25.00, P<0.0154$ ). The training and LOO models correctly classified $88.9 \%$ and $86.1 \%$ of the Big Marsh frogs, 
versus approximately $40 \%$ of the Conboy frogs. Thus, similar to $2^{\text {nd }}$-year frogs, the effect is primarily attributable to the relatively large proportion of Big Marsh frogs having comparatively long FIDs (Table 5.5).

Finally, consistent with our prior findings at Conboy, the largest behavioral change occurred between the YOY frogs, in which there was no difference between sites, versus older frogs in which inter-site differences emerged (Hayes et al. in press) (Fig. $5.1)$

\section{The Relationship of Age and SD at Big Marsh}

Consistent with our prior findings for Conboy (Hayes et al., in press), nondirectional comparisons of distributions of SD values between YOY and $2^{\text {nd }}$-year frogs (moderate ESS $=25.33, P<0.1228$ ), YOY and adult frogs (moderate ESS $=25.56, P$ $<0.1556$ ), and $2^{\text {nd }}$-year and adult frogs (weak ESS $=14.70, P<0.6145$ ) at Big Marsh were not statistically reliable (Table 5.6). These findings parallel the findings presented earlier for comparisons of FID distributions at Big Marsh, which did not differ reliably between frogs of different ages.

\section{Between-Site Comparisons of SD Separately by Frog Age}

At Conboy the sample was nine fewer $(n=91)$ for SD than for FID due to missing values (Hayes et al., in press). The comparison between sites revealed no difference in SD distributions for YOY frogs (weak ESS=15.42, $P<0.6966$ ). 
However, the SD for $2^{\text {nd }}$-year frogs was greatest for Conboy (moderate ESS $=$ 45.78, experimentwise $P<0.00052$ ), and LOO analysis suggested this effect may replicate for independent samples of frogs (moderate ESS $=27.26, P<0.0191$ ).

Similarly, the SD for adult frogs is greatest for Conboy (moderate ESS $=34.03, P$ $<0.0234$ ), and LOO analysis suggests this effect may replicate for independent samples of frogs (moderate ESS = 34.03, experimentwise $P<0.0036$ ).

\section{The Relationship of Age and Cover at Big Marsh}

Prior analysis for Conboy identified a relatively strong, statistically reliable relationship between cover and FID for adult frogs (Hayes et al., in press). An attempt to confirm this finding for the adult frogs at Big Marsh was unsuccessful (ESS= -1.96, i.e., marginally worse than expected by chance, $P<0.9755)$. Accordingly, exploratory analysis discriminating cover on the basis of attribute was conducted separately for each age class (Table 5.3). Consistent with findings for Conboy, there was no omnibus relationship between cover and FID for YOY frogs (moderate ESS = 31.1, $P<0.4874$ ).

In contrast to findings for Conboy (for which no relationship was identified), at Big Marsh there was a relatively strong $(E S S=54.29)$ relationship between cover and FID for $2^{\text {nd }}$-year frogs (experimentwise $P<0.0001$ ), that is likely to cross-generalize if used to classify an independent sample of $2^{\text {nd }}$-year frogs (LOO ESS $=47.14$, experimentwise $P<0.0001)$. The nature of the relationship for $2^{\text {nd }}$-year frogs at Big Marsh was linear; the greater the cover, the longer the FID.

Finally, consistent with findings for Conboy, for adults at Big Marsh we found a statistically reliable $(P<0.0192)$ moderate $(\mathrm{ESS}=43.81)$ relationship between cover and 
FID for adult frogs. However, at Big Marsh the nature of the relationship was that FID was shortest for least cover, and FID was greatest for intermediate cover. This finding is unlikely to cross-generalize to an independent sample, however (LOO ESS = 3.53, $P$ $<0.3786)$.

\section{DISCUSSION}

The striking finding of this study is that the FID of Oregon Spotted Frogs at Big Marsh, a site without predatory bullfrogs, did not change with frog age. Confidence in the validity of our comparison of this pattern, versus the age-related change in FID observed for Oregon Spotted Frogs at bullfrog-occupied Conboy, is supported by the finding that the YOY Oregon Spotted Frogs at both sites behaved consistently. Specifically, Big Marsh and Conboy had the same proportion of YOY frogs that allowed themselves to be touched $(\mathrm{FID}=0$ ), and had similar FID distributions for YOY frogs (Table 5.2), thus confirming that the naïve age class had the identical behavioral response pattern at both sites. The contrast between the absence of age-linked change in Oregon Spotted Frog FID at bullfrog-free Big Marsh, and the marked age-based change in FID observed for Oregon Spotted Frogs at Conboy Lake (Hayes et al., in press), suggests that bullfrogs are driving this difference (Fig. 5.1).

The differential pattern we observed in Oregon Spotted Frogs at Conboy versus Big Marsh is consistent with developmental behavioral patterns observed in other naïve prey populations, similarly suggesting that predation by introduced predators leads to an increased FID. For example, a study of the island-dwelling Galapagos marine iguana 
(Amblyrhynchus cristatus) conducted in the late 1960s found no difference in FID among age classes (Shallenberger, 1970). However, more than 30 years later Berger and colleagues (2007) re-examined FID in the same species on different islands, where cats and dogs had been introduced and were observed preying on marine iguanas (Kruuk \& Snell, 1981; Konecny, 1983; Laurie, 1983). The age class most vulnerable to introduced cats, juvenile iguanas, had disproportionately increased FIDs. Moreover, FIDs increased across all age classes in the presence of introduced predators (Berger et al., 2007). Similarly, reef fish have been observed to alter their FID behavior with the novel predation pressure of human spearfishing. Gotanda et al. (2009) found that parrot fishes outside marine reserves, where spearfishing is allowed, have longer FIDs than parrot fishes within reserves, where no spearfishing occurs. This finding has been confirmed in studies of diverse fish species exposed to spearfishing (Feary et al., 2011; JanuchowskiHartley et al., 2011; Benevides et al., 2016; Tran et al., 2016), and is consistently documented in other taxa where human-effected predation appears (Stankowich, 2008; Tarakini et al., 2014; Sreekar et al., 2016).

The aforementioned studies parallel our findings for Oregon Spotted Frogs whereby the most vulnerable portions of the population, the YOY, display the shortest FID, while more mature frogs detecting a novel predator display an increased FID. Among Oregon Spotted Frogs, the youngest (almost invariably the smallest) are arguably the most intrinsically vulnerable because of limited predator experience; a widely recognized pattern among diverse taxa (Lima, 1998; Hopkins et al., 2011; Lea \& Blumstein, 2011). Moreover, vulnerability of Oregon Spotted Frogs to bullfrog predation 
may be acute because the latter's broad post-metamorphic size range enables maintaining a size differential that facilitates predation regardless of Oregon Spotted Frog size, which reflects age.

However, species vulnerability does not necessarily have to reflect lower age or less experience if older age groups are the focus of predation. For example, human spearfishers typically target larger fish (i.e., the older fish within a given species), which, as a consequence, manifest longer FIDs, but which represents a pattern clearly demonstrated to be unrelated to fish size per se (Januchowski-Hartley et al., 2011). Accordingly, targeted (larger, older) fish outside marine reserves have been reported to adapt to human predation (spearfishing) by exhibiting FIDs exceeding the effective range of spearguns (Feary et al., 2011). Increased FID may also occur along a predation gradient, as exemplified in the Coral trout (Plectropomus leopardus). Trout within marine reserves have the shortest FIDs; trout within marine reserves, but exposed to predation due to non-compliant local spearfishers have intermediate and variable FIDs; and trout outside the reserve have the longest FIDs (Bergseth et al., 2016).

Despite differences in age-based variability in Oregon Spotted Frog FID observed between Big Marsh and Conboy Lake, one underlying similarity is prominenta near-constant proportion of frogs, regardless of age class, displayed an FID of 0 (i.e. allowed themselves to be touched by the predator). Close approach agrees with a crypsisbased anti-predator tactic whereby animals use immobility and color-pattern match to their environment to avoid detection, and is invariably linked with short FIDs (Heatwole, 1968; Cooper \& Sherbrooke, 2010; Camp et al., 2012). Among anurans the extreme use 
of this tactic is exhibited by leaf litter-dwelling robber frogs (Craugastor), which allow investigators to touch $>90 \%$ of the frogs approached (Cooper et al. 2008). A subset of Oregon Spotted Frogs have been observed to employ a similar strategy (Tidwell \& Hayes, 2013), but the dichotomy of their escape behavior (either allowing touch or fleeing at an FID $>0 \mathrm{~m}$ ), now documented at two sites regardless of the difference in predator set, suggests a hard-wired evolutionary pattern with limited plasticity. This conclusion is based on the fact that even though $76.9-86.00 \%$ (i.e. $3 / 4$ to $7 / 8$ ) of Oregon Spotted Frogs diverge from the "absolute immobility" tactic (FID = 0), divergent individuals flee at relatively short distances, which increase, but not greatly, when faced with a novel predator (Hayes et al., in press). Such restricted variability in FID may be linked to basic life history traits, and have particular value in elucidating phylogenetically significant differences between species.

Variation of life history traits may explain fundamental differences in antipredator tactics of lower vertebrate taxa. In most situations, effective crypsis relies on immobility (Ruxton et al., 2004). Anurans, which typically move only in short bursts, may be physiologically incapable of sustained movement (Gatten et al., 1992), and thus pre-adapted to depend on crypsis, at least at some level, as an anti-predator tactic. Some anurans, like the Oregon Spotted Frog, display some plasticity in FID, but that flexibility seems limited, since even exposure to an introduced predator (e.g. the bullfrog) only increases FID to a limited extent (Hayes et al., in press). In contrast, many fishes, including the reef fishes previously discussed, may be incapable of remaining stationary without exhibiting some kind of limited movement (Webb, 1994; Domenici, 2010), 
which would make the immobility needed to maintain crypsis unattainable as an antipredator tactic. Such physiological limitations may constrain anti-predator tactics in other taxa, such as diverse lizard groups (Cooper \& Sherbrooke, 2010; Samia et al., 2015), and may prove particularly valuable for understanding evolutionary pathways.

Recent investigations of SD - FID relationships have yielded differing results that may be taxon-driven, but no studies to date have addressed the relationship in aquatic anurans (Cooper \& Blumstein, 2014, 2015; Cooper et al., 2015). Given the lack of information for the taxon, we addressed the effects of ontogeny on SD as it has been found to be controversially important in the study of escape behavior (Cooper, 2005; Dumont et al., 2012; Samia et al., 2013) and is a foundational element to the advanced study of SD influence on FID. Supporting our previous finding (Hayes et al., in press), we found no evidence that SD varied with age for the Big Marsh frogs or that it would cross-generalize, and we affirmed that the SD values we observed were not artificially truncated; we did not detect large frogs only at greater distance or only detect small frogs at close distances.

Previous examination of the influence of vegetative cover on FID for Oregon Spotted Frogs revealed a negative relationship, but not a consistent one with age class between studies (YOY, Tidwell \& Hayes, 2013; adults, Hayes et al. in press). The present study exacerbated this inconsistency by revealing a negative relationship in the only age class not previously reported — the $2^{\text {nd }}$-year age class. The appearance of the same pattern in at least one age class in each study implies an underlying pattern, which is consistent with previous studies indicating that crypsis-dependent species rely on 
concealment and have short predicted FIDs relative to conspicuous animals (Stankowich \& Blumstein, 2005; Cooper et al., 2008; Cooper \& Sherbrooke, 2010). Relative to other aquatic ranids (Martin et al., 2005, 2006; Cooper, 2011a; McKnight \& Howell, 2014; Cloyed \& Eason, 2015), the FID of Oregon Spotted Frogs is short and supports a more crypsis-mediated close approach. Our inability to find consistency in the cover relationship across studies may indicate that our measurement scale is insufficiently precise to effectively quantify cover in this context. Future study of cover, which is likely worthwhile based on the repeated albeit age class-inconsistent appearance of the pattern, should consider refining the cover variable to perhaps include parameters more biologically relevant to the species (e.g., proximity to subsurface matrix that is versus is not structurally supportive of a low-risk, high-likelihood and perhaps frequently-utilized escape route).

Our present study suggests that inter-population variation in escape behavior for endangered Oregon Spotted Frogs at Conboy Lake NWR reflects a survival-facilitative adaptation to the introduction of predatory bullfrogs. We hypothesize that for Oregon Spotted Frogs the pattern observed at Big Marsh reflects the species norm in the absence of bullfrog predation, whereas the pattern observed at Conboy reflects the species norm in the presence of bullfrog predation. Unfortunately, all reported studies of ectotherms that evaluate the impact of an introduced predator employ a cross-sectional design in which independent samples of frogs of different ages are compared. Such studies cannot demonstrate the effect of an introduced predator on the escape behavior of individual frogs. Rather, longitudinal study of the behavior of individual frogs-before versus after 
exposure to a predator-is needed to clearly ascertain the specificity of the threat (bullfrog) to the sensitivity of the emergence of the behavioral response, as well as to assess the success of the behavioral FID response (including FID $=0$ ) measured in terms of survival of actual predator encounters. For example, Cinner et al. (2006) reported anecdotal evidence of a before-and-after-impact (BACI) assessment of the effect of the introduced predator on escape behavior where surveys of local indigenous people indicated that a moratorium on human spearfishing decreased the FID of reef fishes. However direct evidence for such a reversal of reef fish escape behavior is lacking (Feary et al., 2011).

We mention this because a more rigorous test of the linkage between escape behavior and an introduced predator may be possible at Conboy, where personnel are working to eradicate bullfrogs. If successful and if one assumes that the currently observed increase in FID has not become genetically fixed, the ontogeny of FID in Oregon Spotted Frogs should revert to one of no change among age classes once bullfrogs are effectively removed. We emphasize that the mechanism of increased FID in Oregon Spotted Frogs at Conboy remains unclear, and as noted previously, could result from bullfrog depletion of animals allowing close approach, learning after exposure to non-lethal predation attempts, intrinsic crypsis reflecting size, or some combination of all three.

Lastly, if lack of age-based change in FID is truly a fundamental characteristic to Oregon Spotted Frogs, then close approach should be uniform at all ages in other populations. What is currently unclear is whether the very close approach exhibited by 
YOY Oregon Spotted Frogs places them at greater likelihood of predation by bullfrogs.

The answer is likely to lie in details of their behavioral interactions at Conboy. 


\section{CHAPTER 5 TABLES}

Table 5.1. Flight initiation distance and starting distance metrics (in meters) by age class for Oregon Spotted Frogs from Big Marsh and Conboy. Abbreviated statistics are coefficient of variation (CV), interquartile range (IQR), and standard error (SE).

\begin{tabular}{ccccccc}
\hline Site $\quad$ Age Class & $\mathrm{n}=$ & Mean \pm SE & CV & Median & IQR Range \\
\hline Conboy & & & & & & \\
Flight Initiation Distance & & & & & \\
YOY & 32 & $0.41 \pm 0.90$ & 1.23 & 0.21 & 0.63 & $0.0-2.0$ \\
2nd_Year & 32 & $1.59 \pm 2.28$ & 1.28 & 0.96 & 2.24 & $0.0-11.3$ \\
Adults & 36 & $2.28 \pm 2.73$ & 1.18 & 1.63 & 3.00 & $0.0-11.3$ \\
Starting Distance & & & & & & \\
YOY & 32 & $3.41 \pm 0.32$ & 0.53 & 2.85 & 2.90 & $1.3-7.4$ \\
$2^{\text {nd_Year }}$ & 27 & $7.78 \pm 0.92$ & 0.61 & 7.00 & 6.00 & $2.7-22.9$ \\
Adults & 32 & $5.19 \pm 0.50$ & 0.54 & 1.63 & 3.85 & $1.6-11.1$
\end{tabular}

Big Marsh

Flight Initiation Distance

$\begin{array}{ccccccc}\text { YOY } & 30 & 0.55 \pm 0.12 & 1.19 & 0.23 & 0.78 & 0.0-2.3 \\ 2^{\text {nd }}-\text { Year } & 50 & 0.80 \pm 0.18 & 1.59 & 0.11 & 1.28 & 0.0-5.3 \\ \text { Adults } & 36 & 0.88 \pm 0.18 & 1.22 & 0.22 & 1.62 & 0.0-3.4\end{array}$

Starting Distance

\begin{tabular}{ccccccc} 
YOY & 30 & $3.25 \pm 0.36$ & 0.60 & 2.30 & 2.37 & $1.7-10.9$ \\
$2^{\text {nd_Year }}$ & 50 & $3.93 \pm 0.29$ & 0.52 & 3.30 & 2.50 & $1.4-9.8$ \\
Adults & 36 & $4.01 \pm 0.38$ & 0.57 & 3.00 & 3.08 & $1.4-9.7$ \\
& & & & & & \\
\hline
\end{tabular}


Table 5.2. Comparison of the proportions of zero versus non-zero flight initiation distances (FID) among Oregon Spotted Frogs between sites, separately by age class. Effect strength for sensitivity (ESS) statistic and probability $(P)$ are reported for each analysis.

\begin{tabular}{|c|c|c|c|c|c|c|}
\hline Site & Age Class & $\mathrm{n}=$ & $\mathrm{FID}=0$ & FID $\ddagger 0$ & ESS & Probability \\
\hline $\mathrm{BM}$ & YOY & 30 & 5 & 25 & 16.4 & $<0.3740$ \\
\hline CB & YOY & 32 & 9 & 23 & & \\
\hline $\mathrm{BM}$ & $2^{\text {nd }}-Y e a r$ & 50 & 18 & 32 & 24.0 & $<0.0745$ \\
\hline $\mathrm{CB}$ & $2^{\text {nd }}-Y e a r$ & 32 & 5 & 27 & & \\
\hline $\mathrm{BM}$ & Adults & 36 & 13 & 23 & 9.6 & $<0.6125$ \\
\hline CB & Adults & 36 & 10 & 26 & & \\
\hline
\end{tabular}


Table 5.3. Training (total sample) and LOO validation analyses assessing the relationship between flight initiation distances (FID) and cover, for post-metamorphic Oregon Spotted Frogs from Big Marsh partitioned by age class. Significant relationships that held up under LOO validation analysis are in bold face type.

\begin{tabular}{|c|c|c|c|c|c|c|}
\hline \multirow[b]{2}{*}{ Age Class } & \multirow[b]{2}{*}{$\mathrm{n}$} & \multicolumn{2}{|c|}{ ODA training } & \multicolumn{3}{|c|}{ LOO validation } \\
\hline & & ESS & Probability & & ESS & Probability \\
\hline YOY & 30 & 31.06 & $<0.4874$ & & - & - \\
\hline $2^{\text {nd }}-$ Year & 50 & 54.29 & $<0.0001$ & 47.14 & & $<0.0001$ \\
\hline Adult & 36 & 43.81 & $<0.0192$ & & 3.53 & $<0.3786$ \\
\hline
\end{tabular}




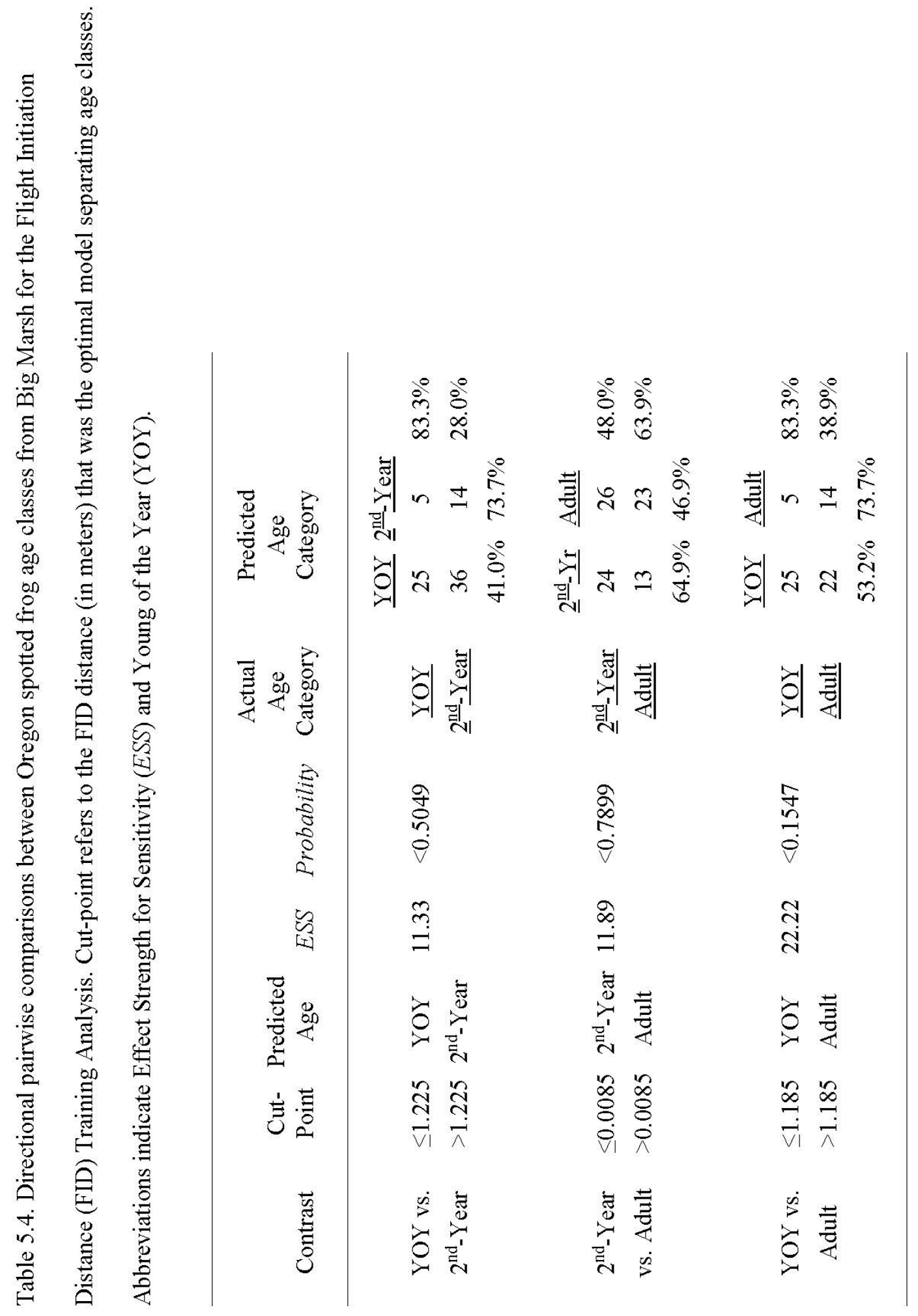




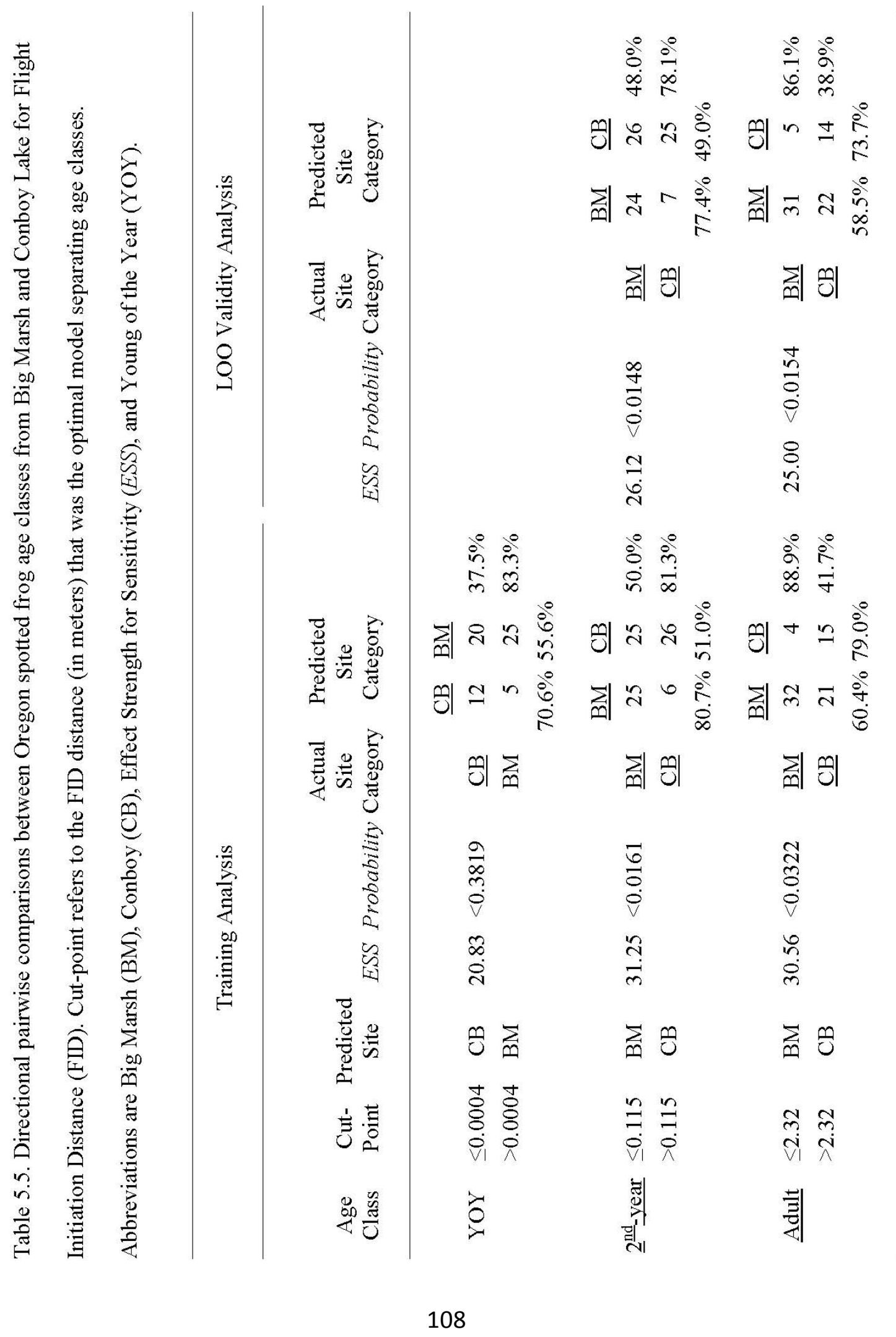




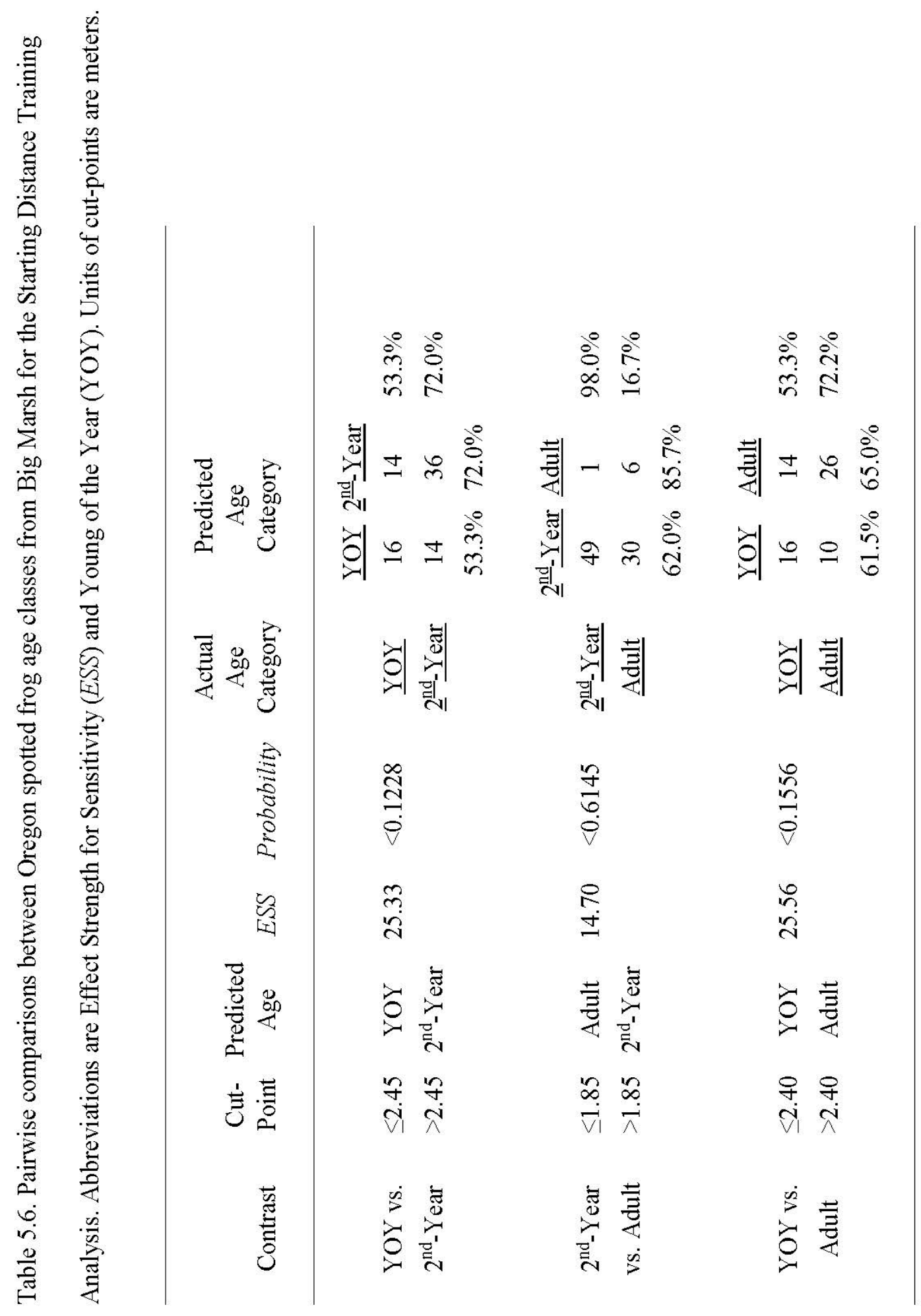




\section{CHAPTER 5 FIGURES}

Figure 5.1. Distribution of flight initiation distance by age class (Young-the-Year [YOY], $2^{\text {nd }}$-year, and adult [ $>2^{\text {nd }}-$ year] $)$ Oregon Spotted Frogs sampled at Big Marsh and Conboy in 2013. Box and whisker plots encompass the median within the box (25 $5^{\text {th }}$ and $75^{\text {th }}$ percentiles) and whiskers (10 ${ }^{\text {th }}$ and $90^{\text {th }}$ percentiles $)$. Outliers are black dots.

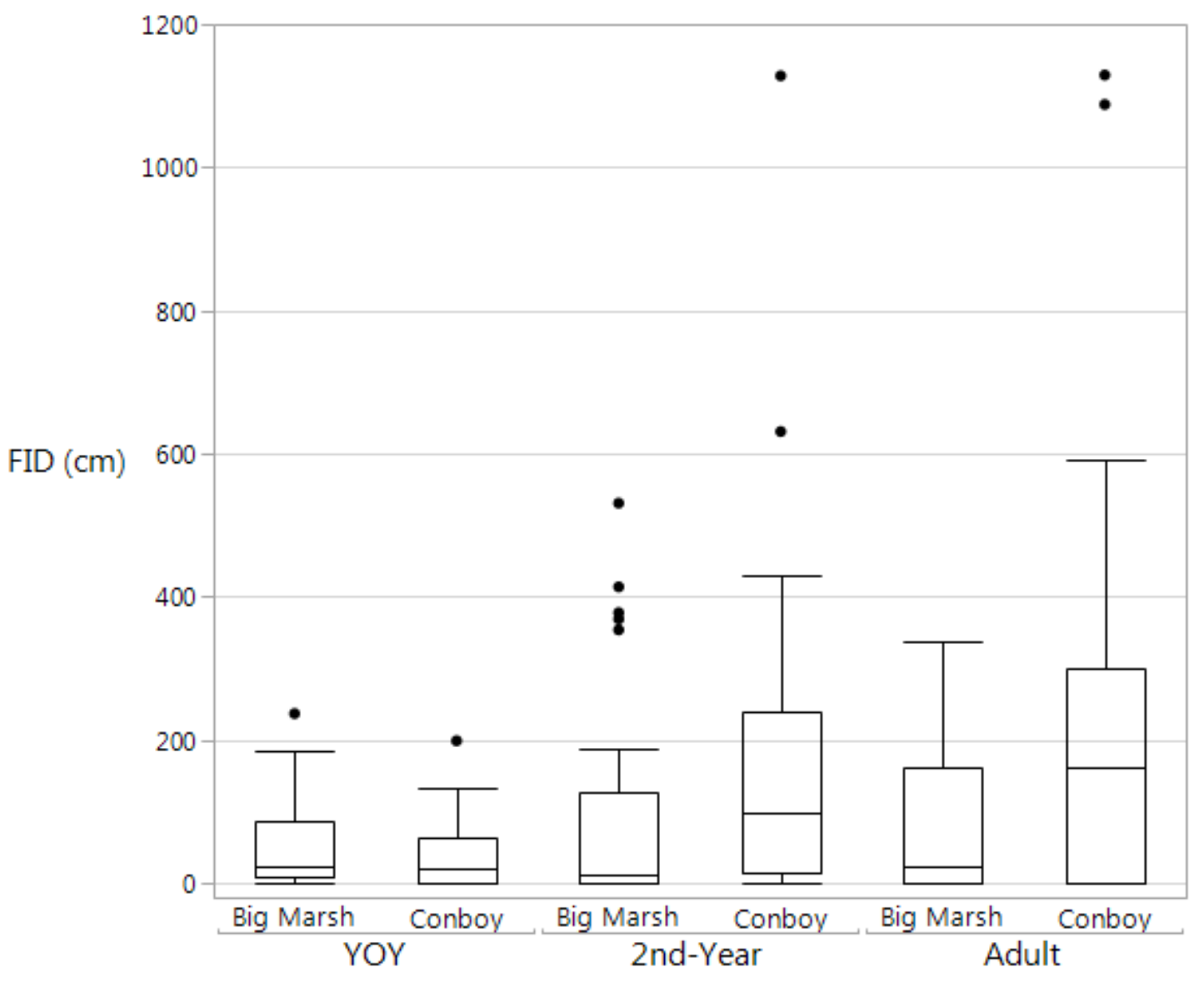




\title{
CHAPTER 6
}

\section{PREDATORY STRIKE DISTANCE OF THE AMERICAN BULLFROG (RANA (AQUARANA) CATESBEIANA) AND THE DYNAMIC RESPONSE OF A NATIVE ANURAN.}

\begin{abstract}
Studies of anti-predator behavior have frequently focused on the distance at which prey takes evasive action from an approaching predator, the Flight Initiation Distance (FID). Here we assess the predator behavior that likely influences the evolution of FID, the distance at which a predator can effectively capture a prey animal. Previous study of Oregon Spotted Frogs (OSF; Rana pretiosa) identified an ontogenetic increase in FID in the Conboy Lake population of OSFs, which co-occur with bullfrogs, suggesting the increase in FID is bullfrog-driven. We explored this with both laboratory and field experiments. In laboratory experiments, we found that $100 \%$ of young, but only $20.75 \%$ of older, OSFs at Conboy Lake had FIDs less than the upper limit of the bullfrog strike distance. Field trials at this same site validated this trend, wherein, $75 \%$ of young, $46 \%$ of $2^{\text {nd }}$-year, and only $30 \%$ of adult OSFs had FIDs shorter than the bullfrog strike distance. We then compared the bullfrog strike distance to the FIDs of an OSF population lacking bullfrogs and found $>50 \%$ of OSFs in all age groups had FIDs within bullfrog strike distance. The latter pattern reinforces our hypothesis that bullfrogs are responsible for the increased FID in older OSF at Conboy Lake.
\end{abstract}

INTRODUCTION 
Deleterious impacts of invasive species have been widely reported for decades (Elton 1958; Lowry et al., 2013). However, the effects of invasive species are often analyzed at a systems or biodiversity level (Parker et al., 1999; Sakai et al 2001; Bellard et al., 2016), and therein fail to observe impacts of the functional unit of a system, the species, when invasion is occurring (Groom et al., 2006). How native species respond to the introduced organism is paramount to differentiating the potential and actual impact of the introduction (Sakai et al., 2001; Lowry et al., 2013). In the case of invasive predators, both behavioral responses and morphological adaptations of native prey taxa have been documented, but problematic invasive species numerically far outweigh the number of studies addressing invasive species impacts (Lowe et al., 2000; Lowry et al., 2013).

Here we assess the impact of introduced American Bullfrogs (Rana (Aquaana) catesbeiana) on the federally listed threatened Oregon Spotted Frog (Rana pretiosa) (USFW 2014) by measuring the escape behavior of OSFs in populations with and without bullfrogs. The negative interaction of these species has long been discussed (Hayes and Jennings, 1986, Pearl et al., 2004; Adams et al., 2011), but documenting direct evidence of post-metamorphic bullfrog impact in-situ has been elusive (D’Amore et al., 2009; Bucciarelli et al., 2014; Rowe et al., 2014; but see Chivers et al., 2001; Pearl et al. 2004 for potential impact $e x$-situ). Our previous studies indicate that where bullfrogs have been introduced, OSF escape behavior is significantly altered in older animals, which suggests that bullfrogs may be the behavior-modifying agent (Hayes et al, in press; Tidwell et al. in prep). Here we examine this by contrasting the Flight Initiation Distance (FID: the distance allowed between prey and predator before evasive action is 
taken) of OSFs and the predatory strike distance (StrkD) of bullfrogs to determine if the latter metric influences the former.

Although studied worldwide and recognized as a predator by the IUCN Top Worst 100 invasive species list (Lowe, 2000), bullfrog predatory ecology has yet to be examined beyond dietary analysis (Chapter 7). As such, our first objective was to describe and quantify the predatory StrkD of the bullfrog to determine the distance at which the species can initiate prey capture. As dietary generalists, metamorphosed bullfrogs are known to prey on diverse vertebrates, including OSFs (Bury and Whelan, 1984; Werner et al., 1995; Pearl et al. 2004), and are consistently blamed for OSF extirpation due to their presence at every site of recent OSF disappearance (Hayes, 1997). Because of this, and for reference to previous studies of OSF escape behavior, we elected to study StrkD at the exclusive site of long-term OSF-bullfrog co-occurrence, Conboy Lake National Wildlife Refuge (hereafter, Conboy Lake) in Washington State. Bullfrogs were initially introduced to the site in 1958 by Norman Troh, a rancher who wanted the frogs for food and had nostalgic memories of the species from habitats in their native range (Doug Troh, personal comm.). Since this introduction, the population has grown considerably whereby it is now the most prominent and numerous aquatic anuran in the Conboy Lake complex.

A second objective of our study was to examine the FID of OSFs in relation to the StrkD of bullfrogs. More than 400 studies have assessed the FID of diverse taxa for purposes of informing escape theory (Ydenberg and Dill 1986, Cooper and Blumstein 2015), here, we extend the application of FID by contrasting it to the StrkD of a known 
predator to determine whether the ontogenetic change in FID previously reported in an OSF population could reflect bullfrog predation. To our knowledge, no study has attempted to assess the predatory StrkD of a predator and the resultant FID of the prey population. We use previously reported data of OSF FID in the field and present novel

methods for testing OSF FID data in the laboratory. We compare these FIDs with StrkD measurements of bullfrogs from novel field and lab methods to evaluate if findings in the lab are cross-validated with the field experiments, and to evaluate whether the escape behavior of OSF intersects with the bullfrog predatory StrkD.

\section{MATERIALS AND METHODS}

\section{Study Areas}

Our primary study area was located on Conboy Lake National Wildlife Refuge in Klickitat County, Washington State, USA (455’N, $\left.121^{\circ} 19^{\prime} \mathrm{W}\right)$. As the site of cooccurrence, and previous study of OSF FID, this refuge includes roughly two-thirds of the large (4,046 ha) wetland complex in the Glenwood Valley, which is located $20 \mathrm{~km}$ southeast of Mount Adams at slightly over 550 m above mean sea level. Construction of conveyance channels in the period 1911-1914 (Ladiges 1978) greatly altered drainage patterns across this wetland. These channels now provide extensive permanent aquatic habitat in this system, which is a requirement for both the highly aquatic frog species in this study.

We collected metamorphosed bullfrogs and OSFs for laboratory experiments and performed field experiments in the largest conveyance channels in the system, Cold 
Springs Ditch and Outlet Creek. These are, respectively, 2-3 m and 4-5 m wide channels hosting a diverse mosaic of sparse emergent and dominant floating and submerged vegetation (See Tidwell and Hayes, 2013 for description).

Our reference study area for OSF FID was Big Marsh, an intact site with no bullfrogs managed by the Deschutes National Forest (USDA, 1997) in the upper

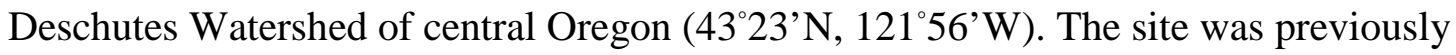
used to address questions of FID variability in OSFs due to the highly similar water channel structure and identical predator sets (for details see Tidwell et al, in prep).

\section{Study Animals}

Animal welfare statement: Handling of amphibians followed the ASIH/HL/SSAR guidelines for use of live amphibians and reptiles in field research (Beaupre et al., 2004) and adhered to the Institution for Animal Care and Use Committee of Portland State University, protocols \#9 and \#30 and permitted to KST.

\section{Experimental Design}

\section{Laboratory analysis of strike distance}

Experimental design - We tested the StrkD of the bullfrog in a controlled setting to test whether the FID of any age class of OSF was beyond the StrkD of bullfrogs. As both species are highly aquatic, spending $>95 \%$ of life in or immediately near water, we constructed three identical, but sequentially labeled aquatic testing platforms of circular 1,136 L Rubbermaid ${ }^{\odot}$ plastic cattle tanks (1.6 m diameter) filled with $45 \mathrm{~cm}$ of water from the conveyance channels (Fig. 1). We added the contents of one 18.92-L bucket of the most common floating vegetation in the conveyance channels, Aquatic Buttercup 
(Ranunculus aquatilis), to provide a floating platform that would provide refuge for test subjects and minimize energy expenditure (Pough et al., 1992a). To enable videoarchiving of the experiments and presentation of the prey model, wooden frames were constructed over the tanks with a tank-spanning central boom fixed with a through-bolt that allowed it rotate through 360 degrees above the tank. Affixed to this boom was a Canon $^{\odot}$ Vixia HF 200 video camera and a pulley system composed of two 2.54-cm eyebolts strung with 200-lb test monofilament line connected with a T-swivel that suspended the prey model, and, when pulled, moved it across water surface. A Livetarget ${ }^{\circledR}$ Hollow Frog 13/4” brown/black lure $(49 \mathrm{~mm} \times 24 \mathrm{~mm} \times 19 \mathrm{~mm})$, commonly used for surface fishing predatory finfish, was selected for the prey model due to its realism of movement and close color match and markings to OSFs (Fig. 2). The observing investigator was concealed by attaching opaque tarps to the up-right portion of the wooden structure, which were wrapped around the entire tank. Two viewing ports (approximately $2.54 \mathrm{~cm}$ $\times 2.54 \mathrm{~cm}$ ) were cut into the tarps at head level and on opposite sides of the arena to allow investigators to view the testing arena without being seen by test bullfrogs (Fig. 1). Test protocol - After the 18-24 hr holding period, bullfrogs were transferred to testing tanks and acclimated for 60 min. After acclimation, all bullfrogs were in stationary position, either on the Aquatic Buttercup or slightly submerged but with their eyes above water. The investigator then remotely activated the video camera, and rotated the boom to enable model presentation perpendicular to the test bullfrog. The prey model was then strategically thrown over the top of the tank at the point furthest away from the test bullfrog and allowed to float for 10 seconds. Subsequently, the pulley system was used to 
move the prey model across water surface towards the test bullfrog at a practiced rate of $0.5 \mathrm{~m} / \mathrm{s}$ in a fashion that mimicked a real frog. The model was drawn perpendicular towards the snout of the test bullfrog to ensure that the model would be perceived, and if the bullfrog did not strike the model, the model would ultimately touch the test bullfrog. Trial termination was identified by the bullfrog taking action as a result of the model (i.e., either striking the model or taking evasive action). After each trial, the tank number and water temperature was recorded and each test bullfrog was captured and measured for 7 morphometric variables of interest (e.g., eye and tympana width, Snout-Vent-Length [SVL], shank, mass, and sex; see Table 6.3 for details). All tests were conducted during the day between 0855 and 1751 PST with the overhead fluorescent lighting turned on. Quantification of Strike Distance and other variables - Video archives of each trial were reviewed and measurement of distance variables within the test tank were assessed using Image J (http://rsbweb.nih.gov/ij/index.html), wherein, using the known model width for calibration, distances of $0.1 \mathrm{~cm}$ resolution were recorded for the distance between the prey model and test bullfrog when first introduced (Distance Initial; DI), the distance traveled by the test bullfrog prior to striking (Distance Traveled; DT), and the distance between the test frog and model when strike began (StrkD). All measurements were taken from the end of each test bullfrog's snout and the edge of the prey model closest to the test bullfrog. After euthanasia, all frogs were dissected and various parameters thought to potentially influence their predatory behavior were measured (e.g. presence of prey items in G.I tract, gonadal development, and sex; see Table 6.3 for details). 
Study subjects - Bullfrogs used for laboratory experiments were collected at night between 2130 and 0200 hrs in Outlet Creek over the period 25 July - 14 August 2014. Investigators in wetsuits with 200-lumen head lamps located metamorphosed bullfrogs via eyeshine and hand captured three frogs per night over the testing period. Captured bullfrogs were individually bagged and transported to the testing facility where they were separately housed in one of three opaque $567 \mathrm{~L}^{\text {Rubbermaid }}{ }^{\odot}$ plastic holding tanks filled with $45 \mathrm{~cm}$ of water and covered with weighted mesh netting. Natural floating vegetation (e.g. Aquatic Buttercup) and small blocks of floating wood were placed in the tanks to provide rest areas out of the water. We standardized frog metabolism by withholding food at environmental temperatures $\left(17-24^{\circ} \mathrm{C}\right)$, for $18-24 \mathrm{hrs}$ prior to testing. Previous observation established that this period of time at the controlled temperatures was adequate to clear the digestive tract of bullfrogs (KST personal observation).

Holding and testing tanks were housed in an enclosed, lighted, and insulated building at Conboy Lake headquarters. The building provided isolation and lent itself to more effective control of physical variables, wherein disturbance during the holding periods and testing trials was minimized, lighting was timed to match the natural diurnal cycle of sunrise and sunset (8 hours dark and 16 hours light) with overhead fluorescent lighting, and temperature of the air and tank water was modulated, relative to environmental fluctuation, with insulation. Water and vegetation used in tanks was changed and the tanks cleaned between trials to avoid any potential complication with chemical cues. Upon termination of the StrkD trials, all bullfrogs were immediately euthanized and preserved for subsequent dissection and morphometric analysis. 


\section{Field analysis of strike distance}

Experimental design, protocol, and quantification - We tested the StrkD of the bullfrog in the field to validate laboratory findings and determine whether a "laboratory effect" of the tank environment existed. In the water-filled conveyance channels at Conboy Lake, a team of investigators scanned the water's surface with field glasses and identified surface-active metamorphosed bullfrogs and upon identification of a bullfrog, the investigators positioned themselves where they could clearly see the frog and estimate its size to the nearest $5 \mathrm{~mm}$ SVL (Tidwell and Hayes, 2013). To initiate each trial, the same observer (KST) would cast the prey model attached to a fishing pole via 10-lb monofilament line towards the bullfrog and reel the prey model towards the anterior end of the bullfrog in a perpendicular fashion. To enable comparison to the laboratory study, care was taken to present the prey model greater than $1.5 \mathrm{~m}$ from the test frog, and reel (at the same practiced rate of approximately $0.5 \mathrm{~m} / \mathrm{sec}$ ) the prey model so it moved perpendicular to the orientation of the frog. Moreover, to enable direct comparison to the laboratory experiment, we tested frogs of the same sizes as those used in the laboratory. Once action was taken by the test bullfrog, investigators would collectively agree on all measurement points in the water and the on-bank investigator would direct KST through the water to measure the point where the prey model started (i.e. DI), how far the prey model moved (if at all [i.e. DT]), and StrkD using a metric measuring tape.

Study subjects - Bullfrogs used for field trials of StrkD were visually assessed and rarely captured over the period 12-15 August 2016 in Outlet Creek. Only if frogs swallowed the prey model during the trial, were frogs captured. These frogs were transported to the 
laboratory testing facility, where they were euthanized and frozen in a $-20^{\circ} \mathrm{C}$ freezer for morphometric analysis.

\section{Laboratory analysis of FID}

Design, protocol, and quantification - In this experiment, we measured the FID of Conboy Lake OSFs exposed to a bullfrog model to contrast to FIDs assessed in the field using a human subject as a pseudo-predator and to test whether the StrkD of laboratory and field tested bullfrogs was greater than the FID of OSFs. We modified a metal tank to have a test arena rectangular $1.5 \mathrm{~m} \times 0.5 \mathrm{~m}$, filled $10 \mathrm{~cm}$ of water. To encourage frogs to locate to the side of the tank furthest from the bullfrog prey model, a piece of plastic aquarium vegetation was placed in the water at the point furthest away from the bullfrog model (Fig. 6.3). A plastic bullfrog model attached to a fiberglass rod was inserted through the side of the tank where it attached to an electric motor on a suspended track located outside the tank. The rod was hinged to motor driver to allow shifting the bullfrog model so that it could be oriented directly towards each test OSF. The motor propelled the bullfrog model at a controlled rate of $0.5 \mathrm{~m} / \mathrm{sec}$ (similar to the velocity of approach in human based FID trials). A trial terminated when the frog either took evasive action or was touched. Frogs allowing contact were given an FID $=0$. The same camera used for laboratory StrkD analysis was suspended above the tank to enable video-archiving the trials. Measurement was similarly conducted with Image J

(http://rsbweb.nih.gov/ij/index.html) using the known bullfrog model width for calibration. 
Study Subjects - Laboratory analysis of OSF FID was conducted on metamorphosed OSFs collected by net and hand capture during day light hours on 16-17 June 2012 in Cold Springs Ditch. Frogs were transported to Conboy Lake National Wildlife Refuge Headquarters, where they were maintained in individual ventilated $0.95 \mathrm{~L}$ opaque containers with small amounts of water. To equilibrate metabolism, food was withheld for 12-18 hrs and 30 min prior to testing, the containers holding frogs were placed in a temperature-controlled water-filled tank at $26.0^{\circ} \mathrm{C}$. Using bullfrogs as surrogates, we validated (via periodic cloacal probe) that this period of time was sufficient to equilibrate internal frog body temperature. We randomized the order of capture and testing by using a randomly generated sequence of numbers to assign the test series. After the 30-minute holding period, frogs were individually tested and released to the recorded location of capture. All frogs were released within 24 hours of capture.

\section{Field analysis of FID}

Design, protocol, and quantification - OSF FID was tested at Conboy Lake and Big Marsh during the summer of 2013 and these FIDs have been used in several investigations of escape behavior (Hayes et al., in press; Tidwell et al. in prep). Briefly, a team of investigators identified frogs from a distance and approached at a practiced, constant rate with an in-channel investigator holding an arm out towards the frog (see Tidwell and Hayes (2013) for details). Frogs were approached until they took evasive action or were touched. Beyond $0.5 \mathrm{~m}$ the FID was measured to the nearest $0.01 \mathrm{~cm}$ using a digital rangefinder blue-tooth linked to a high resolution GPS. Within $0.05 \mathrm{~m}$ a metric 
tape was used to measure the FID. Frogs allowing touch were given an FID $=0$ (Tidwell and Hayes, 2013; Hayes et al. in press).

Study Subjects - Field analysis of OSF FID were conducted on the Big Marsh and Conboy Lake populations over the summer of 2013. No frogs were handled. For details, see Hayes et al. (in press) and Tidwell et al. (in prep).

\section{Analytical procedure}

\section{Approach to statistical analysis}

We describe the methods used to quantify the predatory action of the bullfrog and then present the algorithm used for analysis. We start by describing the conceptual and analytic mechanics of the algorithm and how we applied this algorithm to our data. Similar to our previous experiments of escape behavior for OSFs (Hayes et al., in press, Tidwell et al. in prep), Optimal Discriminant Analysis (ODA) was used to evaluate the statistical hypotheses investigated herein (Yarnold \& Soltysik, 2005, 2016).

\section{Predatory action of the bullfrog}

Video-archive of StrkD trials in the laboratory allowed detailed observation of bullfrog predatory tactics via review of digital-imaged and calibrated photos in Image J. We present descriptive statistics of behaviors thought pertinent to successful predation events. Previous data describing the predatory action of anurans in the aquatic setting is limited (but see Ingle, 1973; Pough et al., 1992b; Anderson, 1993; Gray et al., 1997 for a review of anuran predation on terrestrial platforms), so we briefly describe the predatory actions utilized by bullfrogs to strike the prey model and for reference, include some parameters documented in the above studies. 


\section{Conceptual description of ODA algorithm}

The ODA algorithm identifies the specific assignment rule-the ordering of the predicted class categories in the model, and the specific cut-points that separate predicted categories - that explicitly maximizes the predictive accuracy of a statistical model (Linden \& Yarnold, 2016). Model predictive accuracy is summarized using the chanceand maximum-corrected $(0=$ predictive accuracy expected by chance; $100=$ perfect accuracy) effect strength for sensitivity (ESS) index (Yarnold \& Soltysik, 2005, 2016). An ESS $<25$ is a weak effect, $25 \leq$ ESS $<50$ is a moderate effect, and ESS $\geq 50$ depicts varying degrees of a strong effect (Yarnold \& Soltysik, 2005, 2016). Permutation probability is used to compute statistical significance ( $P$ value) for ODA analyses. All $P$ values are exact because no distributional assumptions are required of the data (Yarnold \& Soltysik, 1991; Carmony et al., 1998).

The potential cross-generalizability of statistically significant ODA models are assessed using one-sample jackknife analysis, also called leave-one-out (LOO) validity analysis (Lachenbruch \& Mickey, 1968). For LOO analyses, each observation is in turn held out, a model is obtained for the rest of the sample and used to classify the held-out observation. Accuracy is determined as success or failure in predicting the actual class membership of that observation, and the combined results of all $n$ such classifications are used to compute the LOO (validity) ESS (Yarnold \& Soltysik, 2005). The ESS that is obtained in such LOO analyses is considered an upper-bound estimate of potential crosssample reproducibility: similar ESS values for both training and LOO analyses suggest 
the ODA model may cross-generalize with comparable predictive accuracy if it was applied to classify independent samples (Yarnold \& Soltysik, 2005, 2016).

To identify a multivariable relationship between a variable of interest and potential co-factors, multiple ODA analyses are chained together via classification tree analysis (CTA), in order to explicitly maximize ESS (Linden \& Yarnold, 2016; Yarnold \& Soltysik, 2016). “CTA is a 'decision-tree'-like classification model that provides accurate, parsimonious decision rules that are easy to interpret (with visual display), while reporting $P$ values derived via permutation tests performed at each node. All CTA models consist of nodes, each representing a variable (also called an attribute) selected on the basis of the predictive accuracy it achieves. For each potential variable, a predictive model is identified that maximizes the ESS statistic. A sequentially rejective Sidak-Bonferroni-type multiple comparisons methodology is used to ensure the desired experiment-wise Type I error rate, and adjusted for the number of variables (nodes) in the

CTA model” (Linden \& Yarnold, In Press; Yarnold \& Soltysik, 2016).

\section{Analytical approach}

We first evaluated the potential confounding co-factors of StrkD. In this analysis, StrkD was treated as an ordered class variable and potential confounding cofactors including both ordered (DI, DT, water temperature and morphometric measurements of ear, eye, fat bodies, mass, shank, and SVL) and categorical (sex of frog [male or female] and the presence of prey contents in the stomach [yes or no]) variables were treated to determine if a significant relationship (i.e. model) existed. As field tested frogs were 
rarely captured, we only evaluate the potential confounding effects of DI, DT, and SVL on StrkD.

We then expressed the cumulative frequency of bullfrog StrkDs for raw scores (meters), and superimposed the cumulative frequency of OSF FID, also expressed as a function of raw scores (meters), to make a plot to facilitate comparison of distributions and assess OSF FID in relation to StrkD (Figs. 6.4-6.5). Based on previous research of OSF FID that found an age differential in FID (Hayes et al., in press, Tidwell et al. in prep), we partitioned FID by age class. Plots were used to identify OSFs exhibiting FIDs that were either inside or outside the Strkd of all or some bullfrogs. For instance, in laboratory tested frogs (Fig. 6.4), $2^{\text {nd }}$ year or adult OSFs with an FID of $0.18 \mathrm{~m}$ have $23 \%$ of sampled bullfrogs capable of successful strike, and 78\% not capable. Similarly, for that FID, 35\% of OSFs are within bullfrog StrkD and 55\% are not. This information was integrated to identify strike and FID measures that reflect absolute physical distances that estimated the relative potential for predation of the sample population.

For any measure of FID, it was therefore possible to determine the proportion of bullfrogs in our sample capable of successfully striking OSFs. The focus of this analysis is of the estimated parameters of absolute and not relative vulnerability to bullfrog predation based on our samples. We made an attempt to focus this analysis because the absolute condition represents the potential maximal capacity for survival, and the relative condition is the resultant spectrum of potential survival. We recognize that our sample may not exactly represent the true population estimates of the parameters. Accordingly, 
we use the maximum StrkD of all measured bullfrogs for reference in this analysis, as this measure represents the cut point of absolute survival.

Statistical analysis was conducted to compare the proportion of OSF FID below and above the maximum StrkD of bullfrogs (the class variable) as a function of ontogeny (the ordered attribute). Based on prior research which identified ontogenetic differences in FID thought to be driven by bullfrog predation (Hayes et al. in press, Tidwell et al., in prep), we used a priori directional tests in each analysis when comparing proportions by age class in an attempt to replicate the differences previously identified (Hayes et al. in press, Tidwell et al., in prep.). Specifically, we addressed this with three independent analyses. First, we tested bullfrog StrkD and OSF FID from Conboy Lake in the laboratory, and then we evaluated the same parameters in the field. Lastly, we estimated the vulnerability of OSFs from Big Marsh, a bullfrog-free site, to bullfrog StrkD.

\section{RESULTS}

\section{Predatory action of the bullfrog}

At StrkD trial initiation, most bullfrogs $(>83 \%, n=43)$ were located on floating vegetation in (or near) the center of the tank, the prey model was tossed into the tank at the point furthest from, but perpendicular to, the bullfrog $(\bar{x}=0.97 \mathrm{~m} \pm 0.05 \mathrm{~m} \mathrm{SE})$. Upon breaking the surface of the water, $83.3 \%$ of 43 bullfrogs reoriented from their initial position towards the model an average of $89.0^{\circ} \pm 8.6^{\circ} \mathrm{SE}$, confirming that it was generally placed at an angle perpendicular to the bullfrog at the start of the trial. After reorientation, $95 \%$ of the bullfrogs swam towards the prey as it was pulled towards them. 
Using their hind limbs for propulsion, and forelimbs to maneuver through the vegetation, bullfrogs traveled an average of $0.45 \mathrm{~m} \pm 0.05 \mathrm{~m} \mathrm{SE}$ (DT) towards the prey model. Prior to striking the prey, all bullfrogs momentarily ceased forward movement, contracted their hind limbs under their body, and then lunged out of the water in an arc towards the prey model. During the strike, we observed that bullfrogs would close their nictitating membranes to cover their eyes, open their mouth, and retract their forelimbs prior to making contact with the prey model. Two-thirds of the frogs engulfed the prey model with their mouth then dove below the water's surface and either, resurfaced and attempted to swallow the model using the forelimbs to stuff it into their mouth, or released the prey model and remained below the water's surface.

\section{Comparison of bullfrog strike distance and OSF FID in the laboratory}

We estimated the StrkD of 43 bullfrogs in the laboratory (Tables 6.1-6.2). Every bullfrog reacted and displayed a measurable StrkD. Analysis of the 11 co-factors evaluated failed to identify any significant models, that is, no combination of co-factors influenced bullfrog StrkD (all $P>0.05$ ). Moreover, analysis to detect a potential tank effect (treated as a multi-categorical class variable) failed to reveal any significant effect on StrkD. Thus, StrkD can be directly compared to the FID of laboratory-tested OSFs without concern of obvious confounds.

We measured the FID of 32 OSFs: 12 Young-of-year (YOY), three $2^{\text {nd }}-$ year, and 17 adult OSFs (Table 6.1). Due to low sample size, we combined the $2^{\text {nd }}$-year and adult age FIDs frogs. As prior research found no difference with these two age classes, such treatment was evaluated with sensitivity analysis (see Fig. 6.5). Cumulative frequency 
distributions of StrkDs and FIDs revealed that $100 \%$ of YOY and $75 \%$ of the older age class frogs were below the maximum StrkD of bullfrogs (Fig. 6.4). Examination of the $2^{\text {nd }}$-year and adult frogs FIDs could not be discriminated from each other in sensitivity analysis, justifying our treatment of the group inclusively and which is supported by previous work (Hayes et al., in press, Tidwell et al., in prep). The proportions of these groups (i.e. the proportion above or below the maximum StrkD) were significantly different by age class, with results stable in LOO analysis (moderate ESS=30.00, $P<$ 0.04) (Table 6.4). Most of the effect was attributable to the majority of YOY frog FIDs being below the maximum bullfrog StrkD (Fig. 6.6).

\section{Comparison of bullfrog strike distance and OSF FID in the field}

We tested the StrkD of 27 bullfrogs in the field (Table 6.1-6.2). Every bullfrog reacted and displayed a measurable StrkD. Consistent with findings in the laboratory, no significant model was identified that would support the effect of the three co-factors measured in the field on StrkD. Accordingly, we compared maximum bullfrog StrkD directly to the FID of OSFs using cumulative frequency distribution of field data.

We measured the FID of 32 YOY, $322^{\text {nd }}$-year, and 36 adult OSFs (Table 6.1). As seen, cumulative frequency distributions of StrkD and FIDs revealed that 75\% of YOY, $46 \%$ of $2^{\text {nd }}$-year, and only $30 \%$ of adults were below the maximum StrkD of bullfrogs (Fig. 6.5). Comparison of OSF FID groups below and above the maximum bullfrog StrkD (class variable) found significant differences, stable in LOO analyses, between YOY and the $2^{\text {nd }}$-year (moderate ESS $=28.12, P<0.0197$ ) and adult age classes (moderately strong ESS $=41.67, P<0.007$ ). Again, the effect was attributable to YOY 
frogs being significantly more vulnerable to bullfrog predation (Fig. 6.6). And, consistent with laboratory analysis and previous report (Hayes et al., in press), we found no difference between $2^{\text {nd }}$-year and adult age classes (weak ESS $\left.=13.54, P<0.1865\right)$ (Table 6.5).

\section{Comparison of bullfrog strike distance and OSF FID of a non-bullfrog impacted}

\section{population}

Having assessed the vulnerability of OSFs at Conboy Lake, we next conducted parallel analyses of OSFs at non-bullfrog impacted Big Marsh. Specifically, using the StrkDs measured in the field for 27 bullfrogs at Conboy Lake, we evaluated the proportion of OSF FIDs below and above the maximum bullfrog StrkD of 32 YOY, 32 $2^{\text {nd }}$-year, and 36 adult OSFs from Big Marsh (Table 6.1). Cumulative frequency distributions of StrkD and FIDs revealed that $73.3 \%$ of YOY, $66 \%$ of $2^{\text {nd }}$-year, and $50.5 \%$ of OSF adults were below the maximum bullfrog StrkD. Consistent with prior findings of FID, comparison of groups below and above the maximum StrkD of bullfrogs found no significant differences between YOY, the $2^{\text {nd }}$-year age class (very weak ESS = 7.33, $P<0.3341$ ) and the adult age classes (weak ESS $=17.78, P<0.1075$ ), nor between $2^{\text {nd }}$-year and adult classes (weak ESS $=10.44, P<0.2240$ ) $($ Table 6.6, Fig. 6.3). These findings are attributable to the uniformly short FIDs displayed by all age groups of frogs, the median value of which is well within the maximum StrkD of bullfrogs.

\section{DISCUSSION}


Negative effects of bullfrogs on native amphibian populations have been hypothesized since their introduction in the western United States, however, no studies have identified mechanisms of direct post-metamorphic bullfrog impact. Here, we investigated whether the bullfrog could be responsible for the age-based change in FID documented at the only site of long term co-occurrence, Conboy Lake (Hayes et al., in press). We discovered in the laboratory, and then validated in the field, that the maximum StrkD of bullfrogs is significantly greater than the FID of Conboy YOY OSFs, but not of most older frogs. The structure of our analysis allows interpretation of potential age class vulnerability to bullfrog predation, whereby, we regarded OSFs vulnerable to predation as those with an FID less than or equal to the maximum StrkD of a bullfrog. Alternatively, we regarded OSFs with FIDs outside of bullfrog StrkD not immediately vulnerable to predation. The YOY OSFs, with a significant proportion of FIDs less than the maximal StrkD of bullfrogs, are between 25\% (laboratory) and 70\% (field) more vulnerable to bullfrog predation than older frogs. Conversely, at Big Marsh, an OSF population with no bullfrogs, all age classes were similar with more than $50 \%$ of each age class being regarded as vulnerable.

Given the similarity between the two sites except for bullfrog presence (Tidwell et al., in prep), the differential in vulnerability and increased FID by age class at Conboy Lake seems to reflect bullfrog predation. Furthermore, the homogeneity of FIDs among OSF age classes at Big Marsh, and the large proportion of the population that we would regard as vulnerable suggests that if bullfrogs were introduced to Big Marsh, they could have a significant impact via predation. As stated above, such impacts have long been 
hypothesized, however the experimental work has focused either on behaviors that may indirectly facilitate predation on native amphibian larvae (Kiesecker and Blaustein, 1998; Kupferberg, 1997; Pearl et al., 2003; Paoletti, 2009) or in-situ experiments of bullfrog predation (Pearl et al., 2004; Fuller 2008), making this the first testable hypothesis to examine potential bullfrog impact on metamorphosed anurans in the field. Important to this study, and different from Pearl et al. (2004), is the contextual use of life history traits in the experimental design. In the Pacific Northwest, the OSF is the anuran most likely to be impacted by bullfrogs given the extensive overlap in aquatic habitat use and almost entirely aquatic life history traits (See Hallock in press for review). As such, our study tested the vulnerability of OSFs in the aquatic platform both in and ex-situ and therefore has specificity lacking in other studies.

The techniques applied herein are novel and two points merit discussion. First, is the cross-generizability of the findings in the laboratory and field experiments. Direct comparison of field and laboratory experiments was not the aim of this investigation, however, future work examining the relationships presented here may be enhanced by doing so. To that end, we highlight that differences of scale between both behaviors measured (FID and StrkD) were found between the laboratory and field; the measurements in the laboratory were on average shorter than those taken in the field. Whether this reflects the resolution of field measurements, or more likely, a function of artificial truncation of the laboratory measurements due to limiting the size of the testing tanks cannot be determined with existing data, but the consistent trends in both methods 
suggests that the differences of scale reflect the totality of the potential effect, and not the realized effect of the proportions of populations vulnerable to predation.

Second, we highlight the application of cumulative frequently distributions and their use to determine relative and absolute vulnerability. Using the maximum StrkD of the bullfrog allowed examination of a potential predation interactions of bullfrogs and OSFs and allowed interpretation of the absolute vulnerability of the prey species, however, this measure may not reflect the total range of bullfrog StrkD given the moderate sampling. Furthermore, this analysis did not investigate the relative vulnerability of OSFs to bullfrogs with StrkD less than the maximum. Such investigations are possible using integral segmentations of the cumulative frequency display and may shed light on the interplay between absolute and relative vulnerabilities of the prey taxa.

Finally, we discuss the predatory action of the bullfrog with respect to the current findings. Often described as sit and wait predators, bullfrogs have also been described as opportunistic consumers that will readily attack any animal smaller than themselves (Bury and Whelan, 1984). Here we document that the species is perhaps more ambulatory and strategic than previously documented. In the laboratory (where all measures of FID and StrkD were shorter), we found that 95\% of bullfrogs swam an average of $0.45 \mathrm{~m}$ towards a prey item (DT) before initiating a strike, a distance greater than the average FID of YOY OSFs measured in both field and laboratory studies and great enough that it would put the average FID of all age classes at Big Marsh within the 
StrkD. Which, with the observed approach distance, the average FID of $2^{\text {nd }}$-year and adult frogs at Conboy Lake remain outside the bullfrog StrkD (Table 6.1).

This investigation provides evidence for direct effects of introduced bullfrogs by modulation of escape behavior of a native prey species faced with bullfrog predation. The analyses of predator and anti-predator tactics is a novel approach and can be visualized with cumulative frequency distributions. Implementation and refinement of this approach can provide insight to the predator-antipredator interplay of other species and be used to identify potential vulnerabilities of native prey to introduced predators.

\section{ACKNOWLEDGMENTS}

We thank Lisa Wilson and USF\&W staff for help with lodging and/or logistics at Conboy Lake National Wildlife Refuge. The Mid-Columbia National Wildlife Refuges complex provided the Special Use Permit to work on the refuge. Financial support was provided by the Oregon Zoo Foundation and the Forbes-Lea Endowment Fund at Portland State University. We thank Andre Garret, Bill Brady, and Ricky Scott for the help in field collections. 


\section{CHAPTER 6 TABLES}

Table 6.1 Descriptive statistics of bullfrog strike distance and OSF FID for laboratory and field experiments at Conboy Lake and OSF FID at Big Marsh. All measurements of distance are in meters.

$$
\mathrm{n}=\overline{\boldsymbol{x}} \pm \mathrm{SE} \quad \text { Median } \mathrm{CV} \text { Range }
$$

\begin{tabular}{|c|c|c|c|c|c|c|c|}
\hline \multirow{3}{*}{ Lab } & $\begin{array}{l}\text { Strike } \\
\text { Distance }\end{array}$ & & 43 & $0.14 \pm 0.15$ & 0.13 & 0.68 & $0.01-0$. \\
\hline & & & & $\cap 08+\Omega \Omega 2$ & & & \\
\hline & FID & $\begin{array}{l}2^{\text {nd }} \text {-year \& } \\
\text { Adult }\end{array}$ & $\begin{array}{l}12 \\
20\end{array}$ & $\begin{array}{l}0.08 \pm 0.03 \\
0.31 \pm 0.08\end{array}$ & $\begin{array}{l}0.05 \\
0.18\end{array}$ & $\begin{array}{l}1.20 \\
1.10\end{array}$ & $\begin{array}{l}0.0-0.3 \\
0.0-1.2\end{array}$ \\
\hline
\end{tabular}

Strike

Distance

$27 \quad 0.34 \pm 0.03 \quad 0.34 \quad 0.41 \quad 0.10-0.6$

Field

$\begin{array}{lllllll} & \text { YOY } & 32 & 0.41 \pm 0.09 & 0.21 & 1.23 & 0.0-1.9 \\ \begin{array}{l}\text { Conboy } \\ \text { FID }\end{array} & 2^{\text {nd }} \text {-year } & 32 & 1.59 \pm 2.28 & 0.96 & 1.28 & 0.0-11.3 \\ & & & & & & \\ & \text { Adult } & 36 & 2.28 \pm 2.73 & 1.63 & 1.18 & 0.0-11.3 \\ \text { Big } & \text { YOY } & 30 & 0.55 \pm 0.12 & 0.23 & 1.19 & 0.0-2.3 \\ \begin{array}{l}\text { Marsh } \\ \text { FID }\end{array} & & & & & & \\ & 2^{\text {nd }} \text {-year } & 50 & 0.80 \pm 0.18 & 0.12 & 1.59 & 0.0-5.3 \\ & \text { Adult } & 36 & 0.88 \pm 0.18 & 0.22 & 1.22 & 0.0-3.4\end{array}$


Table 6.2 Descriptive statistics of snout-vent-length (SVL) for bullfrogs used in laboratory and field experiments at Conboy Lake to measure strike distance. All measurements of distance are in millimeters.

\begin{tabular}{llllll} 
Bullfrog & $\mathbf{n}=$ & $\overline{\boldsymbol{x}} \pm \mathbf{S E}$ & Median & $\mathbf{C V}$ & Range \\
\hline Lab SVL & 43 & $118.65 \pm 3.23$ & 119 & 0.13 & $92-187$ \\
Field SVL & 27 & $129.48 \pm 3.16$ & 130 & 0.18 & $90-150$
\end{tabular}


Table 6.3 Measurement of variables taken on frogs used in laboratory analysis of bullfrog strike distance.

\begin{tabular}{|l|l|}
\hline Variable & Description \\
\hline Eye & $\begin{array}{l}\text { Diameter of the eyes, measured from the } \\
\text { anterior to posterior point of the eye lids with } \\
\text { a metric ruler (0.50 mm). }\end{array}$ \\
\hline Gonad length and width & $\begin{array}{l}\text { Gonads measurements (left and right) were } \\
\text { taken to determine the state of development. } \\
\text { Measurements were taken with a digital } \\
\text { caliper (0.01 mm) }\end{array}$ \\
\hline Gonad Mass & $\begin{array}{l}\text { Gonad weight (Left and right) were weighed } \\
\text { for mass using a precision balance (0.01 g). }\end{array}$ \\
\hline Mass & $\begin{array}{l}\text { Mass: Body mass measured with precision } \\
\text { balance (0.01 g). }\end{array}$ \\
\hline Prey & $\begin{array}{l}\text { Presence of prey items in bullfrog stomach. } \\
\text { Assessed by removing the G.I. tract of the } \\
\text { frog from the cardiac sphincter to anus and } \\
\text { inspecting for prey contents. }\end{array}$ \\
\hline Sex & $\begin{array}{l}\text { Gender of a specimen determined by presence } \\
\text { of ovarian (female) or testicular tissue (male). }\end{array}$ \\
\hline Shank & $\begin{array}{l}\text { Measurement of tibia length from femoral } \\
\text { articulation to metacarpal articulation with } \\
\text { metric ruler (0.50 mm). }\end{array}$ \\
\hline SVL & $\begin{array}{l}\text { Body length measurement of distance } \\
\text { between snout to vent with a metric ruler } \\
\text { (0.50 mm). }\end{array}$ \\
\hline Tympana & $\begin{array}{l}\text { Diameter of the tympanic membrane, } \\
\text { measured from the anterior to posterior point } \\
\text { of the tympanic ridge with a metric ruler (0.50 } \\
\text { mm) }\end{array}$ \\
\hline
\end{tabular}




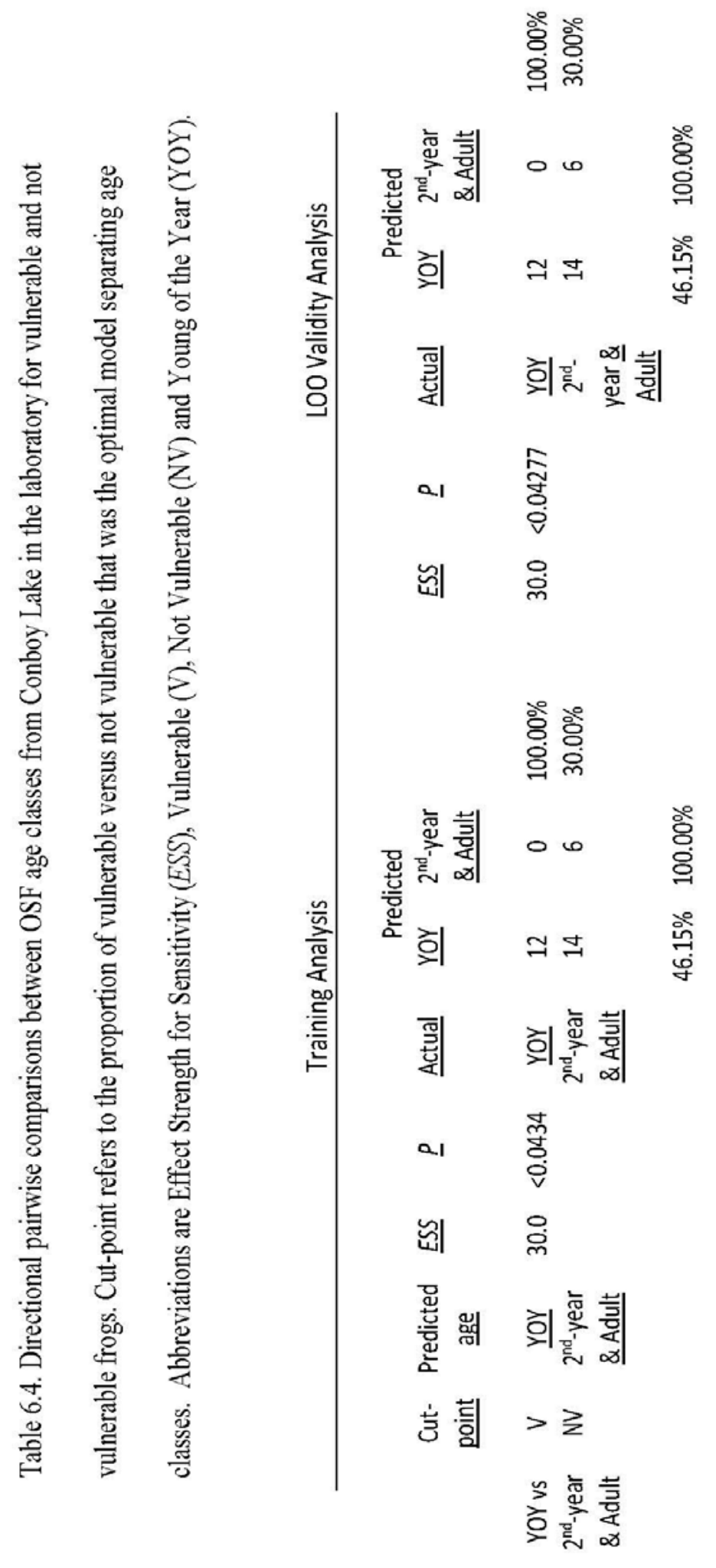




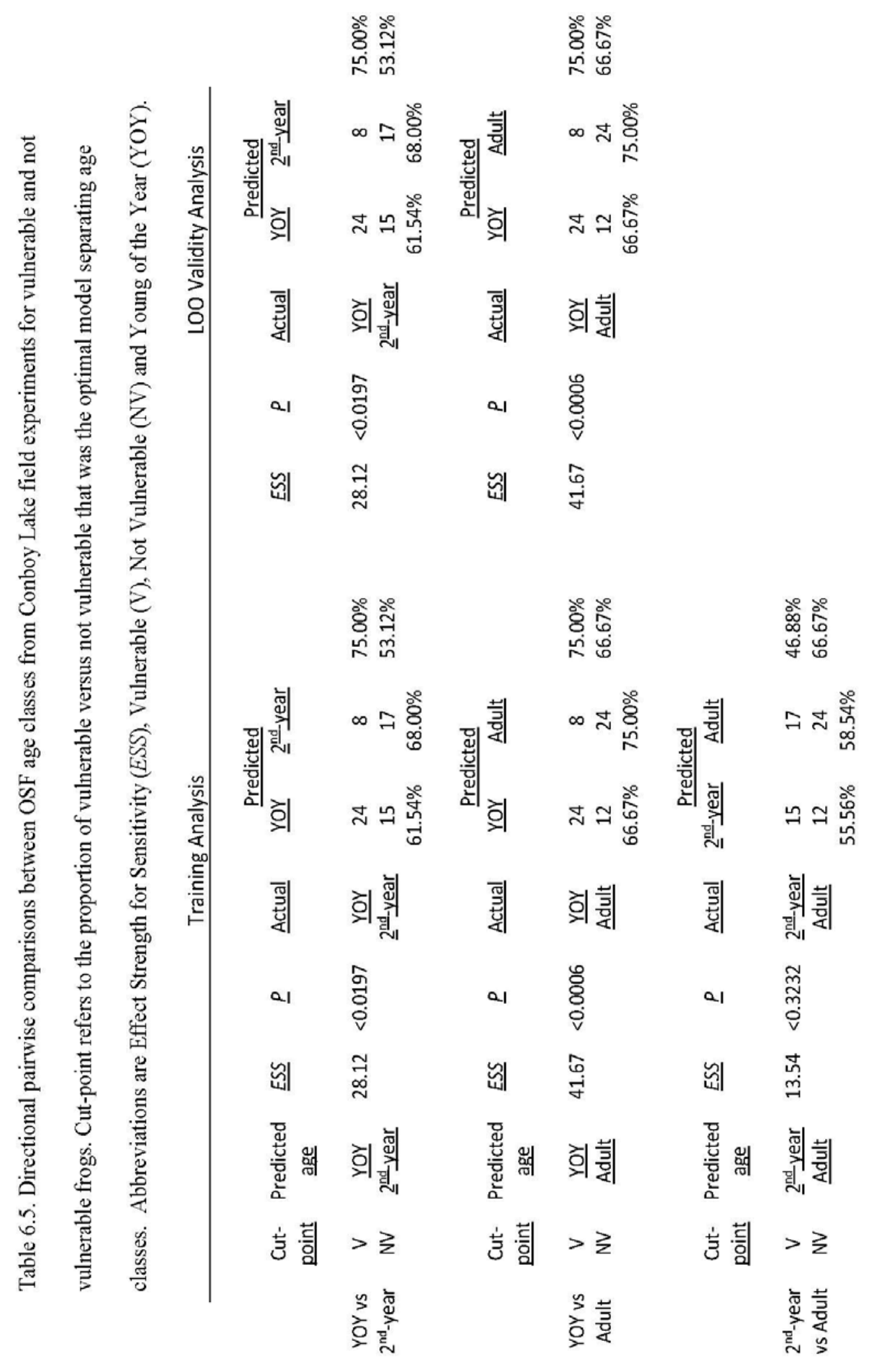




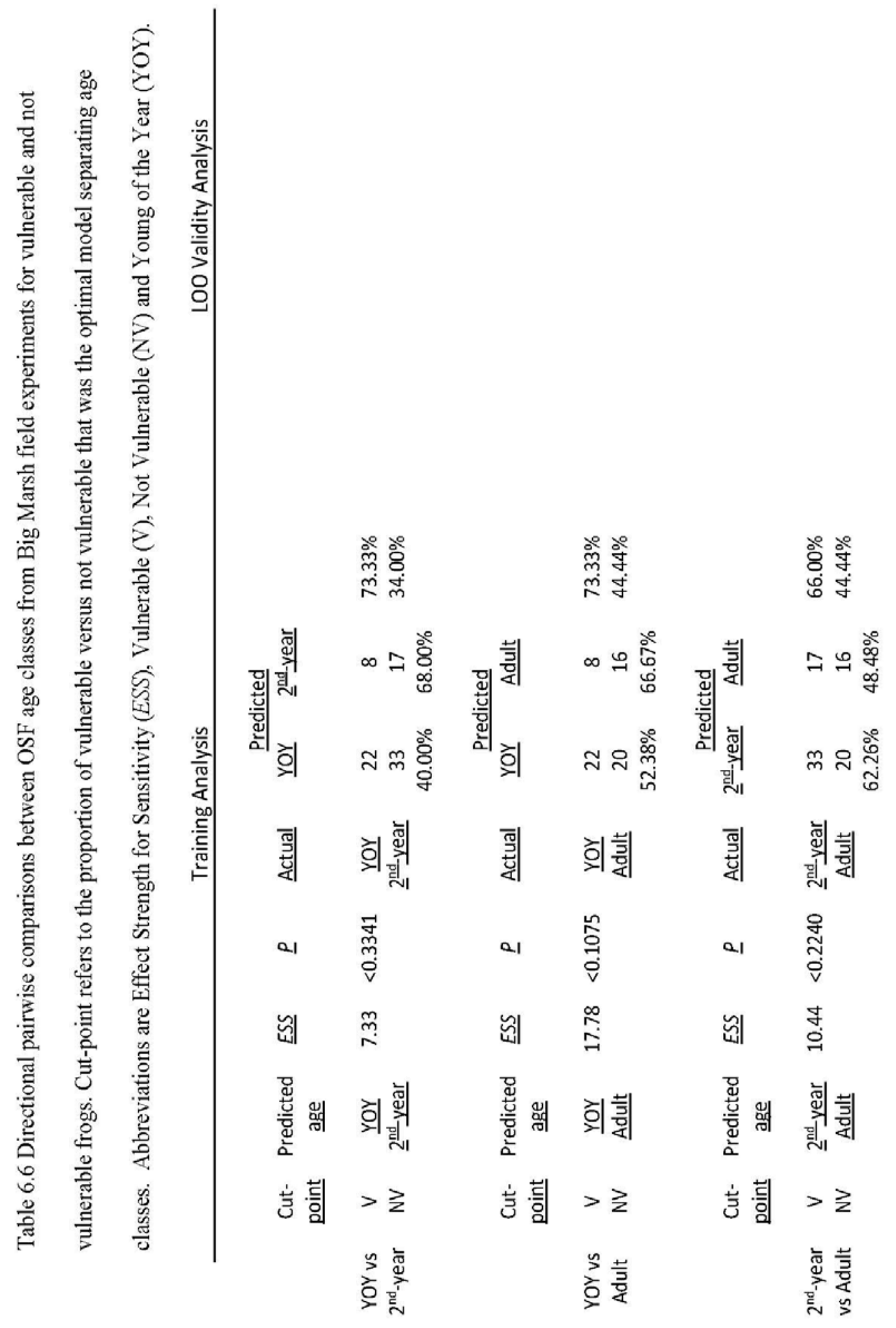




\section{CHAPTER 6 FIGURES}

Figure 6.1 Image of laboratory testing tank with visual barrier.

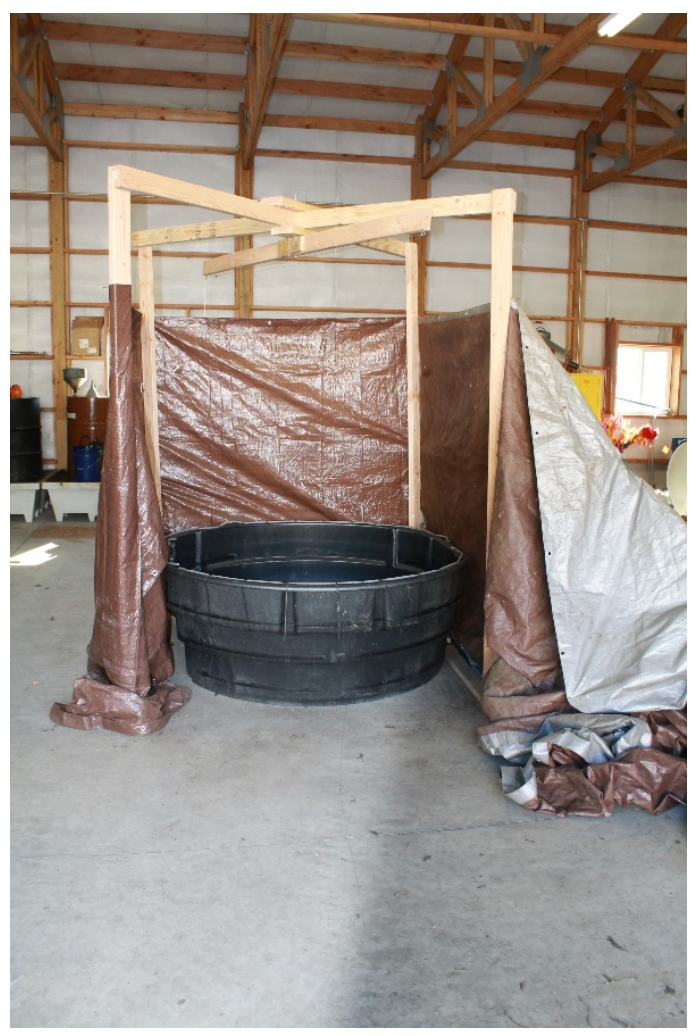

Figure 6.2 Image of OSF prey model.

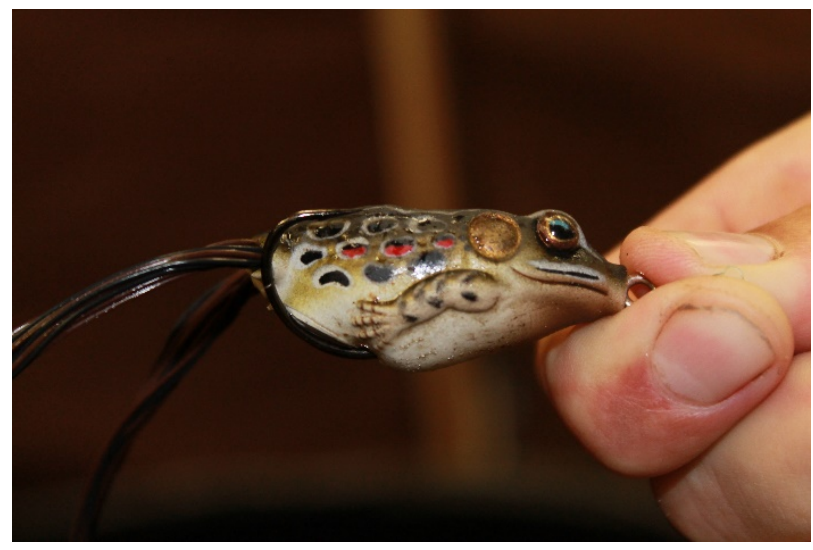


Figure 6.3 Laboratory FID testing tank.

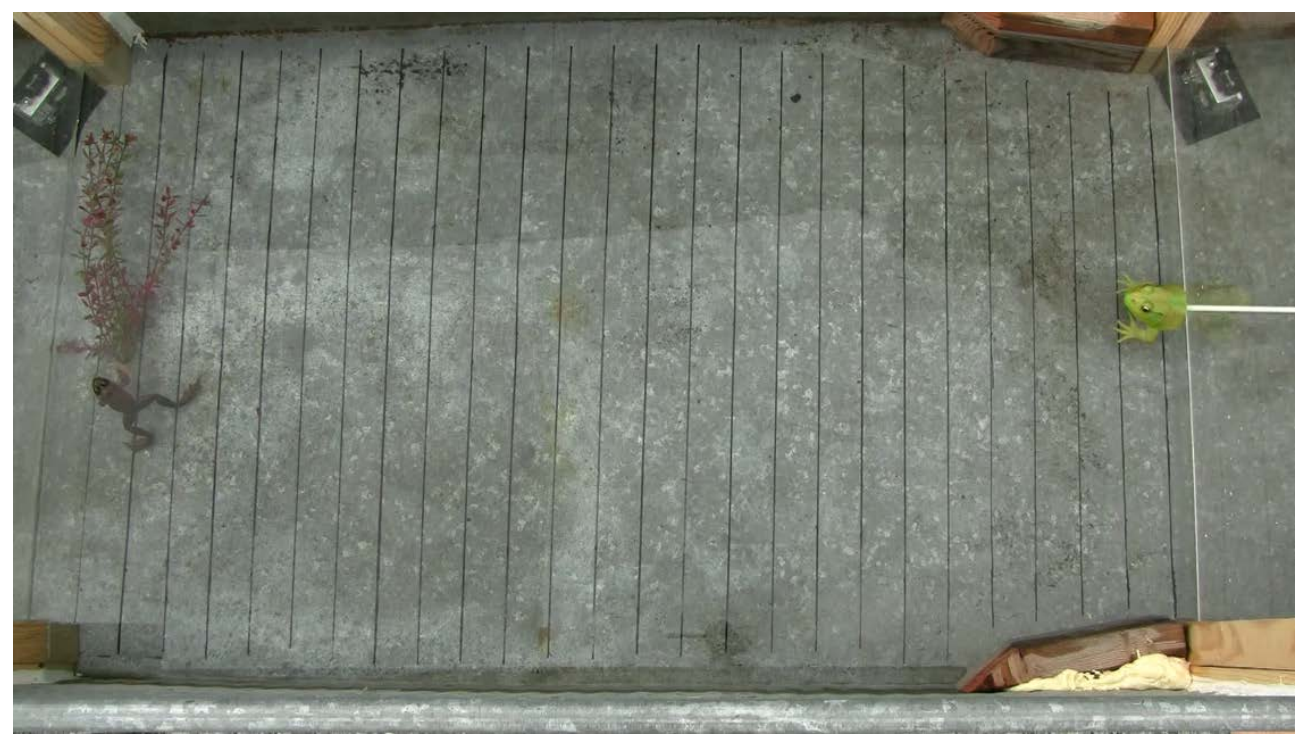


Figure 6.4 Cumulative frequency distribution of OSF FID and bullfrog strike distance from Lab experiments at Conboy Lake. YOY = Young of the Year.

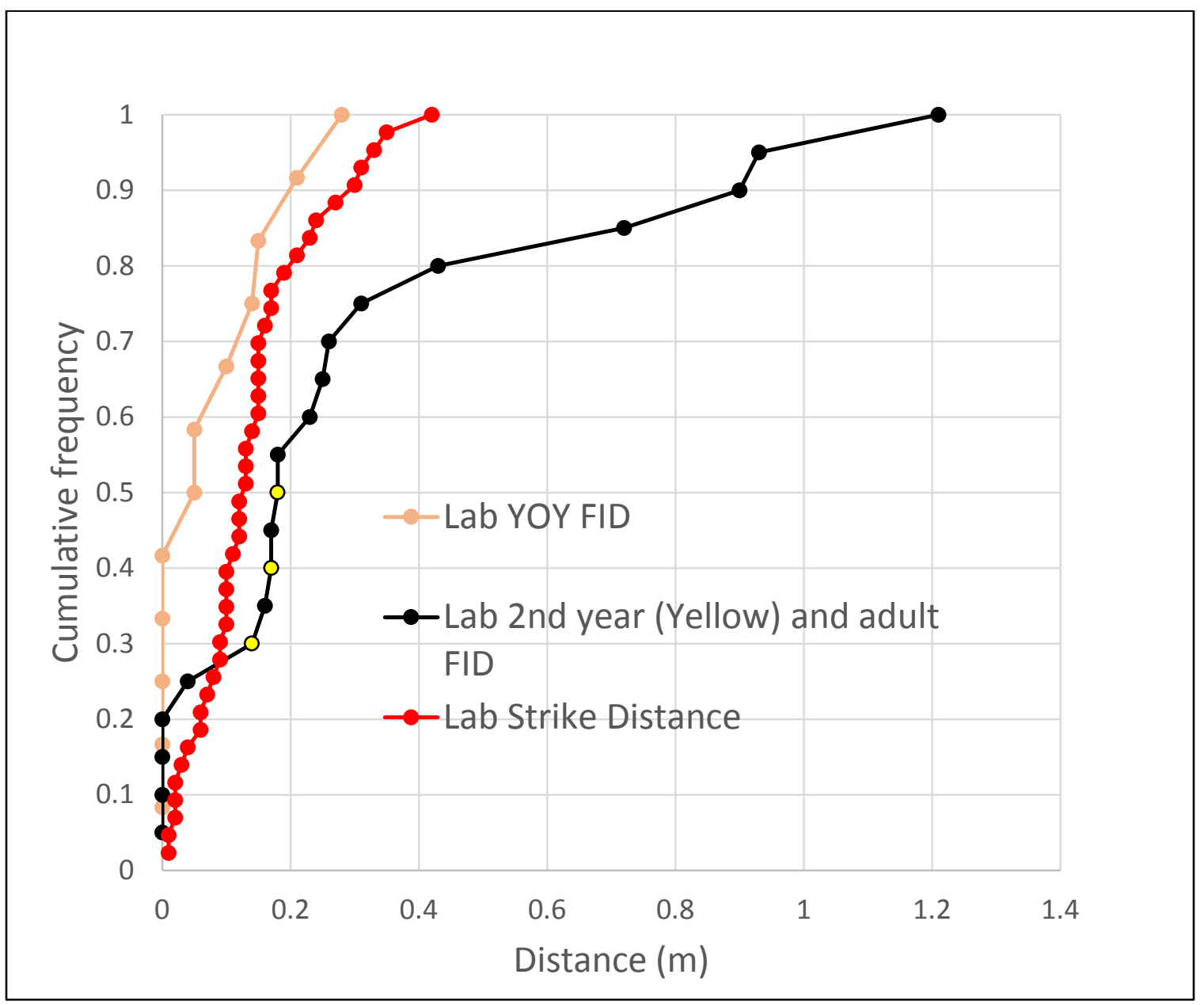


Figure 6.5 Cumulative frequency distribution of OSF FID and bullfrog strike distance from field experiments at Conboy Lake. YOY = Young of year.

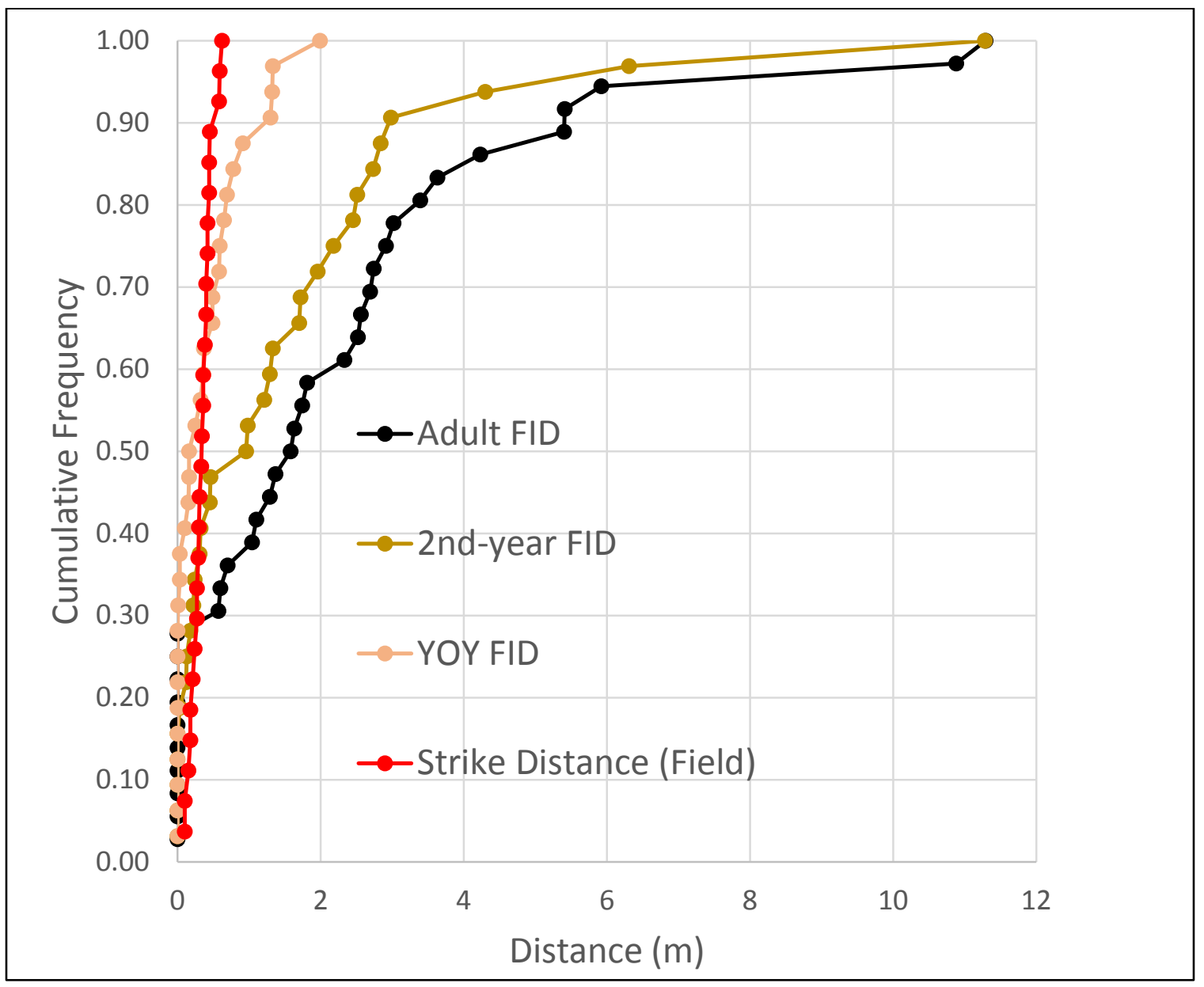


Figure 6.6 Plots of field observations of OSF FID at Big Marsh (BM) and Conboy Lake (CB) and bullfrog strike distance at Conboy Lake. The red line indicates the maximal strike distance of bullfrogs measured in field experiments (aka. vulnerability line).

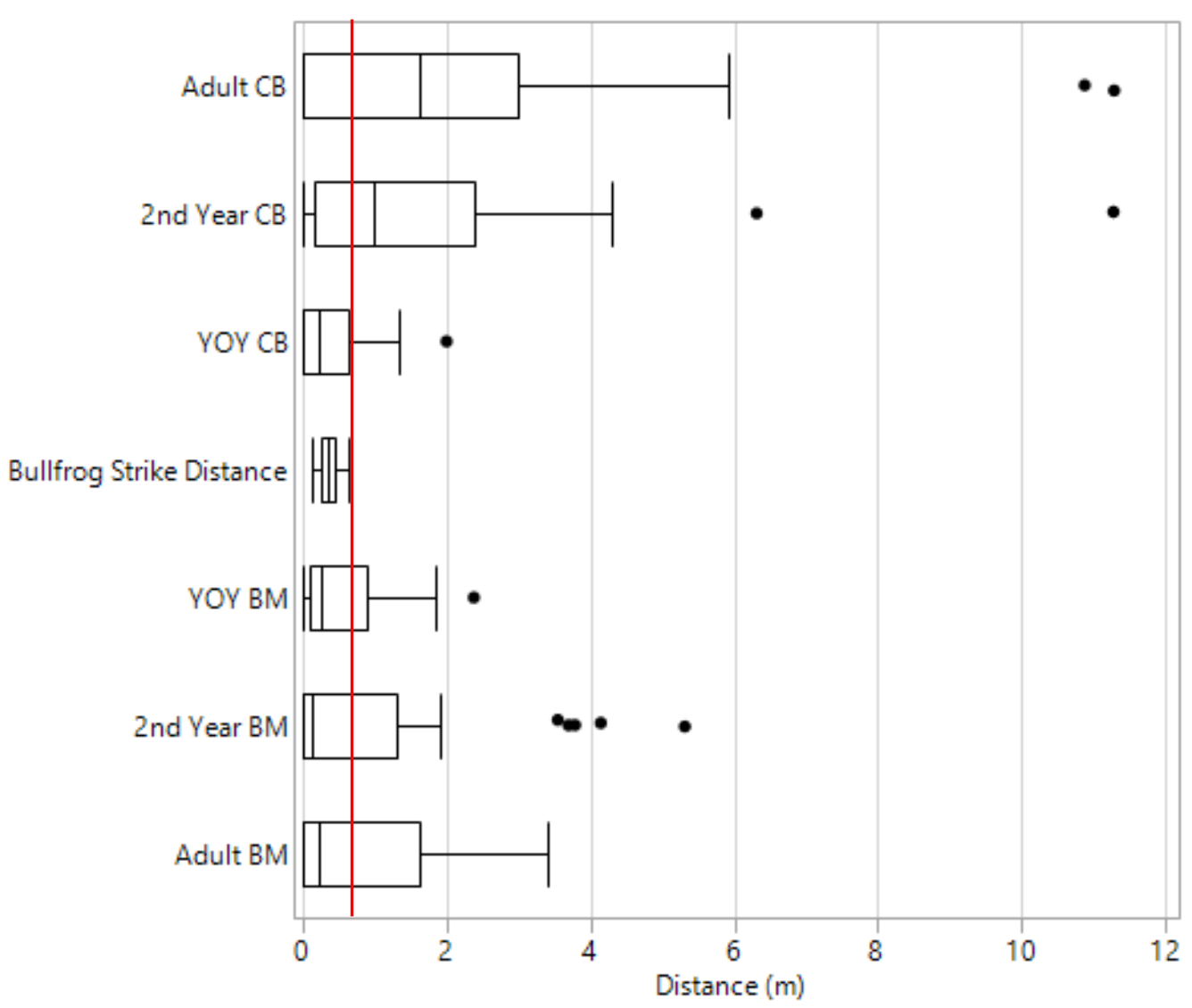




\title{
CHAPTER 7 \\ VERTEBRATE PREY CONTENTS OF BULLFROGS
}

\begin{abstract}
American bullfrog dietary contents have been widely investigated in their introduced range. However, there have been no investigations of dietary contents at a site of co-occurrence with Oregon Spotted Frogs, a species highly suspect to be impact by American bullfrog predation. I compiled and analyzed 887 bullfrog gut contents across the entire surface active season at Conboy Lake National Wildlife Refuge, the only site of long term co-occurrence, over a four year period. Analysis of the size of anuran prey contents consumed by bullfrogs had a significant positive relationship to the size of bullfrog consuming them. The mean and maximum size of bullfrogs and Oregon Spotted Frogs consumed were identical which suggests that gape limitations of bullfrogs at Conboy Lake may restrict the size of vulnerable prey that can be consumed.
\end{abstract}

\section{INTRODUCTION}

Intraspecific differences in feeding ecology can develop with ontogeny (Werner and Anholt 1993; Lind and Welsh, 1994; Woodward and Hildrew, 2002), and drive the generalized pattern found in many gape-limited predators where larger predators eat larger prey (See Werner and Gilliam [1984] for review). Research of anuran predatory ecology largely support the general pattern (Loman 1979; Toft 1980, 1981; Lima, 1998, Thiago et al., 2013). Of particular interest in such studies is the American Bullfrog 
(bullfrog; Lithobates catesbeianus), as it is pervasive and widely introduced. Dietary analyses conducted on bullfrogs in their introduced range conform to the general pattern that larger frogs eat larger (primarily vertebrate) prey (Stewart and Painter, 1994; Werner et al., 1995; Wu et al., 2005; Wang et al., 2008; Boelter et al., 2012; Leivas et al., 2012; Silva et al., 2016, but see Xuan et al., 2015). However, few studies have analyzed the relationship of bullfrog body size and predation on western amphibians (Twedt, 1993; Govindarajulu et al. 2006; Hothem et al., 2009; Jancowski and Orchard, 2013). In the Pacific Northwest, such studies would be particularly illuminating given the large adult bullfrog sizes (and associated large gapes) and the hypothesized impact to native prey populations through direct predation (Hayes and Jennings, 1986; Pearl et al., 2004).

Given the hypothesized impact of bullfrog predation on native amphibians, specifically Oregon Spotted Frogs (OSF; Rana pretiosa) (Pearl et al., 2004, 2005; Hallock in press), it is pertinent to understand the dietary scope of bullfrogs at a site of OSF co-occurrence. In light of the potential bullfrog impact presented in Chapters $2-6$, a detailed investigation of bullfrog diet at Conboy Lake, the only site of long term cooccurrence (Hallock in press), is warranted.

The primary objective of this investigation was to catalogue the dietary contents of a large sample of bullfrogs from Conboy Lake to determine the scope of their diet and better understand the OSF-bullfrog interaction. Here, I present a summary of the data with focus on the vertebrate prey items. For comparison to other studies, I report total invertebrate prey content and the contribution of vertebrate prey items to the total sample. I have narrowed the scope of study to the potential direct impact bullfrog predation may 
have on metamorphosing and metamorphosed anurans by characterizing the relationship between bullfrog body size and consumed anuran prey size. To do this, I; 1) characterize the suite of vertebrate prey items taken at Conboy, 2) highlight whether bullfrogs are consuming metamorphosed anurans (specifically OSFs) at the site, and, 3) identify the size relationships of anurans vulnerable to bullfrog predation.

\section{MATERIALS AND METHODS}

All work conducted for this study was reviewed and approved by the Institution for Animal Care and Use Committee of Portland State University (Protocol \#30). The work was conducted under the Special Use Permit authorized to KST by the MidColumbia National Wildlife Refuge system (permit\# 1018-0102).

\section{Bullfrog Collection}

Over a four-year period (2012-2016), I performed summertime surveys for bullfrogs at Conboy Lake during the months of June to September. This time period represents the active season for the species at the site. Most samples were collected in August of each year, when the weather was warmest, young bullfrogs were completing metamorphosis, and adults were surface-active but no longer breeding. The latter point is especially pertinent to adult male bullfrogs which, during the breeding season are often found with empty stomachs, presumably due to associated breeding behaviors (e.g. territory guarding and calling) (Bury and Whelan, 1984). Thus, the sampling effort here represents the bulk of the active season over four years with a focus on the interval when all life stages of bullfrogs were surface active and actively foraging. 
Working at night with headlamps, frogs were collected by hand and net, or shot with 0.22 caliber long rifle shotshell load and specially designed 0.38 caliber cartridges loaded with small amounts of $0.05 \mathrm{~mm}$ steel shot loaded with 3.6 grains of Bullseye ${ }^{\circledR}$ powder. The use of such loads in firearms maximizes collection efforts and enables collection of large samples in short periods of time. For instance, a four-day sampling effort in August 2016 garnered 465 bullfrogs. Specimens were also collected with fyke nets as part of a removal effort by USFWS employees during the summers of 2014 and 2015. Fyke nets were checked daily and all captured bullfrogs were euthanized and added to the collection of frogs for gut content analysis. All captured frogs were placed in bags containing location and date of collection information and stored at the refuge headquarters $-20^{\circ} \mathrm{C}$ freezers until dissections and morphometric analysis could be conducted.

\section{Specimen handling and dissection procedure}

Bullfrog snout-vent-length (SVL), shank (femoral articulation to metacarpal articulation), tympana, eye, and gape morphometrics were measured using a metric ruler $(0.50 \mathrm{~mm})$, and their mass obtained with a precision balance $(0.01 \mathrm{~g})$. Frogs were then dissected, their stomachs removed via cutting at the cardiac and pyloric sphincters, and measured for mass via water displacement (0.02 ml) (Magnusson et al., 2003). After dissection, the sex of the frog was determined by visual inspection of the gonads, which were measured using digital calipers $(0.01 \mathrm{~mm})$ and their mass determined for purposes of evaluating reproductive state using a precision balance. 
Stomachs were cut open and the contents identified under a binocular dissecting microscope (20×). Invertebrates were individually identified to order, counted, recorded, then collectively measured for total invertebrate volume using water displacement (0.02 ml) and fixed in labeled containers in $70 \%$ alcohol. All vertebrate prey were identified to species level (when possible), measured for morphometrics of total length, width and mass using water displacement $(0.02 \mathrm{ml})$ and fixed in labeled containers in 70\% alcohol. A photograph of each vertebrate prey item was taken for archiving.

Some anuran prey contents were too digested to identify to the species level, making partitioning between OSF and bullfrogs difficult. However, Pacific Treefrogs (Pseudacris regilla) given their small size and unique morphology (relative to aquatic ranids like OSFs and bullfrogs) were distinguishable even in highly digested states. Tissue samples from the other highly digested ranid specimens were collected and will be processed to species using DNA analysis. In some cases, the digested state of some specimens allowed for identification but did not allow measurement of SVL, because the cranial bones were too digested to accurately determine the terminus of the snout. Given these constraints, I collapsed the analysis to include metamorphosed bullfrogs, Pacific Treefrogs, OSFs, and unidentified metamorphosed frogs that had skeletal remains intact enough to allow SVL measurement.

\section{Analytical procedure}

The potential relationship of bullfrog body size (SVL) and metamorphosed anuran prey body size (SVL) was determined by constructing a scatter plot with each bullfrog 
SVL and the corresponding anuran prey SVL for all species. Linear regression was used to examine the relationship between the two parameters.

I tested for a differential in predation on metamorphosed anurans by bullfrogs based on body size by calculating the ratio of consumed anuran prey body size (SVL) to consuming bullfrog body size (SVL) for each species of consumed anuran. I did this for the metamorphosed samples of Pacific Treefrogs, OSFs, bullfrogs and the unidentifiable anuran samples. I compared the species ratios with a non-parametric Kruskal-Wallis test, and conducted post-hoc analysis with individual Mann-Whitney U tests. All analyses were conducted in JMP Pro version 12 with significance set at the $P<0.05$ level.

\section{RESULTS}

A total of 887 bullfrogs were collected and dissected for dietary analysis. Sampled frogs ranged in size from $32 \mathrm{~mm}$ - $168 \mathrm{~mm}$ SVL, of which, 450 were females (205 juveniles [SVL $\leq 70 \mathrm{~mm}$ ], and 245 adults [SVL $>70 \mathrm{~mm}$ ]), and 423 were males (183 juveniles $[\mathrm{SVL} \leq 70 \mathrm{~mm}]$, and 240 adults $[\mathrm{SVL}>70 \mathrm{~mm}])$. Eleven were hermaphrodites (all adults $>70 \mathrm{~mm} \mathrm{SVL,} 4$ appearing female and 7 appearing male), and there were three frogs of indistinguishable sex due to damage of the gonadal tissues during collection. We found no stomach contents in 170 bullfrogs.

A total of 2,199 prey contents were identified, of which 2,034 were invertebrates (92.5\%), and 165 were vertebrates (7.5\%) (Figure 1). Invertebrate prey represented five classes: 1744 insects (88.30\%; Insecta), 93 snails (4.71\%; Gastropoda), 45 leeches (2.28\%; Clitellata), and 93 spiders (4.71\%; Arachnida) (Table 2). 
Of the vertebrate prey, five classes were identified: 94 amphibians (56.97\%; Amphibia), 39 fishes (23.64\%; Actinopterygii), seven snakes (4.24\%; Reptilia), eight mammals (4.85\%; Rodentia), four birds (2.42\%; Aves), and 13 (7.88\%) unidentifiable vertebrate prey remains (Table 2). Interestingly, of the 165 vertebrates consumed, 161 (97.57\%) were consumed by subadult and adult bullfrogs (i.e. SVL> $70 \mathrm{~mm} \mathrm{SVL),} \mathrm{and}$ the balance were consumed by juvenile bullfrogs (SVL $\leq 70 \mathrm{~mm}$ ) (Table 3).

Of the amphibian prey contents, all were consumed by adult bullfrogs and $26.06 \%$ were metamorphosed anurans (Table 3). Amphibian prey contents include: 40 tadpoles (32 unidentifiable, eight bullfrog), 11 salamanders (Ambystoma and Taricha spp.), and 43 metamorphosed anurans (14 bullfrogs, 11 Pacific Treefrogs, 10 OSFs and eight unidentifiable frogs) (Table 2).

I obtained SVL measurements for 14 bullfrogs, 11 Pacific Treefrogs, 10 OSFs, and three of the eight unidentifiable frogs to assess the relationship between bullfrog size and metamorphosed anuran prey size. Despite modest sample sizes $(n=38)$, generalized linear regression found a significant positive relationship between bullfrog body size and the size of consumed anuran prey $\left(R^{2}=0.43, F(1,37)=27.54, P<.0001\right)$ (Figure 1$)$.

I then compared the ratio of bullfrog body size to metamorphosed anuran prey size in order to compare the size of consumed prey and found a significant difference. Bullfrogs consumed OSFs and bullfrogs that were on average 36\% of their total length (Table 3), but consume Pacific Treefrogs that were on average $19 \%$ of their size $(\mathrm{H}=$ 22.44, $\mathrm{df}=3, P<0.0001$ ) (Table 3). Post-hoc analysis of each sample found no significant difference between OSF or bullfrog ratios ( $\mathrm{S}=154, Z=0.57, P<0.563$ ), nor 
between those two species and the unidentifiable frogs (OSF: $S=24, Z=0.16, P<$ 0.8763, bullfrog: $\mathrm{S}=32, Z=0.57, P<0.5703)$. However, I did find significant difference between Pacific Treefrogs and bullfrogs ( $\mathrm{S}=66, Z=-4.19, P<0.0001)$, OSFs ( $\mathrm{S}=68, Z$ $=-3.81, P<0.0001)$, and the unidentifiable anuran samples $(\mathrm{S}=39, Z=2.49, P<$ 0.0127).

\section{DISCUSSION}

This investigation found that bullfrogs at Conboy Lake primarily consume invertebrate prey, but when vertebrate prey were consumed, diverse species were involved. I identified that bullfrogs consumed metamorphosed OSFs and a diversity of other amphibians that are at most $46 \%$ of their body size and moreover, I found that predation of post-metamorphic anurans was directly related to bullfrog body size.

These findings support previous dietary analysis of bullfrog gut content in the Pacific Northwest, suggesting that, the bullfrog is a dietary generalist (Hothem et al., 2009; Jancowski and Orchard, 2013) capable of taking vertebrate prey which often consists of anurans (Govindarajulu et al. 2006). However, this investigation revealed novel findings for bullfrogs in the Pacific Northwest with regard to the relationship of predator and consumed anuran prey size that had only been found for extra-Northwest bullfrog populations (Boelter et al., 2012; Silva et al., 2016). This size-based relationship was supported by the fact that adult bullfrogs consumed $97.5 \%$ of vertebrate prey items, implying that the older (hence larger) bullfrogs generally consume larger prey. Precisely how this relationship impacts predation of Pacific Northwest amphibians is unknown, but 
the relatively large maximum size of anurans consumed in this sample (e.g. $76 \mathrm{~mm} \mathrm{SVL}$ ) by moderate-sized adult bullfrogs (165 mm SVL) suggests that many Pacific Northwest amphibians may be vulnerable to predation.

Rombough et al. (2006) documented the largest OSF at Conboy Lake, a 107-mm SVL female, and postulated that the large OSF body size at Conboy Lake may potentially be a result of bullfrog presence. In light of the results presented here, the hypothesis is plausible given that all metamorphosed anuran prey contents identified were $\leq 46 \%$ of the consuming bullfrog SVL (Table 7.3) and that the largest bullfrog in the sample with anuran prey items was $165 \mathrm{~mm}$ SVL and had consumed a conspecific exactly $46 \%$ of its size (76 mm SVL). Moreover, of the 887 bullfrogs sampled, the largest bullfrog was 168 mm SVL, although the largest Conboy Lake bullfrog on record was a $203 \mathrm{~mm}$ SVL female (M. Hayes unpublished data). Bullfrogs of these sizes could, according to the present data, consume anurans up to $77.28 \mathrm{~mm}$ and $93.38 \mathrm{~mm}$ SVL respectively, indicating that the larger OSFs could have a size-based escape from predation. Clearly, these represent maximal sizes, not population means, and furthermore the sample reported presently was modest (i.e. $n=38$ ) and may not capture the upper end of the relationship, however, such cross-generalizable findings of a potential prey size threshold may hold valuable insight to future study in this and other systems impacted by bullfrogs.

One missing aspect of this, and all other studies of bullfrog dietary analysis conducted in the Pacific Northwest, is a comprehensive measure of prey availability. Although conducted in studies of larval interactions (Werner and Anholt, 1993; Govindarajulu, 1994), the use of such parameters in dietary analyses of post- 
metamorphic interactions is lacking. This dichotomy likely stems from the relative difference in difficulty of taking such measurements in a strictly aquatic-based larval environment versus the terrestrial, aquatic, and aerial post-metamorphic environment. Nonetheless, such analyses are critical to answering questions of abundance, interactions, and impact. In the present study, a 24\% difference existed in bullfrog predation of conspecific versus OSF predation. Whether this reflects availability, abundance, or vulnerability cannot be determined. Future study of such interactions would benefit from acquiring estimates of abundance by prey class so as to direct interpretation of results.

A comprehensive analysis of dietary remains was beyond the scope of this investigation, but is forthcoming in future work. However, the methods and size of sample in this study deserve comment. This study is unique for two reasons, first in the number of samples collected, and second, in the longitudinal design of the study. This analysis is the second largest study of bullfrog dietary analysis in their introduced range, after Jancowski and Orchard (2013), and moreover, holds the insight of four years of data from a single site. Future analysis of the total vertebrate and invertebrate dietary contents will allow determination of inter-year variation of diet for bullfrogs and likely provide insight to bullfrog diet not feasible with other studies that have small sample sizes, multiple locations of collection from different populations, or short sampling durations. 


\section{CHAPTER 7 TABLES}

Table 7.1 Prey items from bullfrogs at Conboy Lake.

\begin{tabular}{|c|c|c|c|c|}
\hline \multirow{2}{*}{ Prey items } & \multirow{2}{*}{ Class } & \multirow{2}{*}{$\begin{array}{l}\text { Number of } \\
\text { prey } \\
\text { remains }\end{array}$} & \multirow{2}{*}{$\begin{array}{c}\begin{array}{c}\% \text { of prey } \\
\text { remains }\end{array} \\
\text { (per total of } \\
\text { vert./or invert.) }\end{array}$} & \multirow{2}{*}{$\begin{array}{c}\begin{array}{c}\% \text { of prey } \\
\text { remains }\end{array} \\
\begin{array}{c}\text { (per total of } \\
\text { prey) }\end{array} \\
\end{array}$} \\
\hline & & & & \\
\hline Vertebrate & & & & \\
\hline Unknown vertebrate & & 13 & 7.88 & 0.61 \\
\hline Fish & Actinopterygii & 39 & 23.64 & 1.82 \\
\hline Unknown Tadpole & \multirow{7}{*}{ Amphibia } & 32 & 19.39 & 1.50 \\
\hline Unknown frog & & 8 & 4.85 & 0.37 \\
\hline Bullfrog tadpole & & 8 & 4.85 & 0.37 \\
\hline Bullfrog & & 14 & 8.48 & 0.65 \\
\hline OSF & & 10 & 6.06 & 0.47 \\
\hline Pacific Treefrog & & 11 & 6.67 & 0.51 \\
\hline Salamander & & 11 & 6.67 & 0.51 \\
\hline Garter Snake & Reptilia & 7 & 4.24 & 0.33 \\
\hline Bird & Aves & 4 & 2.42 & 0.19 \\
\hline Rodent & Mammalia & 8 & 4.85 & 0.37 \\
\hline \multicolumn{5}{|l|}{ Invertebrate } \\
\hline Dytiscid & \multirow{12}{*}{ Insecta } & 171 & 8.66 & 7.99 \\
\hline $\begin{array}{c}\text { Belostomatid (Diving } \\
\text { Beetle) }\end{array}$ & & 11 & 0.56 & 0.51 \\
\hline Odonate & & 356 & 18.03 & 16.64 \\
\hline Apoidea (wasp/ bee) & & 74 & 3.75 & 3.46 \\
\hline Formicidea (ants) & & 130 & 6.58 & 6.07 \\
\hline Beetle & & 472 & 23.90 & 22.06 \\
\hline Acari (Tick/ Mite) & & 53 & 2.68 & 2.48 \\
\hline Mosquito & & 172 & 8.71 & 8.04 \\
\hline Flying insect & & 91 & 4.61 & 4.25 \\
\hline Orthoptera & & 41 & 2.08 & 1.92 \\
\hline True bug & & 105 & 5.32 & 4.91 \\
\hline Unidentified Larvae & & 68 & 3.44 & 3.18 \\
\hline Snail & Gastropoda & 93 & 4.71 & 4.35 \\
\hline Leech & Clitellata & 45 & 2.28 & 2.10 \\
\hline Spider & Arachnida & 93 & 4.71 & 4.35 \\
\hline
\end{tabular}


Table 7.2 Vertebrate Prey contents found bullfrogs at Conboy Lake.

\begin{tabular}{|c|c|c|c|c|c|}
\hline $\begin{array}{c}\text { Vertebrate Prey } \\
\text { Contents }\end{array}$ & $\begin{array}{c}\text { Number } \\
\text { of prey }\end{array}$ & $\begin{array}{c}\text { \%ertebrate } \\
\text { prey }\end{array}$ & $\begin{array}{c}\text { \% of all } \\
\text { vertebrate } \\
\text { and } \\
\text { invertebrate } \\
\text { prey }\end{array}$ & $\begin{array}{c}\text { Number of } \\
\text { prey in } \\
\text { Juvenile } \\
\text { stomach }\end{array}$ & $\begin{array}{c}\text { Number } \\
\text { of prey } \\
\text { in Adult } \\
\text { stomach }\end{array}$ \\
\hline Unknown vertebrate & 13 & 7.88 & 0.59 & 2 & 11 \\
\hline Fish & 39 & 23.64 & 1.77 & 1 & 38 \\
\hline Unknown Tadpole & 32 & 19.39 & 1.46 & 1 & 31 \\
\hline Unknown frog & 8 & 4.85 & 0.36 & 0 & 8 \\
\hline Bullfrog tadpole & 8 & 4.85 & 0.36 & 0 & 8 \\
\hline Bullfrog & 14 & 8.48 & 0.64 & 0 & 14 \\
\hline OSF & 10 & 6.06 & 0.45 & 0 & 10 \\
\hline Pacific Treefrog & 11 & 6.67 & 0.50 & 0 & 11 \\
\hline Salamander & 11 & 6.67 & 0.50 & 0 & 11 \\
\hline Bird & 4 & 2.42 & 0.18 & 0 & 4 \\
\hline Garter Snake & 7 & 4.24 & 0.32 & 0 & 7 \\
\hline Rodent & 8 & 4.85 & 0.36 & 0 & 8 \\
\hline Total & 165 & 100.0 & 7.50 & 4 & 161 \\
\hline
\end{tabular}

Table 7.3 Ratio of consumed prey size by bullfrog body size.

\begin{tabular}{cccc} 
Species & $\mathbf{n}$ & $\bar{\chi} \pm$ S.E. & Range \\
\hline OSF & 10 & $0.36 \pm 0.03$ & $0.23-0.47$ \\
Bullfrog & 14 & $0.36 \pm 0.07$ & $0.27-0.47$ \\
Pacific Treefrog & 11 & $0.19 \pm 0.01$ & $0.15-0.26$ \\
Unidentifiable Frog & 3 & $0.39 \pm 0.06$ & $0.26-0.48$
\end{tabular}




\section{CHAPTER 7 FIGURES}

Figure 7.1 Plot of bullfrog snout-vent-length (SVL) by the SVL of prey items consumed at Conboy Lake.

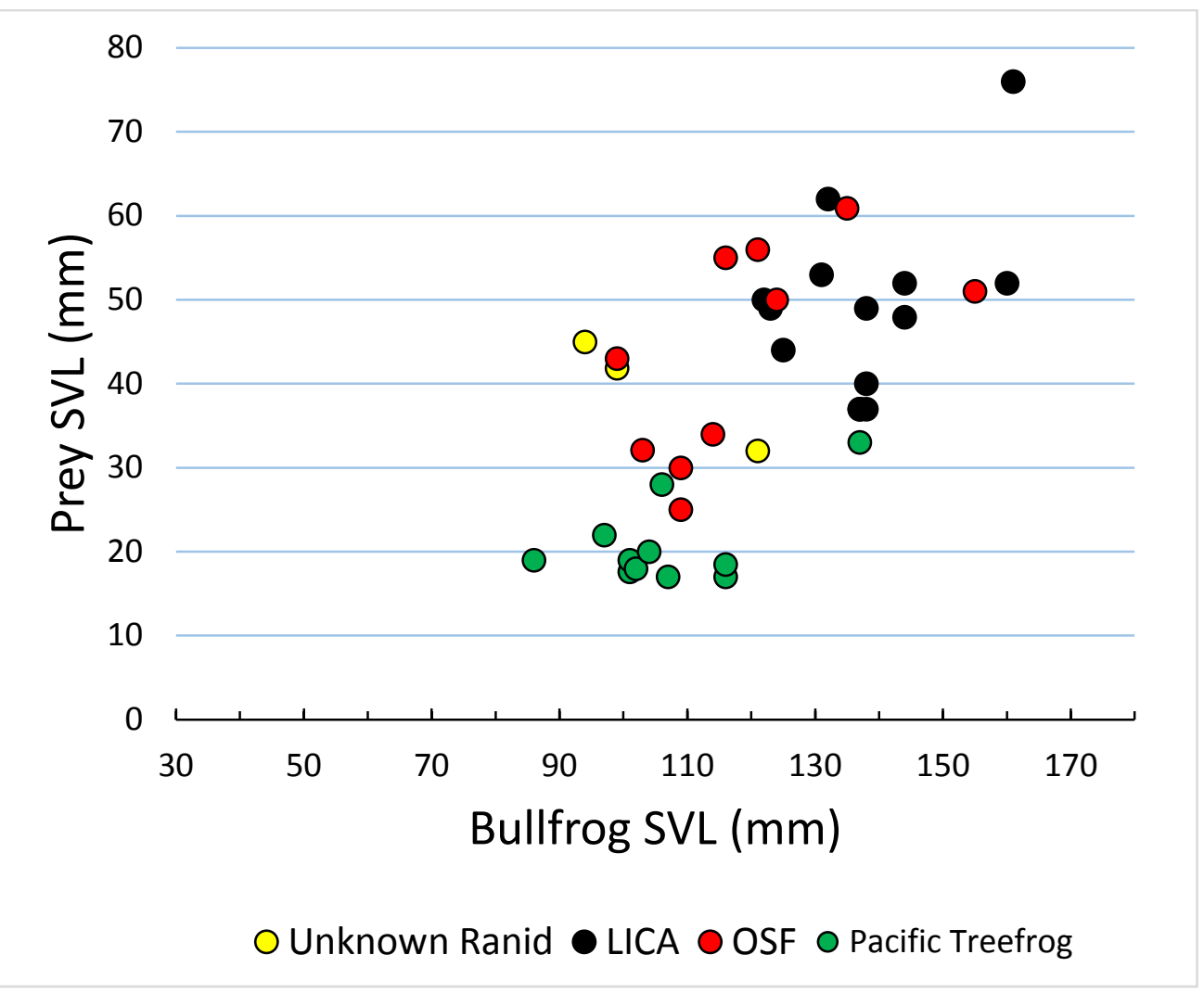




\section{CHAPTER 8 CONCLUSIONS AND FUTURE DIRECTIONS}

I studied the behavioral ecology of the Oregon Spotted Frog (OSF; Rana pretiosa) to determine whether interpopulation differences of escape behavior, first identified in captive-reared frogs, could be related to American Bullfrog (Rana(Aquarana) catesbeiana) co-occurrence. These studies stem from a long-held hypothesis that bullfrog introduction may contribute to native amphibian decline, especially OSF decline. The endangered status of the OSF led to a captive head-start program, spearheaded by USFW and WDFW, which aimed to raise and release OSFs at a site from which they had been historically extirpated. The source populations used for the head-start project were from Puget lowland populations and Conboy Lake National Wildlife Refuge. Conboy Lake represents the only site of long term co-occurrence for bullfrogs and OSFs. At all other sites historically occupied by OSF where bullfrogs have become established, OSFs have gone extinct.

Behavioral differences were observed in the captive-rearing environment that could contribute to the continued OSF-bullfrog co-occurrence at Conboy Lake. I followed the captive studies with field experiments of OSF and bullfrog behavior and analyzed the dietary contents of bullfrogs to establish that bullfrogs consume OSFs as well as examined how the behavioral traits of OSFs at bullfrog impacted and not impacted sites differed. 
Over the course of this dissertation, I designed, implemented, and analyzed a variety of field and laboratory experiments at Conboy Lake, and mirrored the experiments at an OSF site devoid of bullfrogs. The Conboy Lake population of OSFs is indeed unique in that, relative to populations of OSFs not impacted by bullfrogs, captivereared OSFs from Conboy Lake reacted faster to a predator stimulus and the response get faster with age.

I examined OSF antipredator behavior at Conboy Lake by measuring the flight initiation distance (FID) of the frogs in the field. I found that recently metamorphosed OSFs had much shorter FIDs than recently metamorphosed bullfrogs, perhaps indicating life history characteristics beneficial to cohorts co-occurring with cannibalistic older bullfrogs. Moreover, I found in both field and laboratory experiments that recently metamorphosed OSFs reacted significantly differently from $2^{\text {nd }}$-year and adult frogs. Older frogs at Conboy Lake allowed less close approach (i.e. have a longer FID). I then contrasted the FIDs of OSFs from Conboy Lake to the FIDs of OSFs at Big Marsh population, where bullfrogs are absent. I found that unlike the Conboy Lake population, OSFs at Big Marsh did not display an increase of FID with age, and all ages of frogs had short FIDs, distances that were not significantly different than that of the recently metamorphosed OSFs at Conboy Lake.

These observed differences of anti-predator behaviors between the Conboy Lake and Big Marsh populations were hypothesized to be driven by the predatory behavior of the bullfrog. I examined this relationship by measuring the strike distance of the bullfrog 
at Conboy Lake and then comparing it to the FIDs of OSFs at Conboy Lake and Big Marsh. I found that at Conboy Lake, the bullfrog has the potential to strike and capture most of the recently metamorphosed OSFs, but only a portion of the older OSFs, thereby suggesting that the young OSFs are the most vulnerable. In the Big Marsh population, all age classes of OSF, due to their FIDs, would be roughly equally vulnerable to predation. Dietary analysis of bullfrogs at Conboy Lake confirmed the suggestion of greater vulnerability of the youngest OSFs to bullfrogs. In particular, bullfrogs appear to be capable of only eating metamorphosed anurans that are less than roughly half of their body size. Given the size distribution of bullfrogs at Conboy Lake, this prey size class represents a size that OSFs at Conboy Lake can outgrow and thereby, potentially escape predation.

Collectively, these results suggest that the American bullfrog is likely the driving force behind the differential in behavior between Conboy Lake and Big Marsh. Only the youngest frogs at Conboy display the same behavior as control populations devoid of bullfrogs, indicating that post-metamorphic bullfrog predation of OSFs is the proximate mechanism explaining the increased FID of older OSFs at Conboy Lake. However, the ultimate explanation is not clear. Whether the differential in behavior is a result of predatory depletion of young OSFs, experience from unsuccessful predation attempts, some combination of both, or simply explained by body size, cannot be determined with the current studies. Notwithstanding the mechanism, it is apparent that predation on OSFs is highly likely for naïve OSF populations. The extent of the impact would likely be determined by the density of the two species and local patterns of habitat use and habitat 
complexity, but the potential for extensive impact is likely given the high degree of habitat overlap the species share and the propensity of the highly fecund bullfrog to densely populate a new area of invasion.

These integrated studies provide the first documentation of direct bullfrog impact through predation of post-metamorphic frogs. They also represent one of the larger contributions to date for anuran escape theory, and bullfrog dietary analysis. However, as with all research, more questions arose than were answered; some are academic, and some aligned with management applications. I suggest the following for future directions of study and partition them into academic and management sections accordingly. I first address the questions of academic- and theory-based pursuit.

The study of escape theory, specifically FID, was defined and focused by Ydenberg and Dill's (1989) seminal work that detailed the economics of escape theory, and has since been the burgeoning focus of many academic and research laboratories, with more than 400 articles produced over the last decade (Cooper and Blumstein, 2015). The factors that influence FID, the relationships between predator and prey, and the general under-pinning principles that guide selection of escape behavior have been studied in depth for many taxa, but surprisingly, little is known for amphibians.

My work on OSF FID has suggested that the species has at least, in part, a crypsis-based strategy of predator avoidance (i.e. relying on crypsis by allowing very close approach). Such a strategy has received relatively little attention in FID research, as most research has focused on flight-based animals (e.g. lizards, birds, and mammals). 
However, future research that investigates FID of other ranids and amphibian species will undoubtedly produce more species with a crypsis-based anti-predator strategy, and in doing so, may force reconsideration of current models predicting FID. Currently, FID is modeled by taking into account the cost of various cofactors, including, but not limited to; time spent foraging, defending territory, surveying for predators, starting distance, approach angle and speed, and distance to refuge. However, a species dependent to varying degrees on crypsis does not incur the same costs as a flee-based animal, in that an aquatic frog, such as the OSF for example, is able to simultaneously forage, survey for predators, and monitor potential competitors while being effectively in the refuge of the water. Such differences in life history require novel applications to optimal escape modeling, but more information is first required on the escape behaviors of the largely crypsis-based amphibians to identify the patterns.

One ideal candidate for further investigation would be the Northern Red-legged Frog (NRLF; Rana aurora). This species' behavior has been compared to OSF behavior several times (Licht 1986a; Pearl et al., 2004) and has been studied in terms of potential bullfrog impact for the last three decades (Adams, 1999, 2000; Govindarajulu 2004; Kiesecker and Blaustein, 1997; Adams et al., 2011). Moreover, in contrast to the OSF, the NRLF is terrestrial for about three-quarters of its seasonal life history, and thus provides a nice foil to the highly aquatic OSF; and has dense local populations that would facilitate rapid data collection. Another excellent species for comparison, and to validate the patterns in aquatic frogs, would be the highly aquatic Columbia spotted frog (Rana 
luteiventris), the sister taxon of OSFs, and as such, an ideal species to explore phylogenetic differences in a more controlled fashion.

One cofactor of particular interest in current research of escape behavior, and one that was identified in the studies presented here, is the effect of starting distance on FID. An extension of the data analyzed here would be to investigate the pattern of potential influence this cofactor may have on FID, for as stated above, the conditions surrounding the impact of cofactors deviate from the standard models when the species is crypsisdependent. In the present studies, starting distance did not differ with age, but how starting distance may influence FID is largely unanswered for anurans, although it has been of particular interest recently in a study of FID in other taxa (Cooper and Blumstein, 2015).

Management implications may be drawn from these studies. The captive-rearing efforts of the OSF Working Group provided an excellent platform to examine the response of OSFs. Unpublished experiments not included in this dissertation, but conducted on wild and captive-reared animals using the same methods described in Chapter 2, indicated a significant captive-rearing effect that likely reflects habituation to the captive environment. Future examination of such effects are forth-coming and may hold insight to the ultimate success, or lack thereof, realized by frogs reared in the captive environment and targeted for release to the wild.

The study of bullfrog predatory behaviors presented here support that bullfrogs would have impacts through direct predation at other OSF sites if introduced. However, 
more work is needed to address the degree and complexity of potential impact across sites and longitudinally within sites. Samples from Conboy Lake indicated that the size of the bullfrog influences the size of prey consumed and that portions of the Conboy Lake population are effectively safe from bullfrog predation. This relationship of bullfrog size and potential prey size and behavior needs to be further addressed at Conboy Lake and at other OSF sites where bullfrog impact is potentially an issue. Moreover, the anti-predator behaviors change for larger (older) OSFs indicating that a connection may exist between these two findings whereby the larger OSFs frogs at Conboy Lake not only flee at further distances, but are effectively not vulnerable to predation. Whether this is a result of continued bullfrog presence or an engrained trait that is due to surviving through the vulnerable size range is unclear. Examination of these relationships is pertinent to understanding the potential effect bullfrogs could have and would reveal the mechanism behind the bullfrog impact at Conboy Lake.

The most effective experiment would involve manipulation of bullfrog numbers and size to determine the response of OSFs. Although likely not feasible given the density and life history traits of bullfrogs, an experimental design involving bullfrog removal and exclusion of certain size classes over many growing seasons would allow analysis of OSF response to bullfrogs. If OSF response is observed (e.g., shorter FID in areas of bullfrog removal and thus no bullfrog predation), then one would expect a learned behavior to readjust to present state with the removal of treatment. However, such a response would not be observed if the long FID trait has become fixed by selection 
in the population. Such a design would provide conclusive evidence for bullfrog impact and would provide great insight to the mechanism of impact.

Another extension of the present studies is the validation of bullfrog strike distance and potential vulnerability of OSFs at other sites where environmental conditions may alter the structure of the population (i.e. length of growing seasons, elevation, or genetic composition). Given the increase in strike distance with bullfrog body size (Chapter 6), it is likely that bullfrogs from other (larger body size) populations may have greater strike distances than those recorded at Conboy Lake, and therefore would, extend the potential vulnerability of native anuran prey to a greater portion of the population.

Lastly, and perhaps of the most important concern to management, is the totality of bullfrog impact on OSF populations. Given the dietary analysis (Chapter 7), OSFs are consumed by bullfrogs at Conboy Lake, but not as often as conspecifics. Whether this is a function of availability, preference for prey items, or the result of the described enhanced anti-predator tactics cannot be answered presently, but needs to be addressed. During the six years I worked at Conboy Lake, the spring OSF egg mass surveys have found a declining population, while anecdotally, I have observed an increasing population of bullfrogs. The data provided here are limited to the potential predation that could occur, and do not address the totality of the impact. The studies suggested above should answer whether the size of frog and enhanced anti-predator tactics are a result of 
co-occurrence, but questions of availability and preference are needed to answer the realized impact of the bullfrog.

Whether the bullfrog historically (i.e., in the last $~ 60$ years of co-occurrence) altered the Conboy Lake population or is still acting on the population also cannot be determined, but both options are likely. Regardless of the timing, the species are likely responding to each other, hence, examination of how many OSFs and bullfrogs there are, where they prefer to be, and what they prefer to eat could illuminate the current relationship. Since co-occurring species need to be in proximity to one another to have predation occur, the more overlap in the concentration of frogs, the higher the likelihood of predation. Therefore, future studies should detail the abundance of prey and predators and habitat utilization of each species with a select focus on the number and age of both species of frog and the available and utilized habitat preferences used by each species. Such details are vital to understanding the behavioral and size differnces found in the current studies and will provide key insights to the long-held issues surrounding introduced bullfrogs and their potential impact on native prey species. 


\section{REFERENCES}

Adams, M. J. 1999. Correlated factors in amphibian decline: Exotic species and habitat change in western Washington. Journal of Wildlife Management, 63(1):1162-1171.

Adams, M. J. 2000. Pond permanence and the effects of exotic vertebrates on anurans. Ecological Applications, 10(2):559-568.

Adams, M. J., Pearl, C. A., Galvan, S. and McCreary, B. 2011. Non-native species impacts on pond occupancy by an anuran. Journal of Wildlife Management, 75(1):30-35.

Alexander, R. McN. 2000. Hovering and jumping: Contrasting problems in scaling, pp. 37-50. In: Brown, J.H. \& West, G.B. (editors), Scaling in Biology. Oxford University Press, Oxford, United Kingdom.

Altmann, M. 1958. The flight distance in free-ranging big game. The Journal of Wildlife Management, 22(2):207-209.

AmphibiaWeb. 2017. <http://amphibiaweb.org> University of California, Berkeley, CA, USA. Accessed $20 \mathrm{Feb} 2017$.

Anderson, C. W. 1993. The modulation of feeding behavior in response to prey type in the frog Rana pipiens. Journal of Experimental Biology, 179(1):1-12.

Beaupre, S. J., Jacobson, E. R., Lillywhite, H. B., and Zamudio, K. 2004. Guidelines for use of live amphibians and reptiles in field and laboratory research. $-2^{\text {nd }}$ edition, revised by the Herpetological Animal Care and Use Committee (HACC) of the American Society of Ichthyologists and Herpetologists.

Bednekoff, P. A. 1996. Translating mass dependent flight performance into predation risk: An extension of Metcalfe \& Ure. Proceedings of the Royal Society of London $B, 263: 887-889$.

Bellard, C., Genovesi, P., and Jeschke, J. M. 2016. Global patterns in threats to vertebrates by biological invasions. Proceedings of the Royal Society of London B, 283(1823):20152454.

Benevides, L. J., de Anchieta, J., Nunes, C. C., Costa, T. L. A., and Sampaio, C. L. S. 2016. Flight response of the barber surgeonfish, Acanthurus bahianus Castelnau, 1855 (Teleostei: Acanthuridae), to spearfisher presence. Neotropical Ichthyology, 14(1): e150010. DOI: 10.1590/1982-0224-20150010

Berger, S., Wikelski, M., Romero, L. M., Kalko, E. K. V., and Rödl, T. 2007. Behavioral and physiological adjustments to new predators in an endemic island species, the Galapagos marine iguana. Hormones and Behavior, 52(5):653-663. 
Bergseth, B. J., Williamson, D. H., Frisch, A. J., and Russ, G. R. 2016. Protected areas preserve natural behaviour of a targeted fish species on coral reefs. Biological Conservation, 198:202-209.

Blouin, M. S., Phillipsen, I. C. and Monsen, K. J. 2010. Population structure and conservation genetics of the Oregon Spotted Frog, Rana pretiosa. Conservation Genetics, 11(6):2179-2194.

Blumstein, D.T. 2003. Flight-initiation distance in birds is dependent on intruder starting distance. The Journal of Wildlife Management, 67(4):852-857.

Boelter, R. A., Kaefer, I. L., Both, C., and Cechin, S. 2012. Invasive bullfrogs as predators in a Neotropical assemblage: What frog species do they eat? Animal Biology, 62(4): 397-408.

Bohannon, J., Gay, D., Hayes, M. P., Danilson, C. D., and Warheit, K. I. 2016. Discovery of the Oregon Spotted Frog in the Northern Puget Sound Basin, Washington State. Northwestern Naturalist, 97(2):82-97.

Bonenfant, M., and Kramer, D. L. 1996. The influence of distance to burrow on flight initiation distance in the woodchuck, Marmota monax. Behavioral Ecology, 7(3):299-303.

Boone, M. D., Bridges, C. M., Fairchild, J. F., and Little, E. E. 2005. Effects of ammonium nitrate fertilizer and insecticide exposure on populations of the green frog, Rana clamitans. Environmental Toxicology and Chemistry, 24:1267-1272.

Brecko, J., Huyghe, K., Vanhooydonck, B., Herrel, A., Grbac, I. and Van Damme, R. (2008). Functional and ecological relevance of intraspecific variation in body size and shape in the lizard Podarcis melisellensis (Lacertidae) Biol. J. Linn. Soc., 94: 251-264.

Bridges, C. M. 1999. Effects of a pesticide on tadpole activity and predator avoidance. Journal of Herpetology, 33:303-306.

Broom, M., and Ruxton, G. D. 2005. You can run - or you can hide: optimal strategies for cryptic prey. Behavioral Ecology, 16:534-540.

Brodie, E. D., Ducey, Jr., P. K. and Lemos-Espinal, J. 1991. Antipredator behavior of the salamander Bolitoglossa rufescens: Effects of temperature and location of stimulus. Journal of Herpetology, 25(1):99-101.

Brodie, E. D., III, and Russell, N. H. 1999. The consistency of individual differences in behaviour: temperature effects on antipredator behaviour in garter snakes. Animal Behaviour, 57:445-451.

Brown, G. P., and Shine, R. 2004. Effects of reproduction on the antipredator tactics of snakes (Tropidonophis mairii, Colubridae). Behavioral Ecology and Sociobiology, 56:257-262. 
Bucciarelli, G. M., Blaustein, A. R., Garcia, T. S., and Kats, L. B. 2014. Invasion complexities: the diverse impacts of nonnative species on amphibians. Copeia, 2014(4), 611-632.

Burger, J., and Gochfeld, M. 1990. Risk discrimination of direct versus tangential approach by basking black iguanas (Ctenosaura similis): variation as a function of human exposure. J. Comp. Psych., 104:388-394.

Burger, J., and Gochfeld, M. 1991. Human distance and birds: tolerance and response distances of resident and migrant species in India. Environmental Conservation, 18:158-165.

Bury, R. B., and Whelan, J. A. 1984. Ecology and management of the bullfrog. U.S. Fish and Wildlife Service, Resource Publication Number 155, Washington, D.C.

Caldwell, J. P., Thorp, J. H., and Jervey, T. O. 1980. Predator-prey relationships among larval dragonflies, salamanders, and frogs. Oecologia, 46(3):285-289.

Capizzi, D., Luiselli, L., and Vignoli, L. 2007. Flight initiation distance in relation to substratum type, sex, reproductive status and tail condition in two lacertids with contrasting habits. Amphibia-Reptilia, 28:403-407.

Carmony, L., Yarnold, P. R., and Naeymi-Rad, F. 1998. One-tailed Type I error rates for balanced two-category UniODA with a random ordered attribute. Ann. Oper. Res., 74:223-238.

Chivers, D. P., Wildy, E. L., Kiesecker, J. M., and Blaustein, A. R. 2001. Avoidance response of juvenile pacific treefrogs to chemical cues of introduced predatory bullfrogs. Journal of chemical ecology, 27(8):1667-1676.

Collins, J. T., and Collins, S.L. 1991. Reptiles and amphibians of the Cimarron National Grasslands, Morton County, Kansas. U.S.D.A. Forest Service, Washington, D.C.

Camp, M. J., Rachlow, J. L., Woods, B. A., Johnson, T. R., and Shipley, L. A. 2012. When to run and when to hide: the influence of concealment, visibility, and proximity to refugia on perceptions of risk. Ethology, 118:1010-1017.

Chan, A. A. Y.-H., Giraldo-Perez, P., Smith, S., and Blumstein, D.T. 2010. Anthropogenic noise affects risk assessment and attention: the distracted prey hypothesis. Biology Letters, 6:458-461.

Choi, I., and Park, K. 1996. Variation in take-off velocity of anuran amphibians: relation to morphology, muscle contractile function and enzyme activity. Comparative Biochemistry and Physiology Part A: Physiology, 113(4):393-400.

Cinner, J., Marnane, M. J., McClanahan, T. R., and Almany, G. R. 2006. Periodic closures as adaptive coral reef management in the Indo-Pacific. Ecology and Society, 11, 31. 
Cloyed, C. S. and Eason, P. K. 2015. Night and day: comparing the flight initiation dynamics in two closely related species of true frogs. Journal of Zoology, 295:206213.

Cooper, W. E., Jr. 1997a. Escape by a refuging prey, the Broad-Headed Skink (Eumeces laticeps). Canadian Journal of Zoology, 75:943-947.

Cooper, W. E., Jr. 1997b. Threat factors affecting antipredator behavior in the BroadHeaded Skink (Eumeces laticeps): repeated approach, change in predator path, and predator's field of view. Copeia, 1997:613-619.

Cooper, W. E., Jr. 2003a. Effect of risk on aspects of escape behavior by a lizard, Holbrookia propinqua, in relation to optimal escape theory. Ethology, 109:617626.

Cooper, W. E., Jr. 2003b. Risk factors affecting escape behavior by the Desert Iguana, Dipsosaurus dorsalis: speed and directness of predator approach, degree of cover, direction of turning by a predator, and temperature. Canadian Journal of Zoology, 81:979-974.

Cooper, W. E., Jr. 2005. When and how do predators starting distances affect flight initiation distances? Canadian Journal of Zoology, 83: 1045-1050.

Cooper, W. E., Jr. 2006. Risk factors and escape strategy in the grasshopper Dissosteira carolina. Behaviour, 143:1201-1218.

Cooper, W. E., Jr. 2009. Optimal escape theory predicts escape behaviors beyond flight initiation distance: risk assessment and escape by Striped Plateau Lizards Sceloporus virgatus. Amphibia-Reptilia, 32:213-221.

Cooper, W. E., Jr. 2011a. Escape strategy and vocalization during escape by American Bullfrogs (Lithobates catesbeianus). Amphibia-Reptilia 32(2):213-221.

Cooper, W. E., Jr. 2011b. Age, sex and escape behavior in the striped plateau lizard (Sceloporus virgatus) and the mountain spiny lizard (S. jarrovii), with a review of age and sex effects on escape by lizards. Behaviour, 148:1215-1238.

Cooper, W. E., Jr. 2015. Age affects escape behavior by the zebra-tailed lizard (Callisaurus draconoides) more strongly than in other lizards. Amphibia-Reptilia, 36:37-44.

Cooper, W. E., Jr., and Frederick, W. G. 2007. Optimal flight initiation distance. Journal of Theoretical Biology, 244:59-67.

Cooper, W. E., Jr., Caldwell, J.P., and Vitt, L.J. 2008. Effective crypsis and its maintenance by immobility in Craugastor frogs. Copeia, 2008:527-532.

Cooper, W. E., Jr., and Sherbrooke, W.C. 2010. Crypsis influences escape decisions in the Round-tailed Horned Lizard (Phrynosoma modestum). Canadian Journal of Zoology, 88:1003-1010. 
Cooper, W. E., Jr., Pyron, A. E., and Garland, T., Jr. 2013. Island tameness: living on islands reduces flight initiation distance. Proceedings of the Royal Society of London B. 281:20133019.

Cooper W. E., Jr., and Blumstein, D. T. 2014. Novel effects of monitoring predators on costs of fleeing and not fleeing explain flushing early in economic escape theory. Behavioral Ecology, 25, 44-52.

Cooper, W. E., Jr., and Blumstein, D.T. 2015. Escaping from predators: An integrative view of escape decisions. Cambridge, UK: Cambridge University Press.

Cooper, W. E., Jr., Samia, D. S., and Blumstein, D. T. 2015. FEAR, spontaneity, and artifact in economic escape theory: a review and prospectus. Advances in the Study of Behavior, 47, 147-179.

Cox, G. W. 2004. Alien species and evolution: the evolutionary ecology of exotic plants, animals, microbes, and interacting native species. Washington, DC: Island Press.

Cox, J. G., and Lima, S. L. 2006. Naïvete and an aquatic - terrestrial dichotomy in the effects of introduced predators. Trends Ecology and Evolution 21, 674-680.

D'Amore, A., Kirby, E., and McNicholas, M. 2009. Invasive species shifts ontogenetic resource partitioning and microhabitat use of a threatened native amphibian. Aquatic Conservation: Marine and Freshwater Ecosystems, 19(5), 534541.

Dagg, A. I. 2008. The social behavior of older animals. Baltimore, USA: Johns Hopkins University Press.

Da Silvia, E.T., Filho, R., Feio, O.P., and Neves, R. 2011. Predation of native anurans by invasive Bullfrogs in southeastern Brazil: Spatial variation and effect of microhabitat use by prey. South American Journal of Herpetology, 6(1):1-10.

Dill, L. M. 1990. Distance-to-cover and the escape decisions of an African cichlid fish, Melanochromis chipokae. Environmental Biology of Fishes, 27:147-152.

Dill, L. M., and Houtman, R. 1989. The influence of distance to refuge on flight initiation distance in the Gray Squirrel (Sciurus carolinensis). Canadian Journal of Zoology, 67:233-235.

Domenici, P. 2002. The visually mediated escape response in fish: predicting prey responsiveness and the locomotor behaviour of predators and prey. Marine and Freshwater Behavior Physiology, 35:87-110.

Domenici, P. (Ed.). 2010. Fish locomotion: an eco-ethological perspective. Boca Raton, Florida: CRC Press.

Dowdey, T. G., and Brodie, E. D. Jr. 1989. Antipredator strategies of salamanders: Individual and geographical variations in responses of Eurycea bislineata to snakes. Animal Behaviour, 38:707-711. 
Dumont, F., Pasquaretta, C., Reale, D., Bogliani, G., and Hardenberg, Av. 2012. Flight initiation distance and starting distance: Biological effect or mathematical artefact? Ethology, 118:1051-1062.

Elton, C. S. 1958. The Ecology of Invasions by Animals and Plants. London: Methuen. $181 \mathrm{PP}$.

Estes, et al. 2011. Trophic downgrading of planet Earth. Science, 333, 301-306.

Emlen, S. T. 1977. "Double clutching" and its possible significance in the bullfrog. Copeia, 1977(4):749-751.

Feary, D. A., Cinner, J. A., Graham, N. A. J., and Januchowski-Hartley, F. A. 2011. Effects of customary marine closures on fish behavior, spear-fishing success, and underwater visual surveys. Conservation Biology, 25, 341-349.

Fitch, H. S. 1956. Temperature responses of free-living amphibians and reptiles of northeastern Kansas. Bulletin of the Museum of Natural History University of Kansas, (8):417-476.

Fritts, T. H., and Rodda, G. H. 1998. The role of introduced species in the degradation of island ecosystems: A case history of Guam. Annual Review of Ecology and Systematics, 29, 113-140.

Frost, S. W. 1935. The food of Rana catesbeiana Shaw. Copeia, 1935(1):15-18.

Fuller, T. E. 2008. The spatial ecology of the exotic bullfrog (Rana catesbeiana) and its relationship to the distribution of the native herpetofauna in a managed river system. Masters Thesis in Natural Resources, Humboldt State University, Arcata, California. 50 pp.

Funk, W. C., Blouin, M. S., Corn, P. S., Maxell, B. A., Pilliod, D. S., Amish, S. and Allendorf, F. W. 2005. Population structure of Columbia spotted frog (Rana luteiventris) is strongly affected by the landscape. Molecular Ecology, 14(2):483496.

Funk, W. C., Pearl, C. A., Draheim, H. M., Adams, M. J., Mullins, T. D. and Haig, S. M. 2008. Range-wide phylogeographic analysis of the spotted frog complex (Rana luteiventris and Rana pretiosa) in northwestern North America. Molecular Phylogenetics and Evolution, 49(1):198-210.

Funk, W. C., Garcia, T. S., Cortina, G. A., and Hill, R. H. 2011. Population genetics of introduced bullfrogs, Rana (Lithobates) catesbeianus, in the Willamette Valley, Oregon, USA. Biological Invasions, 13(3):651-658.

Gatten, R. E., Jr., Miller, K., and Full, R. J. 1992. Energetics at rest and during locomotion. In W. W. Burggren, \& M. E. Feder (Eds.). Environmental physiology of the amphibians (pp. 314-377). Chicago, Illinois: University of Chicago Press. 
Grant, J. W. A. and Noakes, D. L. G. 1987. Escape behavior and use of cover by youngof-the-year Brook Trout, Salvelinus fontinalis. Can. J. Fish. Aquat. Sci., 44:13901396.

George, I. D. 1940. A study of the bullfrog, Rana catesbeiana Shaw, at Baton Rouge, Louisiana. Ph.D. dissertation. University of Michigan, Ann Arbor, Michigan.

Gomes, F. R., Bevier, C. R. and Navas, C. A. 2002. Enviromental and physiological factors influence antipredator behavior in Scinax hiemalis (Anura: Hylidae). Copeia, 2002:994-1005.

Gotanda, K. M., Turgeon, K. and Kramer, D. L. 2009. Body size and reserve protection affect flight initiation distance in parrot fishes. Behavioral Ecology and Sociobiology, 63:1563-1572.

Govindarajulu, P. 2004. Introduced bullfrogs (Rana catesbeiana) in British Columbia: Impacts on native pacific treefrogs (Hyla regilla) and Red-Legged Frogs (Rana aurora). Doctoral dissertation, University of Victoria.

Govindarajulu, P., Price, W. S., and Anholt, B. R. 2006. Introduced Bullfrogs (Rana catesbeiana) in Western Canada: Has their ecology diverged? Journal of Herpetology, 40(2):249-260.

Gray, L. A., O'Reilly, J. C., and Nishikawa, K. C. 1997. Evolution of forelimb movement patterns for prey manipulation in anurans. Journal of Experimental Zoology, 277(6), 417-424.

Green, N. B., and Pauley, T. K. 1987. Amphibians and Reptiles in West Virginia. University of Pittsburgh Press, Pittsburgh, Pennsylvania.

Green, D. M., Kaiser, H., Sharbel, T. F., Kearsley, J., and McAllister, K. R. 1997. Cryptic species of spotted frogs, Rana pretiosa complex in western North America. Copeia, 1997(1):1-8.

Grimm, L. G. and Yarnold, P.R., eds. 1995. Reading and understanding multivariate statistics. APA Books, DC.

Grimm, L. G. and Yarnold, P.R., eds. 2000. Reading and understanding more multivariate statistics. APA Books, Washington, DC.

Groom, M. J., Meffe, G. K., and Carroll, C. R. 2006. Principles of conservation biology (No. Sirsi) i9780878935185). Sunderland: Sinauer Associates. Pp. 294331.

Grosholz, E. D., and Wells, E. H. 2016. Evolutionary novelty and the behaviour of introduced predators. In J. S. Weis, J. S., and Sol, D. (Eds.), Biological Invasions and Animal Behaviour (pp. 199-220). Cambridge, U.K.: Cambridge University Press.

Hallock, L. in press. Draft State of Washington Oregon Spotted Frog Recovery Plan. Washington Department of Fish and Wildlife, Olympia. 93 + v pp. 
Hallock, L., and Pearson, S. 2001. Telemetry study of fall and winter Oregon Spotted Frog (Rana pretiosa) movement and habitat use at Trout Lake, Klickitat County, Washington. Report prepared by Washington Natural Heritage Program for Washington State Department of Transportation and Washington Natural Areas Program, Department of Natural Resources, Olympia. 19 pp. + appendix

Harding, J. H. 1997. Amphibians and Reptiles of the Great Lakes Region. University of Michigan Press, Ann Arbor, Michigan.

Harvey, P. H., and Greenwood, P. J. 1978. Antipredator defence strategies: some evolutionary problems. Pp. 129-151 In Krebs, J.R., and N.B. Davies (Eds.). Behavioural Ecology: An Evolutionary Approach. Blackwell, Oxford, United Kingdom.

Hayes, M. P., and Jennings, M. R. 1986. Decline of ranid frog species in western North America: Are Bullfrogs (Rana catesbeiana) responsible? Journal of Herpetology, 20(4):490-509.

Hayes, M. P. 1994. The Oregon Spotted Frog (Rana pretiosa) in Western Oregon. Technical Report \#94-1-01, Portland, OR: Oregon Department of Fish and Wildlife, $31 \mathrm{pp}+$ appendices.

Hayes, M. P. 1997. Status of the Oregon Spotted Frog (Rana pretiosa sensu stricto) in the Deschutes Basin and selected other systems in Oregon and northeastern California with a rangewide synopsis of the species' status. Final report prepared for The Nature Conservancy under contract to the U.S. Fish and Wildlife Service, Portland, OR.

Hayes, M. P., Engler, J. D., Van Leuven, S., Friesz, D. C., Quinn, T., and Pierce, D. J. 2001. Overwintering of the Oregon Spotted Frog, (Rana pretiosa) at Conboy Lake National Wildlife Refuge, Klickitat County, Washington, 2000-2001. Interim final report to Washington Department of Transportation by Science Team, Habitat and Wildlife Management Programs, Washington Department of Fish and Wildlife, Olympia, Washington. 32 pp. + appendices.

Hayes, M. P., Rombough, C. J., Hayes, C. B., and Engler, J. D. 2005. Rana pretiosa (Oregon Spotted Frog). Predation. Herpetological Review, 36(3):307.

Hayes, M. P., Engler, J., and Rombough, C. 2006. Rana pretiosa (Oregon Spotted Frog). Predation. Herpetological Review, 37(2):209-210.

Hayes, M. P., Tidwell, K. S., Shepherdson, D. J., and Yarnold, P. R. in press. Age-based shift in flight initiation distance for a crypsis-dependent aquatic frog. Behaviour.

Heatwole, H. 1968. Relationship of escape behavior and camouflage in anoline lizards. Copeia, 1968:109-113.

Hopkins, G. R., Gall, B. G., and Brodie, E. D. 2011. Ontogenetic shift in efficacy of antipredator mechanisms in a top aquatic predator, Anax junius (Odonata: Aeshnidae). Ethology, 117, 1093-1100. 
Hothem, R. L., Meckstroth, A. M., Wegner, K. E., Jennings, M. R., and Crayon, J. J. 2009. Diets of three species of anurans from the Cache Creek Watershed, California, USA. Journal of Herpetology, 43(2), 275-283.

Ingle, D. J. 1973. Size preferences for prey-catching in frogs: relationship to motivational state. Behavioral biology, 9(4), 485-491.

Ingle, D. J., and Hoff, K. S. 1990. Visually elicited evasive behavior in frogs. BioScience, 40(4):284-288.

Jacobson, F., Garrison G., Penner J., Gebin, J. Z., Eifler, M., and Eifler D. 2016. Escape behavior in the leopard lizard (Gambelia wislizenii): effects of starting distance and sex. Amphibia-Reptilia, 37:320-324.

Jancowski, K., and Orchard, S. 2013. Stomach contents from invasive American bullfrogs Rana catesbeiana (= Lithobates catesbeianus) on southern Vancouver Island, British Columbia, Canada. NeoBiota, 16:17-37.

Januchowski-Hartley, F. A., Graham, N. A., Feary, D. A., Morove, T., and Cinner, J. E. 2011. Fear of fishers: human predation explains behavioral changes in coral reef fishes. PLoS One, 6(8), e22761.

Jennings, M. R., and Hayes, M. P. 1985. Pre-1900 overharvest of California red-legged frogs (Rana aurora draytonii): The inducement for bullfrog (Rana catesbeiana) introduction. Herpetologica, 41(1):94-103.

Johnson, C.R. 1970. Escape behavior and camouflage in two subspecies of Sceloporus occidentalis. American Midland Naturalist, 84:280-282.

Jones, L. L. C., Leonard, W. P. and Olson, D. H. 2005. Amphibians of the Pacific Northwest. Seattle Audubon Society, Seattle.

Kaefer, Í. L., R. A. Boelter, and S. Z. Cechin. 2007. Reproductive biology of the invasive bullfrog Lithobates catesbeianus in southern Brazil. Annales Zoologici Fennici, 44(6):435-444.

Kelt, D. A., Karina Nabors, L. and Forister, M. L. 2002. Size-specific differences in tail loss and escape behavior in Liolaemus nigromaculatus. Journal of Herpetology, 36: 322-325.

Kiesecker, J. M., and Blaustein, A. R. 1997. Population differences in responses of redlegged frogs (Rana aurora) to introduced bullfrogs. Ecology, 78(6):1752-1760.

Kiesecker, J. M., and Blaustein, A. R. 1998. Effects of introduced Bullfrogs and Smallmouth Bass on microhabitat use, growth, and survival of native Red-Legged Frogs (Rana aurora). Conservation Biology, 12(4):776-787.

Kupferberg, S. J. 1997. Bullfrog (Rana catesbeiana) invasion of a California river: The role of larval competition. Ecology, 78(6):1736-1751. 
Kiyoko, G. M., Turgeon, K., and Kramer, D. L. 2009. Body size and reserve protection affect flight initiation distance in parrotfishes. Behavioral Ecology and Sociobiology, 63:1563-1572.

Kluge, A. G., 1981. The life history, social organization, and parental behavior of Hyla rosenbergi Boulenger, a nest-building gladiator frog. Miscellaneous Publications of the Museum of Zoology, University of Michigan (160):1-170.

Konecny, M. J. 1983. Behavioral ecology of feral house cats in the Galápagos Islands, Ecuador. Doctoral Thesis, Gainesville, Florida: University of Florida.

Kruse, K. C., and Francis, M. G. 1977. A predation deterrent in larvae of the bullfrog, Rana catesbeiana. Transactions of the American Fisheries Society 106(3):248-252.

Kruuk, H., and Snell, H. 1981. Prey selection by feral dogs from a population of marine iguanas (Amblyrhynchus cristatus). Journals of Applied Ecology, 18, 197-204.

Kupferberg, S. J. 1994. Exotic larval bullfrogs (Rana catesbeiana) as prey for native garter snakes: functional and conservation implications. Herpetological Review, 25(3):95-97.

Kupferberg, S. J. 1997. Bullfrog (Rana catesbeiana) invasion of a California river: The role of larval competition. Ecology, 78(6):1736-1751.

Stebbins, R. C. 2003. A field guide to western reptiles and amphibians, 3rd edition. Boston, MA: Houghton Mifflin Company. 448 p.

Lachenbruch, P. A. and Mickey, M. R. 1968. Estimation of error rates in discriminant analysis. Technometrics, 10:1-11.

Ladiges, J. 1978. Glenwood (formerly known as Camas Prairie). Glenwood, Washington, USA. 201 p.

Lass, S., and Spaak, P. 2003. Chemically induced anti-predator defences in plankton: a review. Hydrobiologia, 491:221-239.

Lampman, B. H. 1946. The coming of the pond fishes: an account of the introduction of certain spiny-rayed fishes, and other exotic species, into the waters of the lower Columbia River region and the Pacific Coast States. Binfords \& Mort, Portland, Oregon.

Laurie, A. W. 1983. Marine iguanas in Galápagos. Oryx, 17:18-25.

Layne, J. R. Jr., and Ford, N.B. (1984). Flight distance of the queen snake, Regina septemvittata. Journal of Herpetology, 18:496-498.

Lea, A. J., and Blumstein, D. T. 2011. Age and sex influence marmot antipredator behavior during periods of heightened risk. Behavioral Ecology and Sociobiology, 65:1525-1533. 
Leivas P. T., Leivas, F. W. T., and Moura, M. O. 2012. Diet and trophic niche of Lithobates catesbeianus (Amphibia: Anura). Zoologia (Curitiba), 29(5):405-412. doi:10.1590/S1984-46702012000500003

Licht, L. E. 1969. Comparative breeding behavior of the red-legged Frog (Rana aurora aurora) and the western spotted frog (Rana pretiosa pretiosa) in southwestern British Columbia. Canadian Journal of Zoology, 47(6):1287-1299.

Licht, L. E. 1971. The ecology of coexistence in two closely related species of frogs (Rana). PhD dissertation, University of British Columbia, Vancouver, British Columbia. 155 pp.

Licht, L. E. 1974. Survival of embryos, tadpoles, and adults of the frogs Rana aurora aurora and Rana pretiosa pretiosa sympatric in southwestern British Columbia. Canadian Journal of Zoology, 52(5):613-627.

Licht, L.E. 1975. Comparative life history features of the Western Spotted Frog, Rana pretiosa, from low- and high-elevation populations. Canadian Journal of Zoology, 53(9):1254-1257.

Licht, L.E. 1986a. Comparative escape behavior of sympatric red-legged frogs, Rana aurora, and spotted frogs, Rana pretiosa, in southwestern British Columbia. American Midland Naturalist, 115(2):239-247.

Licht [sic, given as Light], L. E. 1986b. Food and feeding behavior of sympatric redlegged frogs, Rana aurora, and spotted frogs, Rana pretiosa, in southwestern British Columbia. The Canadian Field-Naturalist, 100(1):23-31.

Lima, S. L. 1998. Nonlethal effects in the ecology of predator-prey interactions. Bioscience, 48:25-34.

Lima, S. L. 2002. Putting predators back into behavioral predator-prey interactions. Trends in Ecology and Evolution, 17:70-75.

Lima, S. L., and Dill, L. M. 1990. Behavioral decisions made under the risk of predation: a review and prospectus. Canadian Journal of Zoology, 68:619-640.

Lind, A. J., and Welsh, H. H. 1994. Ontogenetic changes in foraging behaviour and habitat use by the Oregon garter snake, Thamnophis atratus hydrophilus. Animal Behaviour, 48(6):1261-1273.

Lind, J. and Cresswell, W. 2005. Determining the fitness consequences of antipredation behavior. Behavioral Ecology, 16: 945-956.

Linden, A. and Yarnold, P.R. 2016. Using data mining techniques to characterize participation in observational studies. J. Eval. Clin. Pract., DOI: 10.1111/jep.12515

Loman, J. 1979. Food, feeding rates and prey size selection in juvenile and adult frogs, Rana arvalis (Nilss.) and R. temporaria. Ekol. Polska, 27:581-601. 
Lowe, S., Browne, M., Boudjelas, S., and De Poorter, M. 2000. 100 of the world's worst invasive alien species: a selection from the global invasive species database.

Lowry, E., Rollinson, E. J., Laybourn, A. J., Scott, T. E., Aiello-Lammens, M. E., Gray, S. M., Mickley, J., and Gurevitch, J., 2013. Biological invasions: a field synopsis, systematic review, and database of the literature. Ecology and Evolution, 3(1):182196.

Maia-Carneiro, T. and Rocha, C. F. D. 2015. Flight initiation distance of Tropidurus hispidus and Tropidurus semitaeniatus (Squamata, Tropiduridae) in sympatry. Herpetol. Conserv. Biol., 10: 661-665.

Magnusson W. E., Lima A. P., Silva W. A., Araújo M. C. 2003. Use of geometric forms to estimate volume of invertebrates in ecological studies of dietary overlap. Copeia, 2003:13-19.

Mathews, F., Orros, M., McLaren, G., Gelling, M., and Foster, R. 2005. Keeping fit on the ark: the suitability of captive-bred animals for release. Biological Conservation, 121(4):569-577.

Martin, J., and Lopez, P. 1990. Amphibians and reptiles as prey of birds in southwestern Europe. Smithsonian Herpetological Information Service, 82:1-43.

Martín, J. and López, P. 1999. Nuptial coloration and mate guarding affect escape decisions of male lizards Psammodromus algirus. Ethology, 105:439-447.

Martín, J. and López, P. 2003. Ontogenetic variation in anti-predator behavior of Iberian rock lizards (Lacerta monticola): effects of body-size dependent thermal-exchange rates and costs of refuge use. Canadian Journal of Zoology, 81:1131-1137.

Martin, J., Luque-Larena, J. J., and Lopez, P. 2005. Factors affecting escape behavior of Iberian Green Frog (Rana perezi). Canadian Journal of Zoology 83(9):1189-1194.

Martin, J., Luque-Larena, J. J., and Lopez, P. 2006. Collective detection in escape responses of temporary groups of Iberian Green Frogs. Behavioral Ecology, 17:222-226.

Merovich, C. E., and Howard, J. H. 2000. Amphibian use of constructed ponds on Maryland's eastern shore. Journal of the Iowa Academy of Science, 107(3):151159.

McAllister, K. R., and Leonard, W. P. 1997. Washington State status report for the Oregon Spotted Frog. Washington Department of Fish and Wildlife, Olympia, Washington. 38 pp.

McCallum, M. 2011. Orientation and directional escape by Blanchard's Cricket Frog, Acris blanchardi (Amphibia: Anura: Hylidae), in response to a human predator. Acta Herpetologica, 6:161-168. 
McKnight, D. T., and Howell, H. J. 2015. A comparison of the flight initiation distances of male and female American bullfrogs (Lithobates catesbeianus) and Green frogs (Lithobates clamitans). Herpetol. Conserv. Biol., 10:137-148.

Mori, A., and Burghardt, G. M. 2001. Temperature effects on anti-predator behaviour in Rhabdophis tigrinus, a snake with toxic nuchal glands. Ethology, 107:795-811.

Moyle, P. B. 1973. Effects of introduced bullfrogs, Rana catesbeiana, on the native frogs of the San Joaquin Valley, California. Copeia, 1973(1):18-22.

Nishiumi, N. and Mori, A. 2014. Distance-dependent switching of anti-predator behavior of frogs from immobility to fleeing. Journal of Ethology, DOI: 10.1007/s10164014-0419-z

Noble, G. K., 1931. The Biology of the Amphibia, New York: McGraw-Hill Book Co.

Nussbaum, R. A., Brodie, E. D., Jr., and Storm, R. M. 1983. Amphibians and Reptiles of the Pacific Northwest. University Press of Idaho, Moscow, Idaho.

Ostergaard, E. C., Richter, K. O., and West, S. D. 2008. Amphibian use of stormwater ponds in the Puget Lowlands of Washington, USA. Herpetological Conservation, 3 : 259-270.

Paoletti, D. J. 2009. Responses of foothill yellow-legged frog (Rana boylii) larvae to an introduced predator. MS Thesis, Department of Environmental Science, Oregon State University, Corvallis, Oregon. 58 pp.

Parker, I. M., Simberloff, D., Lonsdale, W. M., Goodell, K., Wonham, M., Kareiva, P. M., Williamson, B. Von Holle, P. B. Moyle, J. E. Byers, and Goldwasser, L. 1999. Impact: toward a framework for understanding the ecological effects of invaders. Biological invasions, 1(1), 3-19.

Pearl, C. A., and Hayes, M. P. 2002. Predation by Oregon Spotted Frogs (Rana pretiosa) on Western Toads (Bufo boreas) in Oregon. American Midland Naturalist, 147(1):145-152.

Pearl, C. A. and Hayes, M. P. 2005. Rana pretiosa, Oregon Spotted Frog. Pp. 577800 in M.J. Lannoo, ed. Amphibian declines: the conservation status of United States species. University of California Press, Berkeley.

Pearl, C. A., Adams, M. J., Schuytema, G. S., and Nebeker, A. V. 2003. Behavioral responses of anuran larvae to chemical cues of native and introduced predators in the Pacific northwestern United States. Journal of Herpetology, 37(3):572-576.

Pearl, C. A., Adams, M. J., Bury, B., and McCreary, B. 2004. Asymmetrical effects of introduced Bullfrogs (Rana catesbeiana) on native ranid frogs in Oregon. Copeia, 2004(1):11-20.

Pearl, C. A, Adams, M. J., Leuthold, N., and Bury, R. B. 2005a. Amphibian occurrence and aquatic invaders in a changing landscape: Implications for wetland mitigation in the Willamette Valley, Oregon, USA. Wetlands 25(1):76-88. 
Pearl, C. A., Bowerman, J., and Knight, D. 2005b. Feeding behavior and aquatic habitat use by Oregon Spotted Frogs (Rana pretiosa) in central Oregon.

Northwestern Naturalist, 86(1):36-38.

Pough, F. H., Magnusson, W. E., Ryan, M. J., Wells, K. D., and Taigen, T. L. 1992a. Behavioral energetics. In M. E. Feder and W. W. Burggren (eds.), Environmental Physiology of the Amphibians, pp. 395-435. Univ. of Chicago Press, Chicago, Illinois.

Pough, F. H., Magnusson, W. E., Ryan, M. J., Wells, K. D., and Taigen, T. L. 1992b. Feeding and Behavior. In M. E. Feder and W. W. Burggren (eds.), Environmental Physiology of the Amphibians, pp. 378-394. Univ. of Chicago Press, Chicago, Illinois.

Poulin, B., Lefebvre, G., Ibáñez, R., Jaramillo, C., Hernández, C., and Rand, A. S. 2001. Avian predation upon lizards and frogs in a neotropical forest understorey. Journal of Tropical Ecology, 17:21-40.

Punzo, F. 2005. Effects of insecticide (carbaryl) exposure on activity and swimming performance of tadpoles of the Rio Grande leopard frog, Rana berlandieri (Anura: Ranidae). Texas Journal of Science, 57(3):263-272.

Rand, A. S. 1964. Inverse relationship between temperature and shyness in the lizard Anolis lineatopus. Ecology, 45:863-864.

Recarte, J. M., Vincent, J. P., and Hewison, A. J. M. 1998. Flight responses of park Fallow Deer to the human observer. Behavioural Processes, 44:65-72.

Relyea, R. A., and Edwards, K. 2010. What doesn't kill you makes you sluggish: How sublethal pesticides alter predator-prey Interactions. Copeia, 2010: 558-567.

Risenhoover, K. L., McBride, T. C., McAllister, K. and Golliet, M. 2001. Overwintering behavior of the Oregon Spotted Frog (Rana pretiosa) along Dempsey Creek, Thurston County, Washington. Unpublished report submitted to Washington Department of Transportation, Olympia. 26 pp. + appendices.

Rocha, C. F. D., and Bergallo, H. G. 1990. Thermal biology and flight distance of Tropidurus oreadicus (Sauria, Iguanidae) in an area of Amazonian Brazil. Ethology, Ecology, and Evolution, 2:263-268.

Rombough, C. J. 2010. Rana catesbeiana (American Bullfrog). Predation. Herpetological Review, 41(3):204.

Rowe, J. C., and Garcia, T. S. 2014. Impacts of wetland restoration efforts on an amphibian assemblage in a multi-invader community. Wetlands, 34(1):141-153.

Rugiero, L. 1997. Tail loss and escape behaviour in the Common Wall Lizard Podarcis muralis Laurenti, 1768. A preliminary analysis (Squamata: Sauria: Lacertidae). Herpetozoa, 10:149-152. 
Ryan, R. A. 1953. Growth rates of some ranids under natural conditions. Copeia, 1953(1):73-80.

Samia, D. S. M., and Blumstein, D.T. 2014. Phi index: A new metric to test the flush early and avoid the rush hypothesis. PLoSONE 9: e113134. DOI:

10.1371/journal.pone.0113134

Samia, D. S. M., Nomura, F., and Blumstein, D.T. 2013. Do animals generally flush early and avoid the rush? A meta-analysis. Biology Letters, 2013 9: 20130016.

DOI: 10.1098/rsbl.2013.0016.

Samia, D. S. M., Blumstein, D.T., Stankowich, T., and Cooper, W.E. Jr. 2015. Fifty years of chasing lizards: new insights advance optimal escape theory. Biol. Rev. DOI: 10.111/brv.12173.

Sakai, A. K., Allendorf, F. W., Holt, J. S., Lodge, D. M., Molofsky, J., With, K. A., Baughman, S., Cabin, R. J., Cohen, J. E., Ellstrand, N. C., McCauley, D. E., O’Neil, P., Parker, I. M., Thompson, J. N., and Weller, S. G. 2001. The population biology of invasive species. Annu. Rev. Ecol. Syst., 32:305-332.

Seale, D. B. 1980. Influence of amphibian larvae on primary production, nutrient flux, and competition in a pond ecosystem. Ecology, 61(6):1531-1550.

Schlaepfer, M. A., Sherman, P. W., Blossey, B., and Runge, M. C. 2005. Introduced species as evolutionary traps. Ecology Letters, 8, 241-246.

Schwalbe, C. R. and Rosen, P. C. 1988. Preliminary report on effect of bullfrogs on wetland herpetofauna in southeastern Arizona. Pp. 166-173. In Szaro, R.C., K.E. Severson and D.R. Patton (Eds.), Proceedings of the Symposium on Management of Amphibians, Reptiles and Small Mammals in North America. U.S.D.A. Forest Service, General Technical Report, RM-166, Fort Collins, Colorado.

Shallenberger, E.W. 1970. Tameness in insular animals: a comparison of approach distances of insular and mainland iguanid lizards. Masters Thesis, University of California at Los Angeles, Los Angeles, CA.

Silva, E. T., Ribeiro Filho, O. P., and Feio, R. N. 2011. Predation of native anurans by invasive bullfrogs in southeastern Brazil: spatial variation and effect of microhabitat use by prey. South American Journal of Herpetology, 6(1):1-10. doi:10.2994/057.006.0101

Silva, E. T. D., Both, C. and Filho, O. P. R. 2016. Food habits of invasive bullfrogs and native thin-toed frogs occurring in sympatry in southeastern Brazil. South American Journal of Herpetology, 11(1):25-33.

Skelly, D. K., Werner, E. E., and Cortwright, S. A. 1999. Long-term distributional dynamics of a Michigan amphibian assemblage. Ecology, 80(7):2326-2337.

Smith, H. M. 1934. The amphibians of Kansas. American Midland Naturalist, 15(4):377528. 
Smith, G. R. 1996. Correlates of approach distance in the striped plateau lizard (Sceloporus virgatus). Herpetological Journal, 6:56-58.

Smith, D. G. 1997. Ecological factors influencing the antipredator behaviors of the ground skink, Scincella lateralis. Behavioral Ecology, 8:622-629.

Soltysik, R. C. and Yarnold, P. R. 1994. Univariable optimal discriminant analysis: onetailed hypotheses. Educ. Psychol. Meas., 54: 646-653.

Sprague, L. A., and Nowell, L. H. 2008. Comparison of pesticide concentration in streams at low flow in six metropolitan areas of the United States. Environmental Toxicology And Chemistry, 27:288-298.

Sreekar, R., Goodale, E., and Harrison, R. 2015. Flight initiation distance as a behavioral indicator of hunting pressure: a case study of the Sooty-headed Bulbul (Pycnonotus aurigaster) in Xishuangbanna, SW China. Tropical Conservation Science, 8:505512.

Stankowich, T. 2008. Ungulate flight responses to human disturbance: a review and meta-analysis. Biological Conservation, 141, 2159-2173.

Stankowich, T., and Blumstein, D. T. 2005. Fear in animals: a meta-analysis and review of risk assessment. Proceedings of the Royal Society of London B, 272:2627-2634.

Stankowich, T., and Coss, R. G. 2006. Effects of predator behavior and proximity on risk assessment by Columbian black-tailed deer. Behavioral Ecology, 17, 246-254.

Stewart M. M., and Sandison, P. 1972. Comparative food habits of sympatric mink frogs, bullfrogs, and green frogs. Journal of Herpetology, 6(3/4):241-244. doi:10.2307/1562781

Strauss, S. Y., Lau, J. A. and Carroll, S. P. 2006. Evolutionary responses of natives to introduced species: what do introductions tell us about natural communities? Ecology Letters, 9, 357-374.

Stuart, J. N., and Painter, C. W. 1993. Rana catesbeiana (Bullfrog). Cannibalism. Herpetological Review 24:103.

Tarakini, T., Crosmary, W. G., Fritz, H., and Mundy, P. 2014. Flight behavioural responses to sport hunting by two African herbivores. South African Journal of Wildlife Research, 44:76-83.

Tattersall, G. J., and G. R. Ultsch. 2008. Physiological ecology of aquatic overwintering in ranid frogs. Biological Reviews, 83(2):119-140.

Thiago, M. A. I. A., Kiefer, M. C., Van Sluys, M., and Rocha, C. F. D. 2013. Feeding habits, microhabitat use, and daily activity period of Rhinella ornata (Anura, Bufonidae) from three Atlantic rainforest remnants in southeastern Brazil. NorthWestern Journal of Zoology, 9(1):157-165. 
Tidwell, K. S., and Hayes, M. P. 2013. Difference in flight initiation distance between recently metamorphosed Oregon Spotted Frogs (Rana pretiosa) and American bullfrogs (Lithobates catesbeianus). Herpetological Conservation and Biology, 8(2):426-434.

Tidwell, K. S., Shepherdson, D. J., and Hayes, M. P. 2013. Inter-population variability in evasive behavior in the Oregon Spotted Frog (Rana pretiosa). Journal of Herpetology, 47(1):93-96.

Tidwell, K. S., Yarnold, P. R., and Hayes, M. P. In prep. Differences in escape behavior between two populations of Oregon Spotted Frogs (Rana pretiosa) identify American bullfrogs (Lithobates catesbeianus) as a behavior-modifying agent. In prep. for submission to Animal Behavior.

Toft, C. A. 1980. Feeding ecology of 13 syntopic anurans in a seasonal environment. Oecologia (Berl.), 45:131-141.

Toft, C. A. 1981. Feeding ecology of Panamanian litter anurans: Patterns in diet and foraging mode. Journal of Herpetology, 15:130-144.

Toledo, L. F., Ribeiro, R. S., and Haddad, C. F. 2007. Anurans as prey: an exploratory analysis and size relationships between predators and their prey. Journal of Zoology, 271(2), 170-177.

Tran, D. S. C., Langel, K. A., Thomas, M. J., and Blumstein, D. T. 2016. Spearfishinginduced behavioral changes of an unharvested species inside and outside a marine protected area. Current Zoology, 62, 39-44.

Twedt, B. 1993. A comparative ecology of Rana aurora Baird and Girard and Rana catesbeiana Shaw at a fresh- water lagoon, Humboldt County, California. Masters Thesis, Humbolt State University, Humbolt, California, USA.

USDA (US Department of Agriculture). 1997. Big Marsh Watershed Analysis. Crescent, Oregon: Deschutes National Forest.

USFWS. 2009. U.S. Fish and Wildlife Service species assessment and listing priority assignment form for the Oregon Spotted Frog (Rana pretiosa). U.S. Fish and Wildlife Service. Region 1, Lacey, Washington. 73 pp.

USFWS. 2010. Endangered and threatened wildlife and plants; Review of native species that are candidates for listing as endangered or threatened; Annual notice of findings on resubmitted petitions; Annual description of progress on listing actions; Proposed rule. Federal Register 75:69222-69294.

USFWS. 2014. Endangered and Threatened Wildlife and Plants; Threatened Status for Oregon Spotted Frog; Final Rule. — Fed. Reg. 79: 51658-51710.

Waddell, C. D. 2014. The Oregon Spotted Frog (Rana pretiosa) in lowland western Washington, USA: a population, parentage, \& non-breeding habitat analysis. Masters Thesis. The Evergreen State College, Olympia, Washington. 140 pp. 
Wang, Y., Wang, Y., Lu, P., Zhang, F., and Li, Y. 2008. Diet composition of postmetamorphic bullfrogs (Rana catesbeiana) in the Zhoushan archipelago, Zhejiang Province, China. Frontiers of Biology in China, 3(2):219-226.

Watkins-Colwell, G. 1997. Approach distance in Galapagos lava lizards (Microlophus (= Tropidurus), Tropiduridae). Bull. Maryland Herpetol. Soc., 33:118-125.

Watson, J. W., McAllister, K. R., and Pierce, D. J. 2003. Home ranges, movements, and habitat selection of Oregon Spotted Frogs (Rana pretiosa). Journal of Herpetology, 37(2):292-300.

Webb, P. W. 1994. The biology of fish swimming. In L. Maddock, Q. Bone, \& J. M. V. Rayner (Eds.), Mechanics and physiology of animal swimming (pp. 45-62). Cambridge, U.K.: Cambridge University Press.

Werner, E. E., and Gilliam, J. F. 1984. The ontogenetic niche and species interactions in size-structured populations. Annual review of ecology and systematics, 15:393-425.

Werner, E. E., and Anholt, B. R. 1993. Ecological consequences of the trade-off between growth and mortality rates mediated by foraging activity. American Naturalist, 242-272.

Werner, E. E., and McPeek, M. A. 1994. Direct and indirect effects of predators on two anuran species along an environmental gradient. Ecology, 75(5):1368-1382.

Werner, E. E., Wellborn, G. A., and McPeek, M. A. 1995. Diet composition in postmetamorphic bullfrogs and green frogs: Implications for interspecific predation and competition. Journal of Herpetology, 29(4):600-607.

Whiting, M. J., Lailvaux, S. P., Reaney, L. T. and Wymann, M. 2003. To run or hide? Age-dependent escape behaviour in the common flat lizard (Platysaurus intermedius wilhelmi). J. Zool. Lond., 260:123-128.

Willis, Y. L., Moyle, D. L. and Baskett, T. S. 1956. Emergence, breeding, hibernation, movements and transformation of the bullfrog, Rana catesbeiana, in Missouri. Copeia, 1956(1):30-41.

Wittmer I. K., Bader, H. P., Scheidegger, R., Singer, H., Luck, A., Hanke, I., Carlsson, C., and Stamm, C. 2010. Significance of urban and agricultural land use for biocide and pesticide dynamics in surface waters. Water Research, 44:2850-2862.

Woodward, G., and Hildrew, A. G. 2002. Body-size determinants of niche overlap and intraguild predation within a complex food web. Journal of Animal Ecology, 71(6):1063-1074.

Wu, Z. J., Li, Y. M., Wang, Y. P., and Adams, M. J. 2005. Diet of introduced Bullfrogs (Rana catesbeiana): Predation on and diet overlap with native frogs on Daishan Island, China. Journal of Herpetology, 39(4):668-674.

Yarnold, P. R. and Soltysik, R. C. 1991. Theoretical distributions of optima for univariate discrimination of random data. Decision Sci., 22:739-752. 
Yarnold, P. R. and Soltysik, R. C. 2005. Optimal data analysis: Guidebook with software for Windows. Washington, D.C., USA: APA Books.

Yarnold, P. R. and Soltysik, R. C. 2016. Maximizing predictive accuracy. ODA Books, Chicago. DOI: 10.13140/RG.2.1.1368.3286.

Xuan, L. I. U., Yu, L. U. O., Jiaxin, C. H. E. N., Yisong, G. U. O., Changming, B. A. I., and Yiming, L. I. 2015. Diet and Prey Selection of the Invasive American Bullfrog (Lithobates catesbeianus) in Southwestern China. Asian herpetological research, 6(1):34-44.

Ydenberg, R. C., and Dill, L. M. 1986. The economics of fleeing from predators. Advances in the Study of Behavior, 16:229-249.

Zar, J. H. 1999. Biostatistical analysis. Prentice Hall, Upper Saddle River, New Jersey, USA. 


\section{APPENDIX}

\section{Copyright information for CHAPTERS 2, 3, and 4}

CHAPTER 2 of this dissertation has been published as a journal article in The Journal of Herpetology. See PREFACE for complete citation. The content and title of this article is the same as what appears in the previously mentioned journal which is published by the Society for the Study of Amphibians and Reptiles. Under the copyright transfer agreement, authors are allowed to grant third parties the right to reproduce published material as long as the content is the same, proper citations are given, and the authors give permission. Therefore, Kyle S. Tidwell, David J. Shepherdson and Marc P. Hayes grant permission to Portland State University to re-publish this article as CHAPTER 2 of this dissertation.

CHAPTER 3 of this dissertation has been published as a journal article in Herpetological Conservation Biology. See PREFACE for complete citation. The content and title of this article is the same as what appears in the previously mentioned journal which is published as an open access journal. Under the copyright transfer agreement, authors are allowed to grant third parties the right to reproduce published material as long as the content is the same, proper citations are given, and the authors give permission.

Therefore, Kyle S. Tidwell and Marc P. Hayes grant permission to Portland State University to re-publish this article as CHAPTER 3 of this dissertation.

CHAPTER 4 of this dissertation is in review to be published as an article in the journal Behaviour. See PREFACE for complete citation. The content and title of this article is the 
same as what appears in the previously mentioned journal which is published by BRILL. Under the copyright transfer agreement, authors are allowed to grant third parties the right to reproduce published material as long as the content is the same, proper citations are given, and the authors give permission. Therefore, Marc P. Hayes, Kyle S. Tidwell, David J. Shepherdson, and Paul R. Yarnold grant permission to Portland State University to re-publish this article as CHAPTER 4 of this dissertation. 